Idalíria de Moraes Dias

\title{
ESTUDO DE SOLOS TROPICAIS PARA USO EM PAVIMENTAÇÃO A PARTIR DE ENSAIOS TRIAXIAIS ESTÁTICOS
}

\begin{abstract}
Dissertação apresentada à Escola de Engenharia de São Carlos, da Universidade de São Paulo, como parte dos requisitos para obtenção do título de Mestre em Engenharia Civil: Área infraestrutura de transporte.
\end{abstract}

Orientador: Prof. Tit. Alexandre Benetti Parreira 
AUTORIZO A REPRODUÇĀO E DIVULGAÇÃO TOTAL OU PARCIAL DESTE TRABALHO, POR QUALQUER MEIO CONVENCIONAL OU ELETRÔNICO, PARA FINS DE ESTUDO E PESQUISA, DESDE QUE CITADA A FONTE.

Ficha catalográfica preparada pela Seção de Tratamento da Infomaçăo do Serviço de Biblioteca - EESC/USP

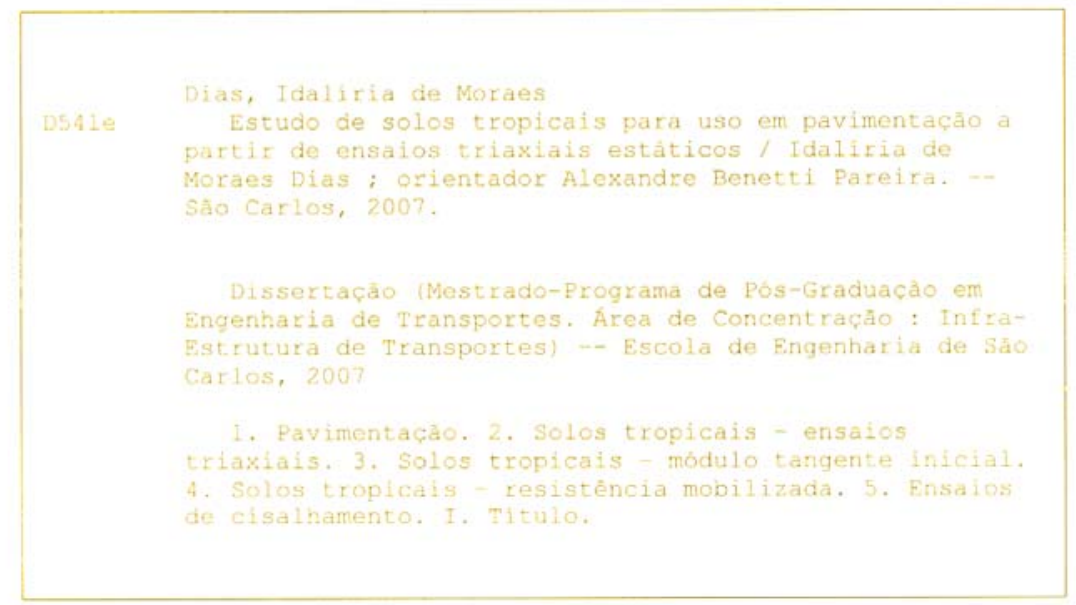




\section{DEDICATÓRIA}

A Deus,

“Porque vossa graça me é mais preciosa do que a vida, meus lábios entoarão vossos louvores.

Assim vos bendirei em toda a minha vida, com minhas mãos erguidas vosso nome adorarei."

Salmo 62 


\section{AGRADECIMENTOS}

A Deus, por minha vida, por todos os ensinamentos, por me permitir servi-vos, por todos os anjos que colocou no meu caminho para me conduzir a Vós, por Vossa infinita misericórdia.

A todos os anjos que passaram e os que ainda estão presentes em minha vida:

Ao prof. Alexandre Benetti Parreira pela orientação, incentivo e aprendizado;

Ao CNPPQ, Conselho $\mathcal{N a c i o n a l ~ d e ~ D e s e n v o l v i m e n t o ~ C i e n t i ́ f i c o ~ e ~ T e c n o l o ́ g i c o , ~ p e l a ~ 6 o l s a ~ d e ~ m e s t r a d o ; ~}$

Aos funcionários e professores do departamento de Transporte pelo apoio em meu aprendizado e pelo carinho;

Aos professores e funcionários do Departamento de Geotecnia da EESC/USP, em especial ao técnico José Luiz pelo apoio e ajuda na realização dos experimentos necessários para o desenvolvimento deste trabalho;

Aos colegas e amigos do Departamento de Transportes e do Departamento de Geotecnia da EESC/USP, Weslley, Eliana, Shirley, Marcelo Takeda, Hélio Marcos, Francis, Roger, Everaldo, Cleber, Ovidio, Vivianne, Celane, Cleber, Tony, Jesner e João Olympio, pela amizade e pelo apoio no desenvolvimento deste trabalho;

A meus pais Milton e Adair pelo apoio incondicional e por acreditarem em mim, mesmo quando eu mesma não acreditava;

A minha vovozinha Luzia pela dedicação e amor;

A meus irmãos, Cristiane e João, a minha madrinha Anéria, aos meus tios Alair, Maria, José e Divina, e em vocês a todos os meus tios, primos, cunhado, cunhada, sobrinhos, que fazem da minha vida um pedacinho do céu; 
A todos os mestres que passaram por minha vida, plantaram e cultivaram em mim este desejo pelo saber, em especial: a "Tia" Mary pelo amor e dedicação no papel de educadora e a Prof. Maria Elisa por me apresentar esta área da Engenharia Civil;

Ao meu anjo protetor Wilson Jose Dino, por me fazer confecer um pouco mais de meu próprio coração, por todo amor e dedicação;

A Aline Patrícia, Vanessa, Julianita, Maria Alice, Heltinho (Padrinho), Marcelo, Fernanda, Sara e Aderson e todos meus irmãozinhos do GPP (Grupo de Partilha e Perseverança) e da "Totus Mariae", pelas orações e pela amizade;

A meus velhos e novos amigos: Jordana, Vanessa Licia, Vanessa Martins, Luciana, Maria Carolina, Ana Beatriz, Junior, Gisele, Jussara, Ro6erta, Lucimar, Vrsula, Dani, pelo apoio.

A todos, meus sinceros agradecimentos!!! Sem a dedicação, o carinho e o amor de cada um este trabalho não seria o mesmo!! 


\section{SUMÁRIO}

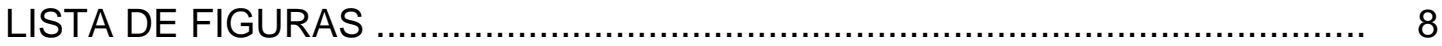

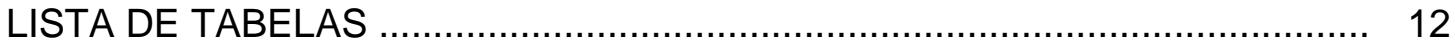

LISTA DE ABREVIATURAS E SIGLAS ……….................................... 14

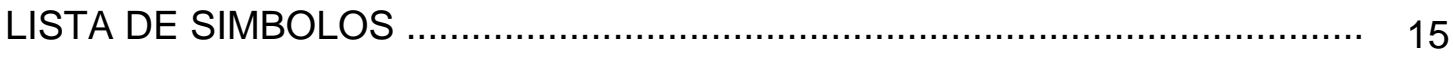

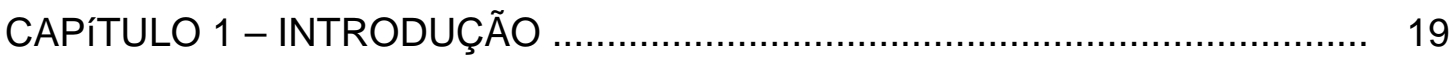

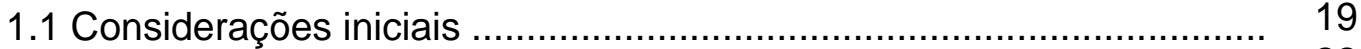

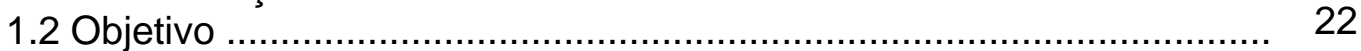

1.3 Organização do trabalho .............................................................. 23

CAPÍTULO 2 - REVISÃO BIBLIOGRAFICA ………............................... 25

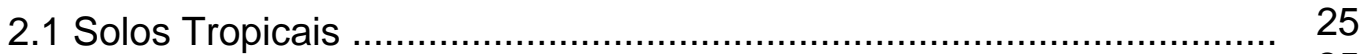

2.1.1 Conceituação ............................................................... 25

2.1.1.1 Solos Lateríticos ................................................... 25

2.1.2 Comportamento de Solos Tropicais em Pavimentação ............. 27

2.1.2.1 Classificações Desenvolvidas para Solos Tropicais ..... 29

2.1.2.2 Comportamento mecânico de solos tropicais .............. 30

2.2 Estudos de Comportamento Mecânico de Materiais Geotécnicos a partir de Ensaios Triaxiais Estáticos .................................................... 36

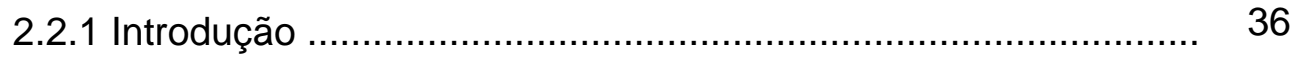

2.2.2 Procedimentos de Ensaios .................................................... 37

2.2.3 Analise de Resistência ....................................................... 29

2.2.3.1 Critério de Ruptura ................................................. 43

2.2.4 Análise de Deformabilidade ............................................... 47

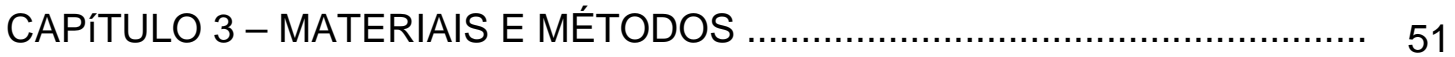

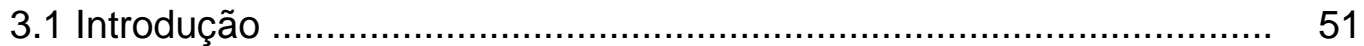

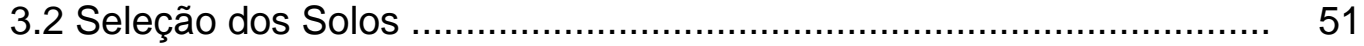

3.2.1 Caracterização e Classificação dos Solos .............................. 53

3.2.2 Ensaios de Compactação .................................................. 59

3.3 Investigação Experimental ........................................................... 60

3.3.1 Moldagem dos Corpos-de-prova ....................................... 60

3.3.2 Ensaio Triaxial Convencional .................................................. 61 
3.3.2.1 Determinação dos Valores de Tensão Confinante ....... 62

3.3.2.2 Equipamentos ................................................ 63

3.3.2.3 Procedimento de Ensaio ........................................ 64

3.3.3 Ensaio sem tensão confinante ......................................... 66

3.3.3.1 Equipamentos .............................................. 66

3.3.3.2 Procedimento de Ensaio ..................................... 66

3.4 Análise dos Resultados ..................................................... 67

3.4.1 Resistência Mobilizadas .............................................. 67

3.4.1.1 Critério de Resistência de Mohr-Coulomb ................. 67

3.4.2 Deformabilidade ...................................................... 68

3.4.2.1 Determinação do Módulo Tangente Inicial ................. 69

3.4.2.2 Modelagem da Variação de $E_{0}$ com a Tensão

Confinante ................................................................... 69

3.4.3 Comparação entre o Comportamento de Solos Lateríticos Não Lateríticos

3.4.4 Análise da Relação entre os Resultados dos Ensaios Triaxiais convencionais e Triaxiais Cíclicos ............................................. 70

CAPÍTULO 4 - APRESENTAÇÃO E DISCUSSÃO DOS RESULTADOS ......... 71

4.1 Introdução .................................................................... 71

4.2 Ensaios de Compactação ....................................................... 71

4.3 Ensaios de Confinados e Não-confinados ................................... 78

4.3.1 Ensaios Saturados ...................................................... 78

4.3.1.1 Resistência a Ruptura ...................................... 82

4.3.1.2 Resistência Mobilizada ........................................ 89

4.3.1.3 Deformação ........................................................... 94

4.3.2 Ensaios Não Saturados ............................................... 104

4.3.2.1 Resistência a Ruptura ..................................... 107

4.3.2.3 Deformação ................................................... 115

CAPÍTULO 5 - CONCLUSÕES E RECOMENDASÕES ............................ 123

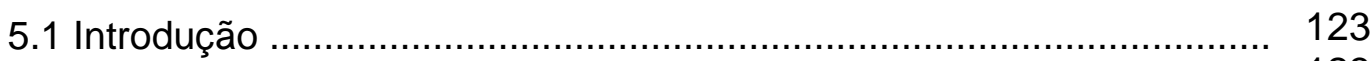

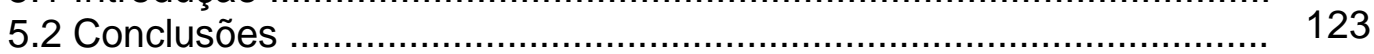

5.2.1 Ensaios Saturados ...................................................... 124

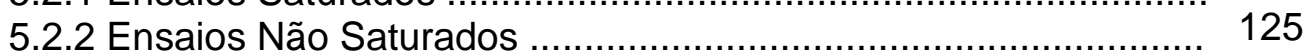

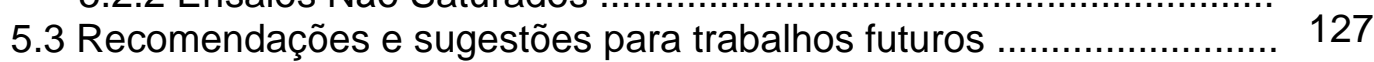

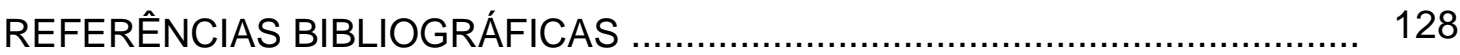

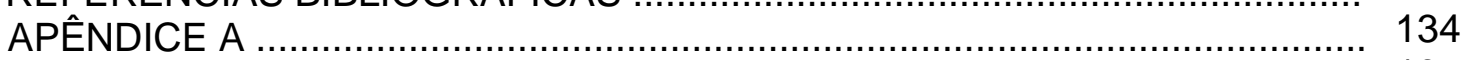

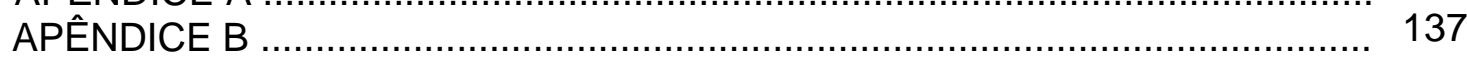




\section{LISTA DE FIGURAS}

FIGURA 2.1 - (a) - ábaco de classificação MCT; (b) - ábaco de classificação MCT-M

FIGURA 2.2 - Esquema de uma câmara de ensaio de compressão triaxial .....

FIGURA 2.3 - Diferentes critérios para definição de ruptura (Head, 1986) ........

FIGURA 2.4 - Contribuição dos vários mecanismos de ligação para a resistência dos solos (Inglês, 1962 in Mitchel, 1976)

FIGURA 2.5 - Representação dos critérios de ruptura: (a) de Coulomb e (b) de Mohr

FIGURA 2.6 - Extensão tridimensional do critério de ruptura de MohrCoulomb proposto por Fredlund (1978)

FIGURA 2.7 - Modelo hiperbólico

FIGURA 3.1 - Amostras selecionadas para estudo

FIGURA 3.2 - Curvas granulométricas dos solos $1 \mathrm{~L}$ e $1 \mathrm{~N}$

FIGURA 3.3 - Curvas granulométricas dos solos $2 \mathrm{~L}$ e $2 \mathrm{~N}$

FIGURA 3.4 - Curvas granulométricas dos solos 3L e 3N 55

FIGURA 3.5 - Curvas granulométricas dos solos estudados 55

FIGURA 3.6 - Carta de Plasticidade de Casagrande

FIGURA 3.7 - Gráficos MCT e MCT-M (Vertamatti, 1988) com a indicação dos seis solos estudados

FIGURA 3.8 - Imagens de microscopia eletrônica de varredura do solo $1 \mathrm{~N} \ldots .$. 
FIGURA 3.10 - Imagens de microscopia eletrônica de varredura do solo 2N ... 57

FIGURA 3.11 - Imagens de microscopia eletrônica de varredura do solo $2 \mathrm{~L} \ldots . . \quad 58$

FIGURA 3.12 - Imagens de microscopia eletrônica de varredura do solo $3 \mathrm{~N} \ldots 58$

FIGURA 3.13 - Imagens de microscopia eletrônica de varredura do solo 3L ... 58

FIGURA 3.14 - Prensa Versatest utilizada para compactação estática de corpos-de-prova

FIGURA 3.15 - Equipamento utilizados para o ensaios triaxial convencional .. 63

FIGURA 3.16 - Módulo de deformabilidade utilizados no estudo .................... 68

FIGURA 4.1 - Curvas de compactação do par 1 ......................................... 72

FIGURA 4.2 - Curvas de compactação do par 2 ..................................... 72

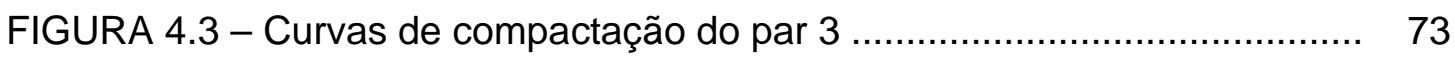

FIGURA 4.4 - Curvas de compactação dos materiais estudados .................. 73

FIGURA $4.5-\rho_{\mathrm{dmax}}$ versus $\mathrm{w}_{\mathrm{ot}}$ para solos lateríticos e não lateríticos ............. 74

FIGURA 4.6 - Porcentagem de finos versus umidade ótima .......................... 75

FIGURA 4.7 - Porcentagem de argila versus umidade ótima ......................... 75

FIGURA 4.8 - Porcentagem de finos versus massa específica seca máxima ... 78

FIGURA 4.9 - Porcentagem de argila versus massa específica seca máxima . 78

FIGURA 4.10 - Curvas tensão desvio versus deformação axial e Variação volumétrica versus deformação axial para os solos do Par 1

FIGURA 4.11 - Curvas tensão desvio versus deformação axial e Variação volumétrica versus deformação axial para os solos do Par 2

FIGURA 4.12 - Curvas tensão desvio versus deformação axial e Variação volumétrica versus deformação axial para os solos do Par 3 ............................

FIGURA 4.13 - Variação da diferença relativa de tensão de ruptura com a tensão de confinamento

FIGURA 4.14 - Variação da diferença relativa de tensão de ruptura com a tensão de confinamento para os ensaios triaxiais 
FIGURA 4.16 - Envoltória de resistência das amostras $2 \mathrm{~L}$ e $2 \mathrm{~N}$

FIGURA 4.17 - Envoltória de resistência das amostras 3L e 3N

FIGURA 4.18 - Variação do atrito interno mobilizado e da coesão mobilizada em função da \% $\varepsilon_{\text {rup }}$ para o Par 1

FIGURA 4.19 - Variação do atrito interno mobilizado e da coesão mobilizada em função da \% $\varepsilon_{\text {rup }}$ para o Par 2

FIGURA 4.20 - Variação do atrito interno mobilizado e da coesão mobilizada em função da \% $\% \varepsilon_{\text {rup }}$ para o Par 3

FIGURA 4.21 - Variação da diferença relativa de deformação axial de ruptura coma tensão confinante para os ensaios triaxiais

FIGURA 4.22 - Variação de $\mathrm{E}_{0} \mathrm{com} \sigma_{\mathrm{c}}$ para cada solo estudado

FIGURA 4.23 - Variação de $E_{0}, E_{50}$ e $E_{\text {rup }}$ com $\sigma_{c}$ para cada solo do par $1 \ldots \ldots$ 102

FIGURA 4.24 - Variação de $E_{0}, E_{50}$ e $E_{\text {rup }}$ com $\sigma_{c}$ para cada solo do par 2 ...... 102

FIGURA 4.25 - Variação de $E_{0}, E_{50}$ e $E_{\text {rup }}$ com $\sigma_{c}$ para cada solo do par $3 \ldots .$. 103

FIGURA 4.26 - Curvas tensão desvio versus deformação axial e variação volumétrica versus deformação axial dos solos do par 1 relativos aos ensaios não saturados

FIGURA 4.27 - Variação da diferença relativa de tensão de ruptura com a tensão de confinamento para os ensaios triaxiais saturados e não saturados do par 1

FIGURA 4.28 - Variação porcentagem de queda de resistência devido à saturação com a tensão de confinamento para os ensaios triaxiais do par 1 ....

FIGURA 4.29 - Envoltória de resistência das amostras $1 \mathrm{~L}$ e $1 \mathrm{~N}$ para corposde-prova saturados e não saturados

FIGURA 4.30 - Extensão tridimensional do critério de ruptura de Mhorcoulomb proposto por Fredlund (1978)

FIGURA 4.31 - Variação da diferença relativa de deformação axial de ruptura com a tensão confinamente para os ensaios triaxiais saturados e não saturados do par 1

FIGURA 4.32 - Variação de $E_{0}$, $E_{50}$ e $E_{\text {rup }}$ com $\sigma_{c}$ para os ensaios não saturados do par 1 
FIGURA 4.33 - Variação de $E_{0}, E_{50}$ e $E_{\text {rup }}$ com $\sigma_{c}$ para os ensaios saturados e não saturados do solo $1 \mathrm{~L}$

FIGURA 4.34 - Variação de $E_{0}, E_{50}$ e $E_{\text {rup }}$ com $\sigma_{c}$ para os ensaios saturados

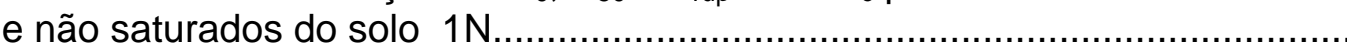




\section{LISTA DE TABELAS}

TABELA 3.1 - Localização, coordenadas e posição em relação à linha de seixos dos solos estudados

TABELA 3.2 - Caracterização e classificação dos solos estudados

TABLEA 3.3 - Resultados do ensaio de compactação, energia Proctor Normal

TABELA 3.4 - Características das camadas dos pavimentos modelados

TABELA 4.1 - Tensão de ruptura das amostras e diferença relativa de tensão de ruptura para cada tensão de confinamento

TABELA 4.2 - Valores de $\phi^{\prime}$ e c' para a envoltória de ruptura de MohrCoulomb dos solos estudados

TABELA 4.3 - Deformação axial de ruptura da amostras e diferença relativa de deformação axial de ruptura para cada tensão de confinamento

TABELA 4.4 - Módulo tangente inicial das amostras e parâmetros $\mathrm{K}, \mathrm{n}$ e $\mathrm{R}^{2}$ da equação 3.5 para cada tensão de confinamento

TABELA 4.5 - Modelos para cálculo do módulo de resiliência calibrados por Takeda (2006) para os solos estudados

TABELA 4.6 - Módulos de deformação secante a 50\% da tensão de ruptura, módulos de deformação secante na ruptura e módulos de deformação tangente inicial dos solos estudados

TABELA 4.7 - Tensões de ruptura e diferença absolutas e relativas de tensão de ruptura para cada tensão de confinamento dos ensaios saturados e não saturados dos solos $1 \mathrm{~L}$ e $1 \mathrm{~N}$

TABELA 4.8 - Tensões de ruptura e porcentagem de queda de resistência devido a saturação para cada tensão de confinamento dos ensaios saturados e não saturados dos solos $1 \mathrm{~L}$ e $1 \mathrm{~N}$ 
TABELA 4.9 - Valores de umidades e graus de saturação para os corpos-deprova ensaiados sob as condições saturadas e não saturadas e valores de sucção dos solos $1 \mathrm{~L}$ e $1 \mathrm{~N}$

TABELA 4.10 - Valores de $\phi$ e c para as envoltórias de ruptura de MohrCoulomb saturada e não saturada dos solos $1 \mathrm{~L}$ e $1 \mathrm{~N}$

TABELA 4.11 - Deformação axial de ruptura das amostras e diferença relativa de deformação axial de ruptura para cada tensão de confinamento

TABELA 4.12 - Módulo tangente inicial e parâmetros $K, n$ e $R^{2}$ da equação 3.5 para cada tensão de confinamento dos ensaios saturados e não saturados do par 1

TABELA 4.13 - Módulos de deformação secante a 50\% da tensão de ruptura, módulos de deformação secante na ruptura e módulos de deformação tangente inicial para as condições saturada e não saturada dos solos do par 1 


\section{LISTA DE ABREVIATURAS E SIGLAS}

AASHTO - American Association of State Highway and Transportation Officials;

ABNT - Associação Brasileira de Normas Técnicas;

CBR - Índice de Suporte Califórnia;

COPPE/UFRJ - Coordenação dos Programas de Pós-graduação de engenharia da Universidade Federal do Rio de Janeiro;

DER - Departamento de Estrada de Rodagem

DNER - Departamento Naional de Estrada de Rodagem;

EESC - Escola de Engenharia de São Carlos;

IP - Índice de Plasticidade;

IPT - Instituto de Pesquisas Tecnológicas do Estado de São Paulo;

LL - Limite de Liquidez;

LVDT - Linear Variable Differential Transducers;

MCT - Miniatura Compactada Tropical;

NBR - Norma brasileira;

NS - Não saturado;

S - Saturado;

Sat - Saturado;

USCS - Unified Soil Classification System;

USP - Universidade de São Carlos. 


\section{LISTA DE SÍMBOLOS}

a' - ponto de interseção da reta que une os pontos de máximos com o eixo das ordenadas no gráfico pxq;

a e b-coeficientes de regressão do modelo hiperbólico;

$\alpha$ - ângulo de inclinação da reta que une os pontos de máximos no gráfico pxq;

B - parâmetro de Skempton;

c - intercepto coesivo;

c' - intercepto coesivo efetivo;

$\mathrm{C}_{\mathrm{mob}}$ - coesão mobilizada;

$\Delta \varepsilon$ - Diferença realtiva de deformação axial de ruptura;

$\Delta \mathrm{v}$ - variação de volume;

$\Delta \mathrm{u}$ - variação de pressão neutra;

$\Delta \sigma$ - Diferença relativa de tensão de ruptura;

$\Delta \sigma_{3}$ - variação de tensão confinante;

E - módulo de elasticidade;

$\mathrm{E}_{0}$ - Módulo tangente inicial;

$E_{50}$ - Módulo secantes correspondente a 50\% da tensão de ruptura;

$E_{\text {rup }}$ - Módulo secantes correspondente na ruptura;

$\varepsilon$ - deformação;

$\varepsilon_{\text {rup }}$ - deformação de ruptura;

$\varepsilon_{\text {rupN }}$ - deformação axial de ruptura para o solo não laterítico;

$\varepsilon_{\text {rupL }}$ - deformação axial de ruptura para o solo laterítico;

$\mathrm{K}$ e $\mathrm{n}$ - constantes da equação de Janbu;

$\mathrm{Pa}$ - Pressão atmosférica;

$\mathrm{Pq}$ - Porcentagem de queda de tensão de ruptura devida à saturação; 
$\mathrm{p}=\left(\sigma_{1}+\sigma_{3}\right) / 2$;

$q=\left(\sigma_{1}-\sigma_{3}\right) / 2$

$\sigma$ - tensão;

$\sigma_{\mathrm{C}}$ - tensão confinante;

$\sigma_{3}$ - tensão confinante;

$\sigma_{1}-$ tensão axial;

$\sigma_{\text {rupN }}$ - tensão desvio de ruptura para o solo não laterítico;

$\sigma_{\text {rupL }}$ - tensão desvio de ruptura para o solo laterítico;

$\sigma_{\text {rupNs }}$ - tensão desvio de ruptura não saturado;

$\sigma_{\text {rups }}$ - tensão desvio de ruptura saturado;

$\tau$ - tensão de cisalhamento;

u - pressão neutra;

$\mathrm{u}_{\mathrm{a}}$ - pressão de ar;

$\mathrm{u}_{\mathrm{w}}$ - pressão de água;

$v$ - coeficiente de poisson;

$\phi$ - ângulo de atrito;

$\phi^{\prime}$ - ângulo de atrito efetivo;

$\phi^{\mathrm{b}}$ - ângulo de atrito interno relativo às variações de $\left(\sigma-u_{\mathrm{a}}\right)$;

$\phi_{\text {mob }}$ - ângulo de atrito mobilizado;

$\{\sigma\}$ - tensor de tensão;

$\{\varepsilon\}$ - tensor de deformação;

$\mathrm{ICI}=-$ matriz dos coeficientes elásticos;

$\rho_{\mathrm{s}}$ - massa especifica dos sólidos;

$\rho_{d}-$ massa específica seca;

$\rho_{\mathrm{dmax}}$ - massa específica seca máxima;

W - umidade;

$\mathrm{W}_{\mathrm{ot}}$ - umidade ótima; 


\section{Resumo}

DIAS, IDALÍRIA DE MORAES (2007). Estudo de solos tropicais para uso em pavimentação a partir de ensaios triaxiais Estáticos. São Carlos, 2006 - Dissertação de Mestrado. Escola de Engenharia de São Carlos, Universidade de São Paulo.

O presente trabalho discute comparativamente o comportamento mecânico de solos lateríticos e não lateríticos para uso em pavimentação. Para tanto foram ensaiados 3 pares de solos, sendo cada par constituído por solos de curvas granulométricas semelhantes, mesma classificação HRB e comportamentos distintos quanto à laterização. Foram realizados ensaios triaxiais convencionais do tipo CD saturado e não saturado sem controle de sucção e ensaios de compressão simples. A partir dos resultados dos ensaios foram modeladas as deformações elásticas em função das tensões de confinamento e determinadas as envoltórias de ruptura de MohrCoulomb. Concluiu-se que a maior resistência dos solos lateríticos está representada na componente coesão da envoltória de Mohr-Coulomb e que esta é mobilizada praticamente ao máximo desde o início em um ensaio triaxial. A diferença de resistência entre os ensaios saturados e não saturados também se mostrou na coesão, com a soma nesta da componente coesão aparente, fruto da sucção. O ângulo de atrito mostrou-se constante para as duas gêneses, tanto para a condição saturada como para a condição não saturada. Os solos lateríticos apresentam rigidez maior que os não lateríticos, tanto na condição saturada como na condição não saturada. Para os níveis de tensão de confinamento utilizados, a rigidez dos solos, de ambas as gêneses, na condição saturada, diminui com o aumento da tensão confinante. Também se observou que a ação da sucção existente nos ensaios não saturados proporciona, para ambas as gêneses, uma mudança da sensibilidade da rigidez ao aumento da tensão confinante.

Palavras-chave: ensaios triaxiais, Solos tropicais, Módulo Tangente Inicial, Resistência mobilizada, Resistência ao cisalhamento. 


\section{Abstract}

DIAS, IDALÍRIA DE MORAES (2007). Study of Tropical Soils for use in pavement through static compression test. São Carlos, 2006 - Master's dissertation. Escola de Engenharia de São Carlos, Universidade de São Paulo.

The present paper discusses the mechanical behavior of lateritic and no-lateritic soils for use in pavement. To attain that goal, 3 pair soils were rehearsed, being each pair constituted by soils of similar granulometric curves, same HRB classification and different genesis. The experimental program was constituted of static triaxial compression test of the type saturated $C D$ and of the type unsaturated without suction control and unconfined compression strength test. With the results of the tests, the elastic strains were modeled in function of the confinement stresses and the rupture paths of Mohr-Coulomb were determined. The analysis that the shear strength of the lateritic soils is greater than no-lateritic soil because of the cohesion. Since the begin it, the cohesion is mobilized practically to the maximum for both soils. The difference of shear strength between the saturated and unsaturated tests it is also cohesion, with the sum in that component of the cohesion apparent produced for suction. The angle of internal friction is constant for the two genesis as much for the saturated test as for the unsaturated test. The lateritic soils present greater stiffness than the no-lateritic soils, as much for saturated test as for unsaturated test. For the levels of confinement stresses used, in the saturated condition the stiffness of the soils decreases with the increase of the confinement stresses of both genesis. In addition, It was observed that the suction existent in the unsaturated testing produce a change of the sensibility of the soils stiffness to the increase of the confinement stress for both genesis.

Key word: static triaxial compression test, tropical soils, young's moduli, mobilized strength, shear strength. 


\section{INTRODUÇÃO}

\subsection{Considerações iniciais}

$\mathrm{Na}$ segunda metade do século $\mathrm{XX}$ iniciaram-se no país estudos sobre as peculiaridades dos solos tropicais como materiais de construção de estradas. Presentes em quase todo território nacional, a utilização desses solos na pavimentação vem apresentando vantagens econômicas e técnicas quando comparados aos materiais tradicionalmente empregados. De acordo com Villibor et al. (1996), os novos procedimentos de escolha e dosagem de material e de projeto e construção apropriados para o ambiente tropical úmido, proporcionam o uso de camadas de custo relativamente menores em comparação às tradicionais, através da utilização de maior porcentagem de solos locais de comportamento laterítico. Além disso, Villibor et al. (2000) relatam que o uso de solos lateríticos em pavimentação tem garantido às obras vantagens como: deflexões pequenas, ausência ou baixa incidência de ruptura da base, entre outras.

Nos primeiros trabalhos publicados sobre a utilização de solos lateríticos na pavimentação foram analisados o uso desses materiais como subleito, reforço de subleito, sub-base e base, utilizando-os isoladamente ou em misturas solo-brita, solo-cimento, ou ainda solo-cal. Entre eles pode-se citar os trabalhos de Villibor (1974), Correa (1975), Barros (1978), Bernucci e Serra (1990) e Aranovich e 
Ogurtsova (1987). De forma geral, obtiveram-se resultados satisfatórios para trechos com tráfego variando de médio a leve.

Verificado o bom desempenho desses solos como material de construção para pavimentação, adveio a necessidade de se desenvolverem novos procedimentos laboratoriais que possibilitassem sua melhor caracterização e classificação, uma vez que não se enquadravam nas especificações das normas vigentes.

Largamente utilizado no meio rodoviário para seleção de material e dimensionamento de pavimentos flexíveis, o Índice de Suporte Califórnia (ISC ou CBR) foi o primeiro ensaio a comprovar as qualidades dos solos lateríticos para pavimentação. Buscando a obtenção de parâmetros para esses solos Costa (1983) e Camapum de Carvalho et al (1991) analisaram o CBR obtido a partir de ensaios com imersão com o mesmo índice determinado em ensaios sem imersão. Os autores verificaram em seus trabalhos relações satisfatórias entre os dois índices e sugeriram respectivamente, a possibilidade de uma pré-avaliação do valor de CBR com imersão a partir de CBR sem imersão quando for justificado o uso do valor do primeiro, e o uso do CBR sem imersão no controle de capacidade de suportes durante a vida útil dos pavimentos e na obtenção de parâmetro de decisão na manutenção.

Nogami e Villibor (1979) avaliaram que para as regiões tropicais seria necessário efetuar as determinações de suporte e expansão do ensaio CBR para diversas condições de umidade de compactação, imersão, sobrecarga e energias de compactação, o que exigiria uma quantidade de amostra grande para a moldagem dos diversos corpos de prova, além de um grande desgaste físico. Como solução 
para esse problema os autores utilizaram a proposta de Nogami (1972), que propõe o emprego de equipamentos de dimensões reduzidas para prever o valor de Índice de Suporte Califórnia a fim de empregá-lo no dimensionamento de pavimentos flexíveis.

Em 1981, Nogami e Villibor publicaram no I Simpósio Brasileiro de Solos Tropicais em Engenharia uma nova metodologia de estudo e classificação geotécnica para solos tropicais denominada MCT (Miniatura Compactada Tropical). Essa nova metodologia baseia-se nas propriedades mecânicas e hidráulicas de solos, incluindo ensaios de compactação, perda de massa por imersão, permeabilidade, infiltrabilidade, contração e Mini-CBR, e de acordo com os autores, reproduz as condições reais de camadas de solos tropicais compactadas.

Facilitada pela maior disponibilidade de recursos computacionais, a tendência mundial hoje é o emprego dos conceitos da Mecânica dos Pavimentos na análise estrutural de pavimentos. Essas análises utilizam a teoria da elasticidade e consideram a estrutura do pavimento como um sistema de multicamadas, modeladas pelo comportamento elástico para o cálculo de tensões, deformações e deslocamentos gerados pelas cargas.

Para a utilização dessa teoria é necessário o conhecimento do módulo de resiliência e do coeficiente de Poisson dos materiais que compõem a estrutura do pavimento. Sendo assim, surgiu no país uma grande linha de pesquisa onde se procura analisar não só a características dos solos lateríticos em termos de deformações elásticas, como também as relações entre o módulo de resiliência, determinado no ensaio triaxial cíclico, com resultados de ensaios mais simples. 
Em pavimentação, o ensaio de compressão simples tem sido utilizado tradicionalmente na determinação do comportamento mecânico de solos e misturas estabilizadas. Com o advento das análises mecanísticas, o ensaio triaxial cíclico tem se consolidado como a principal ferramenta para a determinação do comportamento tensão versus deformação de materiais geotécnicos. Todavia, é sabido que obras geotécnicas, com destaque para barragens e estruturas de fundações, tem se valido de resultados de ensaios triaxiais com carregamento estático para a avaliação do desempenho destes materiais. Destaca-se que o ensaio triaxial estático permite a simulação de condições de campo variadas e a determinação do comportamento mecânico dos solos segundo diferentes níveis de tensões.

\subsection{Objetivo}

O objetivo principal deste trabalho é analisar o comportamento mecânico de solos tropicais para uso em pavimentação por meio de ensaios triaxiais convencionais, comparando-se resistências e deformabilidades de solos lateríticos e não lateriticos de mesma granulometria.

Para se alcançar o objetivo dividiu-se o trabalho em 3 etapas.

Na primeira etapa, realizou-se a escolha do material. Foram selecionados 6 solos, os quais estavam separados em 3 pares, sendo cada par constituído por solos de semelhantes curvas granulométricas, mesma classificação HRB e comportamentos

distintos quanto a laterização, ou seja, um de comportamento laterítico e o outro não-laterítico. 
Na segunda etapa, efetuaram-se as investigações laboratoriais. Essas investigações incluíram ensaios de compressão simples e ensaios triaxiais convencionais do tipo CD (adensado drenado) com amostras saturadas e não saturadas.

Na terceira etapa, foram executadas as análises dos resultados. Para tanto, além da análise dos resultados obtidos na segunda etapa desse trabalho, foram incluídos no trabalho os resultados de módulo de resiliência obtidos por Takeda (2006) através de ensaios triaxiais cíclicos.

\subsection{Organização do Trabalho}

Este trabalho foi desenvolvido na forma de dissertação de mestrado, estando organizado em 5 capítulos:

O Capítulo 1 é a presente introdução, onde estão descritos também o objetivo e a organização do trabalho.

O Capítulo 2 expõe a revisão bibliográfica que fundamenta os aspectos mais relevantes para o desenvolvimento desta pesquisa. Foram abordados os seguintes tópicos: os solos tropicais, definição e comportamento em pavimentação; e os ensaios triaxiais convencionais, procedimentos e analises de tensão e deformação em solos.

No Capítulo 3 estão descritos as características e critérios de escolha dos materiais, os métodos empregados na investigação experimental e na análise dos resultados. 
O Capítulo 4 apresenta e discute os resultados dos ensaios de compressão triaxiais e ensaios de compressão sem confinamento, comparando-se o comportamento dos solos lateríticos e não laterítico.

No Capítulo 5 estão expostas as principais conclusões do presente trabalho e as recomendações para trabalhos futuros, obtidas a partir dos ensaios e das análises dos seus respectivos resultados. 


\section{REVISÃO BIBLIOGRÁFICA}

\subsection{Solos Tropicais}

\subsubsection{Conceituação}

Adotou-se neste trabalho o conceito de Solos Tropicais, freqüentemente adotado em pesquisas de pavimentação e descrito pelo Committee on Tropical Soils of ISSMFE (1985) e por Nogami e Villibor (1995). Segundo os autores citados, Solos Tropicais são aqueles que apresentam comportamento e peculiaridades decorrentes da atuação de processos geológicos e/ou pedológicos típicos das regiões tropicais úmidas. Assim, para que um solo seja considerado tropical, não basta que tenha sido formado em regiões de clima tropical úmido, é necessário que apresente peculiaridades de interesse geotécnico (Nogami e Villibor, 1995).

\subsubsection{Solos Lateríticos}

Os solos lateríticos são solos superficiais, típicos das partes bem drenadas das regiões tropicais úmidas, altamente intemperizados e lixiviados, constituintes de 
horizontes pedológicos $\mathrm{A}$ e $\mathrm{B}$, podendo atingir espessuras de uma dezena de metros e possuem predominância das cores vermelha e amarela.

A macrofábrica dos solos lateríticos apresenta-se quase sempre homogênea e sua peculiaridade mais característica é a agregação das argilas, formando torrões quase sempre bem distinguíveis e resistentes, mesmo após a molhagem ou umedecimento.

A mineralogia desses solos é relativamente simples. As frações areia e pedregulho são compostas em sua maioria por quartzo, minerais pesados, como magnetita, ilmenita, zircão, etc. O primeiro componente é um elemento comum nessas frações, no entanto, nos solos lateríticos apresenta peculiaridades como a presença de película de óxidos. Similar a fração areia, o silte dos solos lateríticos contam com presença de quartzo, magnetita e ilmenita.

$\mathrm{Na}$ fração argila, podem-se encontrar constituintes minerais, como argilo-minerais, óxidos e hidróxidos de ferro e/ou alumínio e constituintes orgânicos. O argilo-mineral predominante nesses solos é a caolinita, de estrutura atômica tipo 1:1, ou seja, formado por uma repetição sucessiva de pacotes constituídos de uma camada de tetraedros de sílica e de uma camada de octaedros de alumina ligados por uma força atômica do tipo ponte de hidrogênio (ligação considerada forte). Esse tipo de ligação proporciona ao argilo-mineral pequena atividade coloidal, que nos solos lateríticos ainda é reduzida pela associação com óxidos e hidróxidos de ferro e alumínio. Os óxidos, apesar de possuírem elevada superfície específica e diminutas dimensões, não são plásticos, ou são muito pouco plásticos, não são expansivos e possuem uma capacidade de troca catiônica desprezível nas condições de pH 
predominantes nos solos. Além disso, os óxidos de ferro e alumínio hidratados possuem propriedades cimentantes, auxiliando na formação de agregados e concreções lateríticas.

Convêm ressaltar que a designação de solo laterítico aqui, não esta necessariamente vinculada com a classificação pedológica. Do ponto de vista geotécnico, o solo de comportamento laterítico é aquele que possui uma série propriedades que levam a classificá-lo como tal, segundo a classificação MCT. Assim, solos podzólicos ou hidromorficos, também podem ser de comportamento laterítico.

\subsubsection{Comportamento de Solos Tropicais em Pavimentação}

Nos primeiros trabalhos publicados sobre a utilização de solos lateríticos na pavimentação foram analisados o uso desses materiais como subleito, reforço de subleito, sub-base e base, utilizando-os isoladamente ou em misturas solo-brita, solo-cimento, ou ainda solo-cal.

Segundo Villibor e Nogami (1990 e 1995), o Engenheiro Francisco Pacheco e Silva do IPT foi o primeiro especialista em Mecânica dos Solos a valorizar a elevada capacidade de suporte e baixa expansibilidade das argilas lateríticas, coordenando a construção de trechos experimentais com bases de argila vermelha compactada e selada com pintura betuminosa. O desempenho dessa base foi excepcional comparada às bases de pedra britada muito utilizada na época. 
Durante a administração estadual do Governador Jânio Quadros, entre 1956 e 1960, a mistura brita-argila laterítica, popularmente chamada de "virado paulista", foi altamente utilizada, sobretudo na pavimentação de baixo custo. Contrariando os princípios de estabilização tradicional essa mistura apresentava bom resultados e já era utilizada nos arredores da grande São Paulo antes do advento do revestimento betuminoso na pavimentação, no entanto não foram elaborados nesta época normas nem estudos técnicos específicos. Apenas a partir dos estudos de Barros (1978) obtiveram-se fundamentos tecnológicos mais sólidos para o uso da mistura. O autor citado efetuou estudos de bases e sub-bases de misturas brita-argila laterítica e obteve desempenhos considerados satisfatórios comparados ao uso de brita graduada. No fim da década de 80 outros trechos experimentais foram construídos por Bernucci e Serra (1990) entre outros.

Os solos arenosos finos lateríticos foram utilizados pela primeira vez em 1967 em dois trechos como variantes de trânsito na via Washington Luís (SP-310), nas proximidades de Araraquara, no interior do estado de São Paulo (Correa, Villibor e Grande, $1972^{*}$ apud Nogami e Villibor, 1995). Essas variantes foram revestidas de tratamento superficial simples e teriam que funcionar apenas por 3 meses e meio, até a construção do trecho definitivo. Todavia após o termino desse prazo, constatou-se que as variantes estavam em perfeitas condições, fato que incentivou a construção de novos trechos experimentais com uso do tipo de base considerada.

\footnotetext{
* CORRÊA, F.C.; VILLIBOR, D.F., GRANDE, F.G. (1972). Utilização de Solos Finos Estabilizados na Execução de Bases. In II REUNIÃO DAS ORGANIZAÇÕES RODOVIÁRIAS, Brasília.
} 
Verificado o bom desempenho desses solos como material de construção para pavimentação, adveio a necessidade de se desenvolverem novos procedimentos laboratoriais que possibilitassem sua melhor caracterização e classificação, uma vez que não se enquadravam nas especificações das normas vigentes.

\subsubsection{Classificações Desenvolvidas para Solos Tropicais}

Diante da inviabilidade da utilização dos métodos tradicionais no estudo e classificação geotécnica de solos de países de clima tropical, vários métodos específicos para tais solos têm sido avaliados. Entre eles pode-se destacar a Metodologia MCT (Miniatura Compactada Tropical) como a mais aceita no meio técnico rodoviário brasileiro.

Proposta por Nogami e Villibor (1981) essa metodologia separa os solos em duas classes principais, uma correspondente a solos de comportamento laterítico e outra de comportamento não-laterítico. De maneira geral, observou-se que solos pertencentes a classe de comportamento laterítico comportam-se melhor do que o previsto pelos métodos tradicionais, enquanto os solos da classe dos não-lateríticos freqüentemente apresentam pior comportamento (Villibor et. al. 1996).

De acordo com Villibor et al. (1996), os novos procedimentos de escolha e dosagem de material e de projeto e construção apropriados para o ambiente tropical úmido, possibilitaram o uso de camadas de custo relativamente menores em comparação às tradicionais. Essa diferença de custo procede, sobretudo da possibilidade de utilização de maior porcentagem de solos locais de comportamento laterítico. 
A classificação MCT tem se mostrado apta para identificar o comportamento laterítico ou não laterítico dos solos tropicais, no entanto, tendo em vista sua complexidade no que diz respeito aos procedimentos de ensaio e à interpretação dos resultados, tanto os autores dessa classificação como os demais estudiosos dessa área vêm promovendo estudos que objetivam simplificar o método de classificação desses solos.

Fernandes (2006) comparou 3 métodos de determinação expedita de comportamento laterítico com a classificação MCT, para 38 solos do interior do estado de São Paulo. Foram comparados os seguintes métodos:

- O método expedito das pastilhas de Nogami e Villibor (1994), que consiste basicamente na moldagem de corpos-de-prova em forma de pastilhas em anéis de aço inox com dimensões de $20 \mathrm{~mm}$ de diâmetro e $5 \mathrm{~mm}$ de altura, e nas medidas de contração e penetração das pastilhas.

- O método expedito das pastilhas de Godoy e Bernicci (2002), que propõe modificações no método anterior. Entre elas, a mudança das dimensões das pastilhas para $35 \mathrm{~mm}$ de diâmetro e $10 \mathrm{~mm}$ de altura e a utilização de um minipenetrômetro para obtenção das medidas de penetração.

- Ensaio de adsorção de azul de metileno pelo método da manchas de Fabbri (1994), que consiste na determinação do máximo de adsorção de corante pelo argilo-mineral. 
Para os solos estudados por Fernandes (2006), os métodos expedidos apresentaram concordância com a classificação MCT de 82\%, 79\% e 92\%, respectivamente, para o primeiro, o segundo e o terceiro método citados a cima.

Nogami e Villibor (2003) relatam que apesar da classificação geotécnica MCT ter completado mais de 20 anos, não se pode afirmar que ela está perfeitamente consolidada e acrescentam que regionalmente há possibilidade de desenvolvimento de classificações geotécnicas mais específicas e mais simples.

Nesse contexto, Vertamatti (1988), ao aplicar a classificação MCT aos solos da região amazônica, verificou uma tendência de comportamento que não obedecia às linhas pré-determinadas pelo ábaco MCT, apresentado na figura 2.1a. A partir desse estudo o autor propôs a inclusão no ábaco da classificação MCT do grupo de solos transicionais $(\mathrm{T})$ conforme mostra a figura 2.1b. Esse ábaco foi denominado de MCTM.

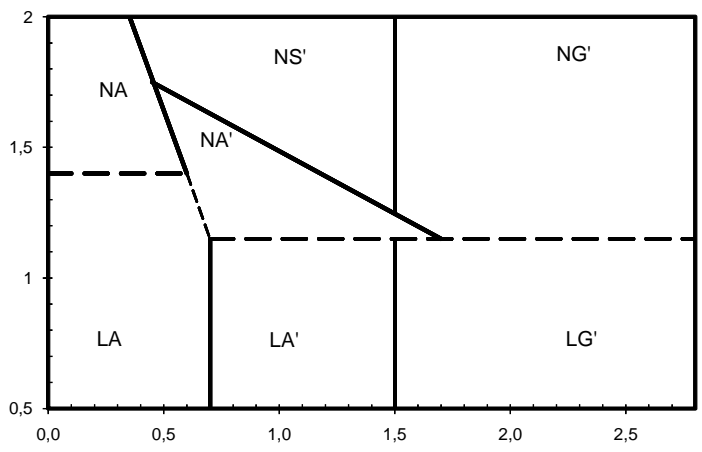

(a)

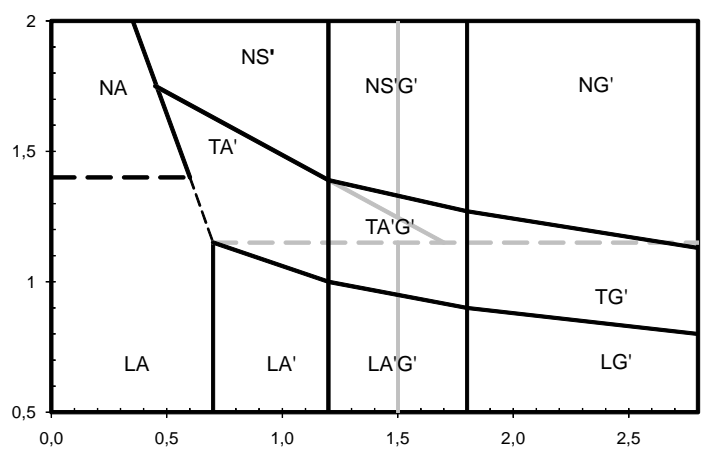

(b)

FIGURA 2.1- (a) - ábaco de classificação MCT; (b) - ábaco de classificação MCT-M 


\subsubsection{Comportamento mecânico de solos tropicais}

Largamente utilizado no meio rodoviário para seleção de material e dimensionamento de pavimentos flexíveis, o Índice de Suporte Califórnia (ISC ou CBR) foi o primeiro ensaio a comprovar as qualidades dos solos lateríticos para pavimentação.

Visando a obtenção de parâmetros para esses solos, alguns autores, como Costa (1983) e Camapum de Carvalho et al (1991), procuraram analisar o CBR obtido a partir de ensaios com imersão com o mesmo índice determinado em ensaios sem imersão. Os autores verificaram em seus trabalhos relações satisfatórias entre os dois índices e sugeriram respectivamente, a possibilidade de uma pré-avaliação do valor de CBR com imersão a partir de CBR sem imersão quando for justificado o uso do valor do primeiro, e o uso do CBR sem imersão no controle de capacidade de suportes durante a vida útil dos pavimentos e na obtenção de parâmetro de decisão na manutenção.

Parreira, Takeda e Luz (2004) avaliaram a influencia do período de imersão nos resultados do ensaio de CBR de solos tropicais para 6 solos do interior do estado de São Paulo. Com esse estudo os autores constataram que, para o universo de solos por eles estudados, a imersão de 4 dias não provoca distorções muito grandes nos resultados e que a absorção de água, a expansão e a variação de CBR durante a imersão são influenciadas em primeiro lugar pela granulometria dos materiais, seguido-se as condições de umidade e a gênese dos solos. 
Nogami e Villibor (1979) avaliaram que para as regiões tropicais seria necessário efetuar as determinações de suporte e expansão do ensaio CBR para diversas condições de umidade de compactação, imersão, sobrecarga e energias de compactação, o que exigiria uma quantidade de amostra grande para a moldagem dos diversos corpos de prova, além de um grande desgaste físico. Como solução para esse problema os autores utilizaram a proposta de Nogami (1972) ${ }^{\star}$, que propõe o emprego de equipamentos de dimensões reduzidas para prever o valor de Índice de Suporte Califórnia a fim de empregá-lo no dimensionamento de pavimentos flexíveis.

De acordo com Nogami e Villibor (1995) os solos lateríticos possuem uma série de peculiaridades quanto ao suporte Mini-CBR, das quais se destaca a pequena redução no valor de suporte pela imersão em água e valor de expansão relativamente pequeno, mesmo nas argilas e solos argilosos, quando compactados nas condições de umidade ótima e massa específica aparente seca máxima. Para os solos não lateríticos, os autores citados acima relatam peculiaridades como valor de expansão relativamente elevado.

Facilitada pela maior disponibilidade de recursos computacionais, a tendência mundial hoje é o emprego dos conceitos da Mecânica dos Pavimentos na analise estrutural de pavimentos. Essas análises utilizam a teoria da elasticidade e

\footnotetext{
* NOGAMI, J.S. (1972). Determinação do Índice de Suporte California com Equipamentos de Dimensões Reduzidas (Ensaio Mini-CBR). In: II REUNIÃO DAS ORGANIZAÇÕES RODOVIÁRIAS, Brasilia.
} 
consideram a estrutura do pavimento como um sistema de multicamadas, modeladas pelo comportamento elástico para o cálculo de tensões, deformações e deslocamentos gerados pelas cargas.

Para a utilização dessa teoria é indispensável o conhecimento do módulo de resiliência e do coeficiente de Poisson dos materiais que compõem a estrutura do pavimento. Sendo assim, surgiu no país uma grande linha de pesquisa onde se procura analisar não só as características dos solos lateríticos em termos de deformações elásticas, como também as relações entre o módulo de resiliência determinado no ensaio triaxial cíclico com resultados de ensaios mais simples.

No Brasil, os estudos sobre as propriedades resilientes dos solos foram iniciados na COPPE/UFRJ, a partir de meados de 1970. Atualmente, vários laboratórios brasileiros estão capacitados para determinação de propriedades resilientes, tanto de solos e solo-agregado como de misturas betuminosas.

Entre os vários trabalhos publicados podemos citar Preussler, Medina e Pinto (1981) e Preussler e Pinto (1982) que propuseram uma classificação de solos tropicais, a qual separa os solos em granulares e finos coesivos e Motta, Aranochi e Ceratti (1985), Vertamatti (1988) e Franzoi (1990) que estudaram o módulo de resiliência de solos tropicais, encontrando valores elevados para solos de comportamento laterítico e valores baixos para materiais de comportamento não laterítico. Takeda (2006) avaliou a influência da variação da umidade pós-compactação no comportamento mecânico de solos de rodovias do interior paulista e constatou que o efeito do umedecimento e secagem na alteração do módulo de resiliência processa-se de maneira similar para solos lateríticos e não-lateríticos quando são atingidos iguais 
patamares de umidade, sendo que os lateríticos demandam períodos de tempo 3,3x maiores para se atingir um determinado patamar de umedecimento quando comparados a solos não-lateríticos.

Contudo, o uso rotineiro da propriedade resilientes é muito limitado pela complexidade e alto custo dos ensaios triaxiais cíclicos. Tal situação motivou pesquisas de correlações que permitissem estimar o módulo de resiliência a partir de parâmetros resultantes de ensaios mais simples.

Os ensaios para determinação de CBR foram os primeiros a serem usados neste sentido, sendo estabelecidas algumas relações entre o CBR e o módulo de resiliência. Posteriormente, verificou-se que os mecanismos envolvidos nestes ensaios são distintos e não seria apropriado relacionar seus resultados.

Atualmente, relações entre o módulo de resiliência e resultados de outros ensaios como compressão simples e triaxial convencional têm sido estudadas. A utilização do ensaio de compressão simples tem a vantagem do mesmo ser de fácil execução. Por meio deste ensaio o módulo de resiliência vem sendo relacionado com a resistência à compressão simples (Thompson e Robnett, 1979), com S $_{u 1,0 \%}$ - tensão correspondente a 1\% de deformação axial (Lee et al., 1995), e com o módulo tangente inicial (Parreira et al., 1998). O ensaio triaxial convencional, apesar de ser mais complexo que o de compressão simples, também tem atraído o interesse de pesquisadores por representar melhor as condições de campo, uma vez que permite o confinamento da amostra. Vem-se estudando relações entre o módulo de resiliência e variáveis obtidas a partir deste ensaio, como a coesão e o ângulo de 
atrito interno do solo (Zaman et al., 1994) e o módulo descarregamento/recarregamento (Kim et al., 2001).

\subsection{Estudos de Comportamento Mecânico de Materiais Geotécnicos a partir de Ensaios Triaxiais Estáticos}

\subsubsection{Introdução}

Em pavimentação, o ensaio de compressão simples tem sido utilizado tradicionalmente na determinação do comportamento mecânico de solos e misturas estabilizadas. Com o advento das análises mecanísticas, o ensaio triaxial cíclico tem-se consolidado como principal ferramenta para a determinação do comportamento tensão versus deformação de materiais geotécnicos para uso em pavimentação. Todavia, obras geotécnicas, como barragens e estruturas de fundações têm se valido de resultados de ensaios triaxiais com carregamento estático para a avaliação do desempenho destes materiais. Destaca-se que o ensaio triaxial estático permite a simulação de condições de campo variadas e a determinação do comportamento mecânico dos solos segundo diferentes níveis de tensões. 


\subsubsection{Procedimentos de ensaios}

No ensaio triaxial convencional o corpo-de-prova é revestido por uma membrana impermeável e colocado em uma câmara onde pode ser submetido a diversas condições de tensão confinante $\left(\sigma_{3}\right.$ ou $\left.\sigma_{c}\right)$ e tensão axial $\left(\sigma_{1}\right)$. A figura 2.2 apresente um esquema da câmara de ensaios de compressão triaxial.

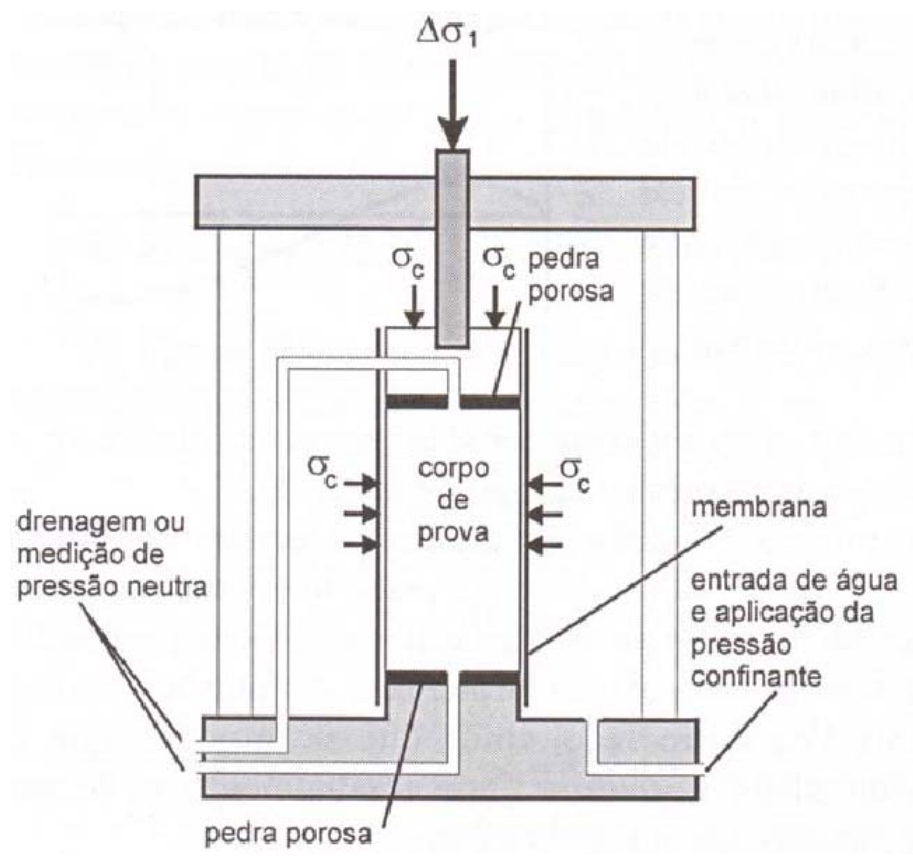

FIGURA 2.2- Esquema de uma câmara de ensaio de compressão triaxial

A tensão confinante é aplicada na câmara através de água ou ar comprimido que por sua vez transmite a pressão para todo o corpo-de-prova. As tensões axiais são transmitidas por um pistão apoiado no cabeçote colocado no topo do corpo-deprova. São colocadas pedras porosas no topo e base do corpo-de-prova para permitir a melhor passagem da água. 
As diversas conexões da câmara com o exterior permitem medir ou dissipar pressões neutras, medir variações de volume e a drenar ou não o corpo-de-prova durante o ensaio.

Dentre as diversas maneiras de conduzir um ensaio de compressão triaxial pode-se destacar:

- Ensaio Lento: neste ensaio há drenagem permanente do corpo-de-prova. Aplica-se a tensão confinante e espera-se que o corpo-de-prova adense. A seguir, a tensão axial é aumentada lentamente para que a água sob pressão possa percolar para fora do corpo-de-prova, até a ruptura. Desta forma a pressão neutra durante o carregamento permanece praticamente nula e as tensões totais medidas são as tensões efetivas. Esse ensaio é também chamado drenado, adensado drenado e é representado pelos símbolos $\mathbf{S}$ (Slow) e CD (Consolidated Drained).

- Ensaio Adensado Rápido: neste ensaio permite-se drenagem do corpo-deprova somente sob a ação da tensão confinante $\left(\sigma_{3}\right)$. Aplica-se a tensão confinante e espera-se que o corpo-de-prova adense. A seguir fecham-se os registros de drenagem e a tensão axial é aumentada até a ruptura, sem que se altere a umidade do corpo-de-prova. As tensões medidas nesse ensaio são totais e poder-se-á ter as tensões efetivas, se forem feitas medidas de pressões neutras após o adensamento inicial. Esse ensaio é também chamado rápido pré-adensado, adensado sem drenagem e representado pelos símbolos R ou CU (Consolidated Undrained). Havendo leitura de pressões neutras costuma-se representa-los por $\bar{R}$. 
- Ensaio Rápido: nestes ensaios o corpo-de-prova é submetido à tensão confinante e ao carregamento axial até ruptura sem qualquer drenagem. $\mathrm{O}$ teor de umidade do corpo-de-prova permanece constante e as tensões medidas são tensões totais. Poder-se-á ter as tensões efetivas se forem feitas medidas de pressões neutras durante o ensaio todo. Esse ensaio é também chamado, sem drenagem e é representado pelos símbolos Q e UU (Unconsolidated Undrained) Havendo leitura de pressões neutras costuma-se representa-lo por $\overline{\mathrm{Q}}$.

Todos esses ensaios podem ser realizados com amostras saturadas ou não saturadas, moldadas em laboratório ou indeformadas.

\subsubsection{Análises de Resistência}

Para obter a tensão de ruptura pode-se analisar o pico das curvas tensão versus deformação traçadas em função da diferença de tensões principais $\left(\sigma_{1}-\sigma_{3}\right)$ ou da relação $\sigma_{1} / \sigma_{3}$ dependendo da finalidade do ensaio. De acordo com Head (1986), a relação $\sigma_{1} / \sigma_{3}$ é preferencialmente utilizada nas argilas, em ensaios não drenados, em que a tensão desviatória continua a aumentar para grandes deformações. A autora citada acima ressalta que outras "opções de ruptura" podem ser escolhidas, como a resistência residual ou a resistência obtida para cisalhamento a volume constante, ou seja, na condição de estado crítico, ou ainda definida a partir das deformações máximas permissíveis no projeto em questão. A figura 2.3 apresenta os critérios para determinação de ruptura. 


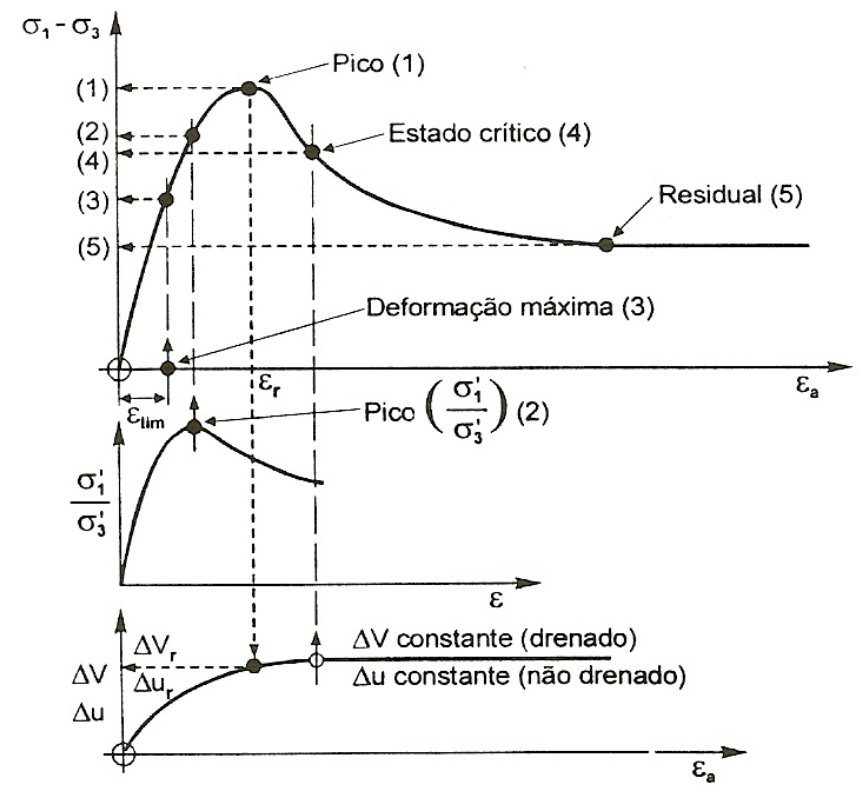

FIGURA 2.3- Diferentes critérios para definição de ruptura (Head, 1986)

A resistência ao cisalhamento dos solos é afetada por diversos fenômenos entre os quais podemos destacar o atrito e a coesão.

A resistência por atrito é função da tensão normal no plano de deslizamento relativo de cada partícula. Segundo Terzaghi, em sua "Teoria Adesiva do Atrito", a superfície de contato real entre dois corpos constitui apenas uma parcela da superfície aparente de contato, dado que em um nível microscópico as superfícies dos materiais são efetivamente rugosas. Considerando que o coeficiente de atrito deve ser governado pelo que ocorre nos pontos reais de contato, as características de rugosidade e de adsorção da superfície da partícula serão relevantes para controlar a resistência que se desenvolve. A rugosidade governa o tamanho das protuberâncias superficiais, que em geral são diferentes quer se consideram partículas grossas ou partículas finas. Por outro lado, a adsorção de água e outras 
substâncias tende a afetar a natureza e tamanho da área de contato entre partículas.

A coesão consiste na parcela da resistência de um solo que existe independente de qualquer tensão aplicada. Várias são as origens da coesão nos solos. A cimentação entre partículas proporcionada por carbonatos, sílica, óxidos de ferro, dentre outras substancias, responde muitas vezes por altos valores de coesão. Além disso, as forças de atração e repulsão causadas pelos fenômenos eletrostáticos e eletromagnéticos e as propriedades da película adsorvida junto às partículas também auxiliam na coesão.

Mitchel (1976) expõe que as atrações de origem eletrostática decorrem da interação entre partículas de cargas opostas distantes entre si de no máximo $2.5 \mu \mathrm{m}$ e evidentemente também ocorrem forças de repulsão quando as partículas apresentam cargas de mesma natureza. Quando partículas menores de $1 \mu \mathrm{m}$ estão a distâncias muito pequenas as atrações eletromagnéticas do tipo das forças de Van der Waals contribuem também para a coesão.

Existe também um tipo de coesão que não tem ligação com cimentação ou com atrações químicas. Essa coesão, chamada de aparente, ocorre em solos não saturados através da adsorção provocada pela pressão neutra negativa. Vilar (1990) relata que embora o princípio das tensões efetivas não possa ser estendido indiscriminadamente aos solos não saturados, pode-se, numa primeira aproximação, utilizá-lo para explicar o aumento da resistência. Para solos saturados tem-se $\sigma^{\prime}=\sigma$ u. Como a água num solo não saturado encontra-se com pressão neutra negativa, 
tem-se uma situação em que a tensão normal efetiva supera a tensão total, donde vem o ganho adicional de resistência. Esse tipo de coesão desaparece caso o solo seja totalmente saturado ou seco e sua intensidade cresce com a diminuição do tamanho das partículas.

A figura 2.4 ilustra a contribuição dos diversos mecanismos de ligação para a resistência.

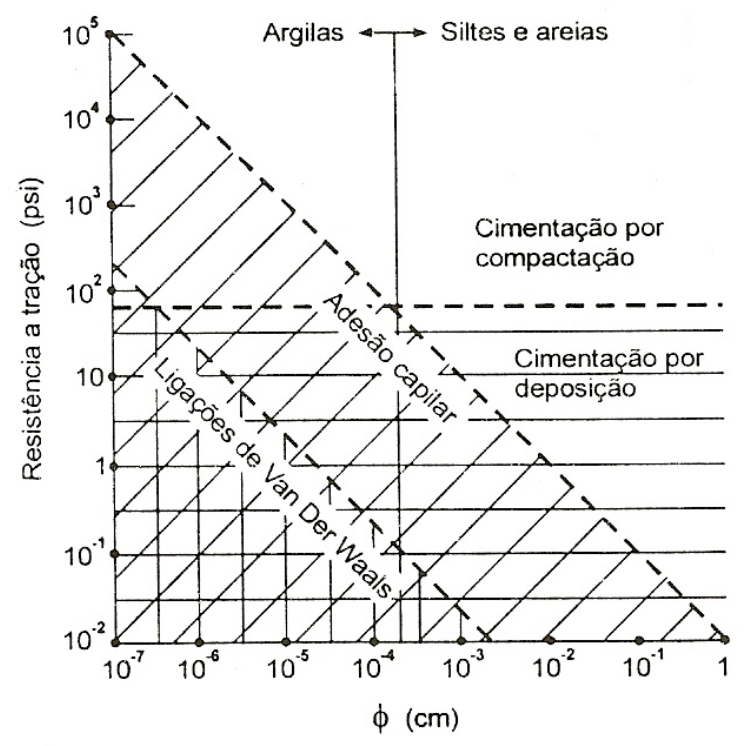

FIGURA 2.4 - Contribuição dos vários mecanismos de ligação para a resistência dos solos (Inglês, 1962 in Mitchel, 1976) 


\subsubsection{Critério de Ruptura}

Souza Pinto (2002) conceitua critérios de ruptura como formulações que procuram refletir as condições em que ocorre a ruptura dos materiais, sendo que esses critérios podem estabelecer máxima tensão de compressão, tração ou cisalhamento ou máxima deformação.

O estudo da resistência ao cisalhamento dos solos é a análise do estado de tensões que provoca a ruptura do mesmo. Entre os diversos critérios os mais aplicados para solos são o critério de Mohr e de Coulomb.

O critério de Coulomb pode ser expresso pela equação:

$$
\tau=c+\operatorname{tg} \phi \cdot \sigma
$$

Onde: $\tau=$ tensão de cisalhamento;

$$
\begin{aligned}
& \sigma=\text { tensão normal existente no plano de ruptura; } \\
& \phi \text { e c = constantes do material. }
\end{aligned}
$$

A ruptura nesse critério ocorre quando a tensão de cisalhamento atinge o valor expresso pela equação acima e ilustrado na figura 2.5 (a).

O critério de Mohr é expresso pela envoltória dos círculos relativos a estados de ruptura como pode ser observado na figura 2.5 (b). A ruptura ocorre quando a tensão de cisalhamento atinge esta envoltória. Como as envoltórias curvas são de 
difícil aplicação, freqüentemente elas são substituídas por retas que melhor se ajustem às curvas.

Fazendo-se uma reta com a envoltória de Mohr, seu critério de resistência fica análogo ao de Coulomb, justificando a expressão Critério de Mohr-Coulomb, costumeiramente empregado na Mecânica dos Solos (Souza Pinto, 2002).

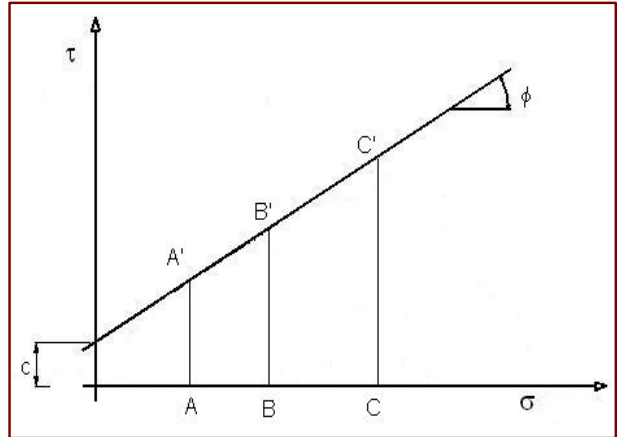

(a)

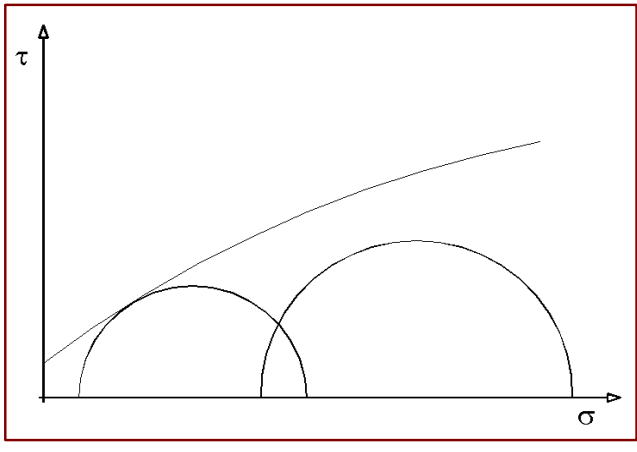

(b)

FIGURA 2.5- Representação dos Critérios de Ruptura: (a) de Coulomb; e (b) de Mohr

Segundo Souza Pinto (2002) apesar desse critério não levar em conta a tensão principal intermediaria, eles refletem bem o comportamento dos solos, uma vez que a experiência tem mostrado que, de fato, a tensão principal intermediaria tem pequena influencia na resistência dos solos. Critérios mais modernos, em que as três tensões principais são consideradas, têm sido desenvolvidos e aplicados a problemas especiais. 
No campo de estudos de resistência ao cisalhamento de solos não saturados destaca-se a atuação da variável sucção, definida como a diferença entre a pressão no ar e a pressão na água nos vazios $\left(u_{\mathrm{a}}-\mathrm{u}_{\mathrm{w}}\right)$, no comportamento dos solos. Fredlund et al (1978) apud Parreira (1991) propõe uma extensão tridimensional do critério de ruptura de Mohr-Coulomb para representar o comportamento desses solos, no qual:

$$
\tau=c^{\prime}+\left(\sigma-u_{a}\right) \cdot \operatorname{tg} \phi^{\prime}+\left(u_{a}-u_{w}\right) \cdot \operatorname{tg} \phi^{b}
$$

Onde: . $\tau=$ Resistência ao cisalhamento $(\mathrm{kPa})$;

c'= Intercepto coesivo efetivo;

$\sigma=$ Tensão normal total (kPa);

$\mathrm{u}_{\mathrm{a}}=$ Pressão de ar;

$\mathrm{u}_{\mathrm{w}}=$ Pressão de água;

$\phi^{\prime}=$ Ângulo de atrito interno efetivo relativo às variações de $\left(\sigma-u_{a}\right)$, quando $\left(u_{a}-u_{w}\right)$ é constante.

$\phi^{b}=$ Ângulo de atrito interno relativo às variações da sucção matricial $\left(u_{a}-u_{w}\right)$, quando $\left(\sigma-u_{a}\right)$ é constante.

* FREDlund, D.G., MORGENSTERN, N.R. E WIDGER, R.A. (1978) The share strength of unsaturated soils. In: CANADIAN GEOTECHNICAL JOURNAL, v.15, n.3, p. 313-321. 
A figura 2.6 ilustra o modelo proposto por Fredlund (1978).

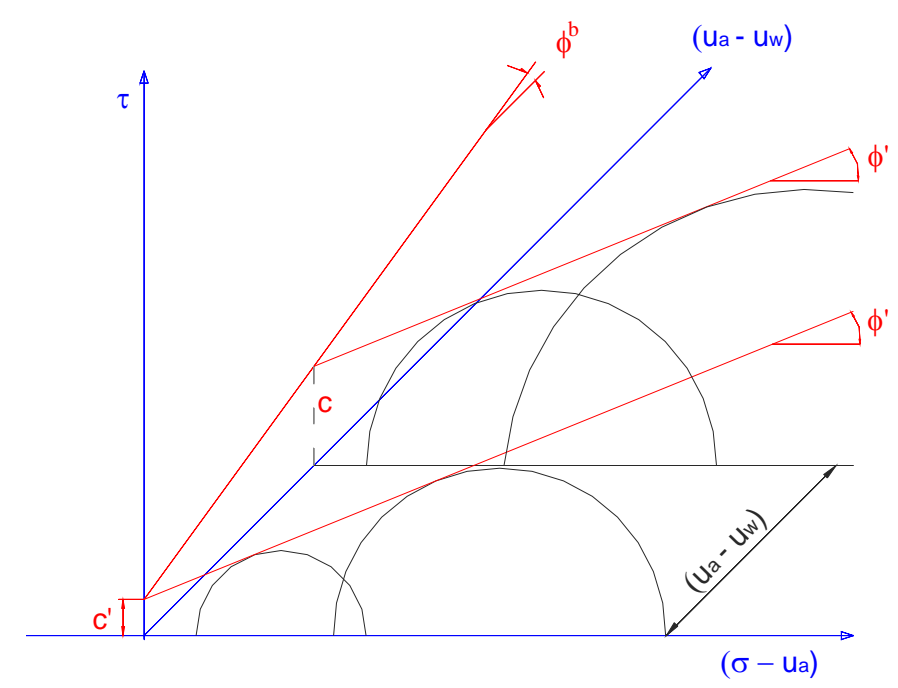

FIGURA 2.6- Extensão tridimensional do critério de ruptura de Mohr-Coulomb proposto por Fredlund (1978)

Pode-se isolar na equação 2.2, o efeito da coesão aparente, conforme a equação 2.3:

$$
c=c^{\prime}+\left(u_{a}-u_{w}\right) \cdot \operatorname{tg} \phi^{b}
$$

Onde: . c = Coesão aparente do solo para um dado valor de sucção (kPa);

$c^{\prime}=$ Intercepto coesivo efetivo;

$\left(u_{\mathrm{a}}-\mathrm{u}_{\mathrm{w}}\right),=$ Sucção matricial $(\mathrm{kPa})$;

$\phi^{\mathrm{b}}=$ Ângulo de atrito interno relativo às variações da sucção matricial. 
Diversos outros autores têm apresentado resultados de ensaios nos quais nota-se uma variação não linear da coesão com a variação da sucção, nesse sentido, Rohm e Vilar (1995) e Reis e Vilar (2004) propõem para a coesão aparente um modelo onde a sua variação se dá segundo um ajuste hiperbólico da sucção, conduzindo à equação 2.4 :

$$
c=c^{\prime}+\frac{\left(u_{a}-u_{w}\right)}{\left[a+b \cdot\left(u_{a}-u_{w}\right)\right]}
$$

Onde: . c = Coesão aparente do solo para um dado valor de sucção (kPa);

$$
\begin{aligned}
& \text { c'= Intercepto coesivo efetivo; } \\
& \left(u_{a}-u_{w}\right),=\text { Sucção matricial }(k P a) ; \\
& \text { "a" e "b" = Parâmetros do ajuste hiperbólico. }
\end{aligned}
$$

Considerando-se os dois modelos descritos anteriormente (equações 2.3 e 2.4), observa-se que, para ensaios não saturados, a coesão obtida poderia ser descrita como a soma de uma parcela correspondente à coesão efetiva com outra parcela oriunda da sucção enquanto o ângulo de atrito interno mantém-se constante independente da existência ou não de sucção.

\subsubsection{Análises de Deformabilidade}

Os solos são materiais de comportamento elasto-plástico, ou seja, podem gerar concomitantemente deformações plásticas e elásticas. As deformações elásticas são 
aquelas que após um ciclo de carregamento-descarregamento são totalmente reversíveis, enquanto as deformações plásticas são aquelas irreversíveis.

O primeiro modelo constitutivo utilizado para solos baseou-se na teoria da elasticidade linear, a partir da relação tensão $(\sigma)$ e deformação $(\varepsilon)$, formulada por Hooke através de observações experimentais em fios metálicos quando submetidos a carregamentos uniaxiais como mostra a expressão:

$$
\sigma=E \cdot \varepsilon
$$

Onde: $\sigma=$ tensão;

$$
\begin{aligned}
& \varepsilon=\text { deformação; } \\
& E=\text { módulo de elasticidade }
\end{aligned}
$$

Para elementos tridimensionais a equação 2.6 pode ser generalizada por:

$$
\{\sigma\}=|C| \cdot\{\varepsilon\}
$$

Onde: $\{\sigma\}=$ tensor de tensão;

$$
\begin{aligned}
& \{\varepsilon\}=\text { tensor de deformação; } \\
& I C \mid=\text { matriz dos coeficientes elásticos. }
\end{aligned}
$$

Apesar de se observar que a grande maioria dos materiais exibe um comportamento mais complexo, o modelo elastico-linear foi amplamente utilizado devido a sua simplicidade e também a inexistência de ferramentas que possibilitassem resolver o comportamento mais complexo dos materiais. 
Esse modelo tem como característica principal representar o comportamento elástico dos materiais através de um valor constante para o módulo de elasticidade. Contudo, os solos podem apresentar um comportamento tensão versus deformação não linear, com o módulo de elasticidade variando com o seu estado de tensão.

Vários autores detiveram-se na tentativa de estabelecer uma relação que pudesse representar o comportamento não linear dos solos. Entre os estudos realizados podemos citar o modelo hiperbólico de Duncan e Chang (1970) ilustrado na figura 2.7 e expresso pela equação:

$$
\frac{\varepsilon}{\left(\sigma_{1}-\sigma_{3}\right)}=\mathrm{a}+\mathrm{b} \cdot \varepsilon
$$

Onde: $\varepsilon=$ deformação axial;

$\sigma_{1}=$ tensão axial;

$\sigma_{3}=$ tensão de confinamento;

$a$ e b = coeficientes de regressão.

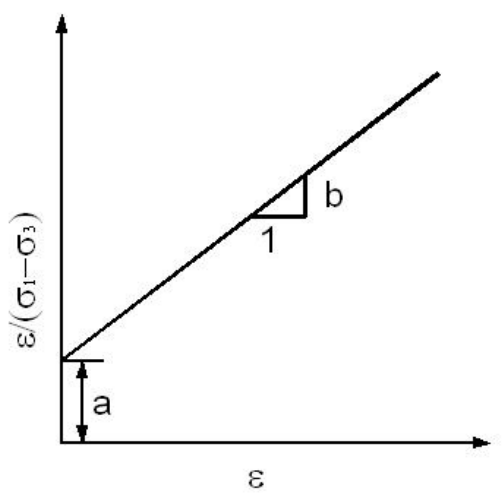

FIGURA 2.7- Modelo hiperbólico 
Por esse modelo o módulo tangente inicial $\left(E_{0}\right)$ é calculado como:

$$
E_{0}=\frac{1}{a}
$$

Onde: $\mathrm{E}_{0}=$ Módulo tangente inicial;

$\mathrm{a}=$ coeficiente de regressão determinado na equação 2.3 .

Os modelos elasto-plásticos são mais complexos que os indicados acima, envolvem aspectos como critérios de plastificação, leis de fluxo e leis de endurecimento e representam melhor o comportamento dos solos. Contudo, como para pavimentação o estudo das deformações elásticas e plásticas dá-se separadamente, esses modelos não foram expostos neste trabalho. 


\section{MATERIAIS E MÉTODOS}

\subsection{Introdução}

A seleção dos materiais para estudo e a investigação experimental foram conduzidos de maneira a possibilitar a análise comparativa do comportamento mecânico de solos lateríticos e não lateríticos.

\subsection{Seleção dos Solos}

Os solos utilizados nesta pesquisa foram selecionados entre as 30 amostras coletadas em rodovias do interior do Estado de São Paulo e estudados por Takeda (2006). Entre estas amostras foram destacados pares constituídos por solos de semelhantes curvas granulométricas, mesma classificação HRB e comportamentos distintos quanto a laterização, ou seja, um de comportamento laterítico e o outro não-laterítico. Entre os pares existentes no trabalho de Takeda (2006) selecionaramse 3, cujos solos tivessem maior variação no índice (e), ou seja, que no gráfico MCT estivessem mais distantes do limite que divide os solos lateríticos dos não lateríticos. A figura 3.1 apresenta os solos estudados e a tabela 3.1 apresenta as regiões, as coordenadas geográficas e a posição em relação à linha de seixos de cada uma das 6 amostras dos 3 pares selecionados. 


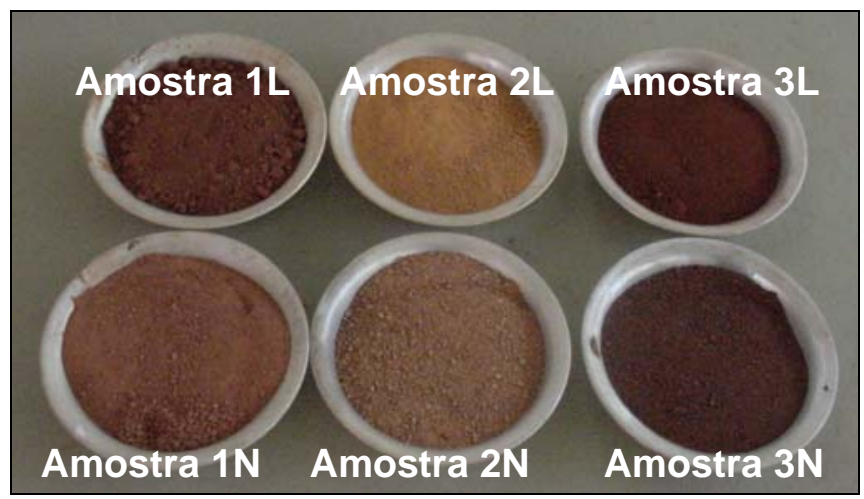

FIGURA 3.1 - Amostras selecionadas para estudo

TABELA 3.1- Localização, coordenadas e posição em relação à linha de seixos dos solos estudados

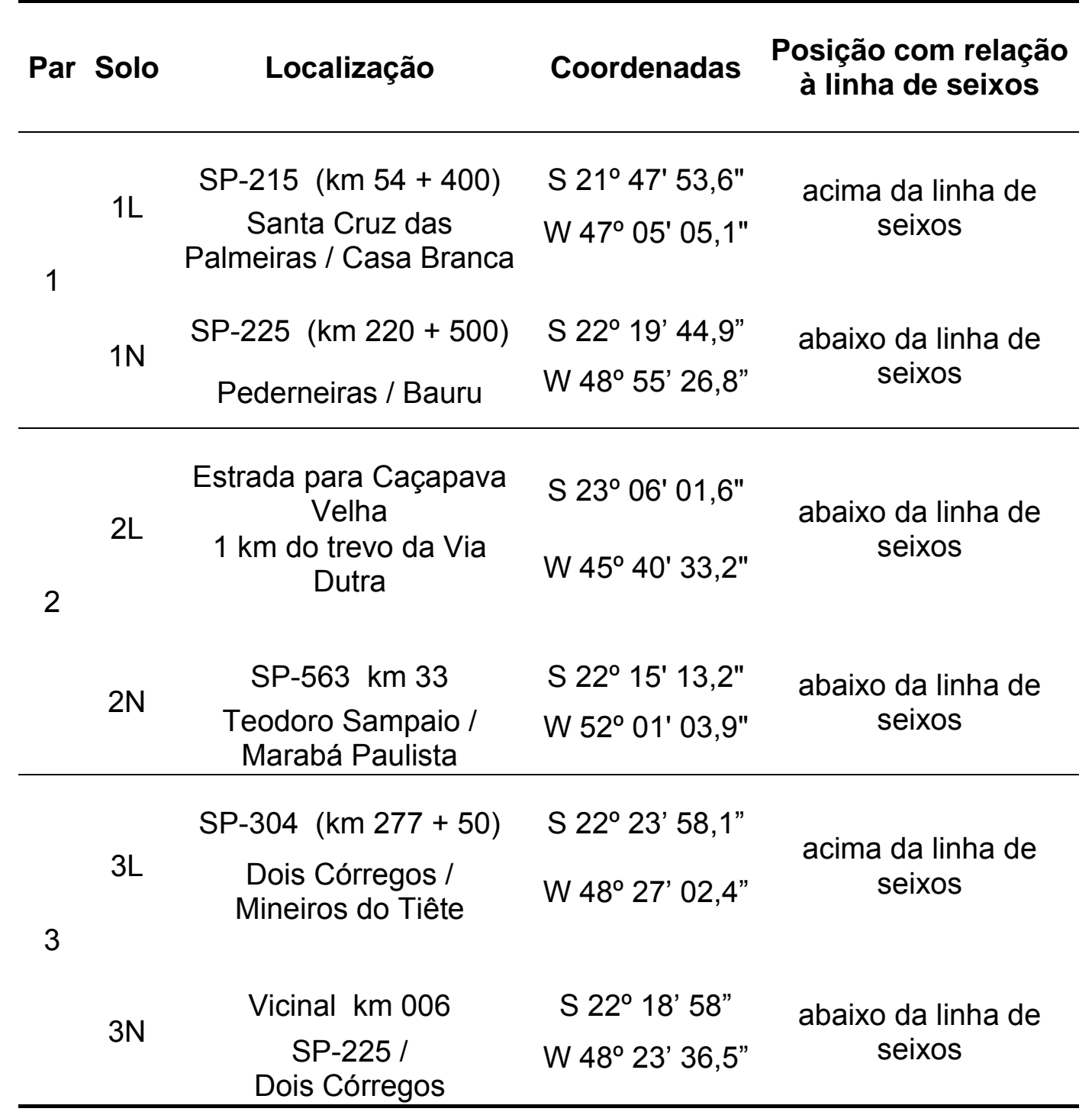




\subsubsection{Caracterização e Classificação dos Solos}

Os ensaios de caracterização e classificação dos solos foram realizados por Takeda (2006).

Para caracterizar os solos foram determinados os limites de consistência, realizados segundo as normas NBR 6459 - "Solo - Determinação do limite de Liquidez" e NBR 7180 - "Solo - Determinação do Limite de Plasticidade"; a massa específica de sólidos, realizada segundo a norma NBR 6508 - "Grãos de solo que passam na peneira 4,8 mm - Determinação da Massa Específica"; e a análise granulométrica conjunta, realizada segundo a norma NBR 7181 - "Solos - Análise Granulométrica". Os resultados desses ensaios permitiram a classificação dos solos segundo o Sistema Unificado e HRB (Highway Research Board).

Para a classificação MCT adotaram-se os procedimentos descritos nas normas DNER - M 256/94 - "Solos compactados com equipamento miniatura Determinação da perda de massa por imersão" e DER - M 196/89 - "Classificação de solos tropicais segundo a metodologia MCT".

As figuras 3.2, 3.3 e 3.4 apresentam as curvas granulométricas dos pares 1, 2 e 3, respectivamente, enquanto a figura 3.5 apresenta as curvas granulométricas de todos os pares conjuntamente. 


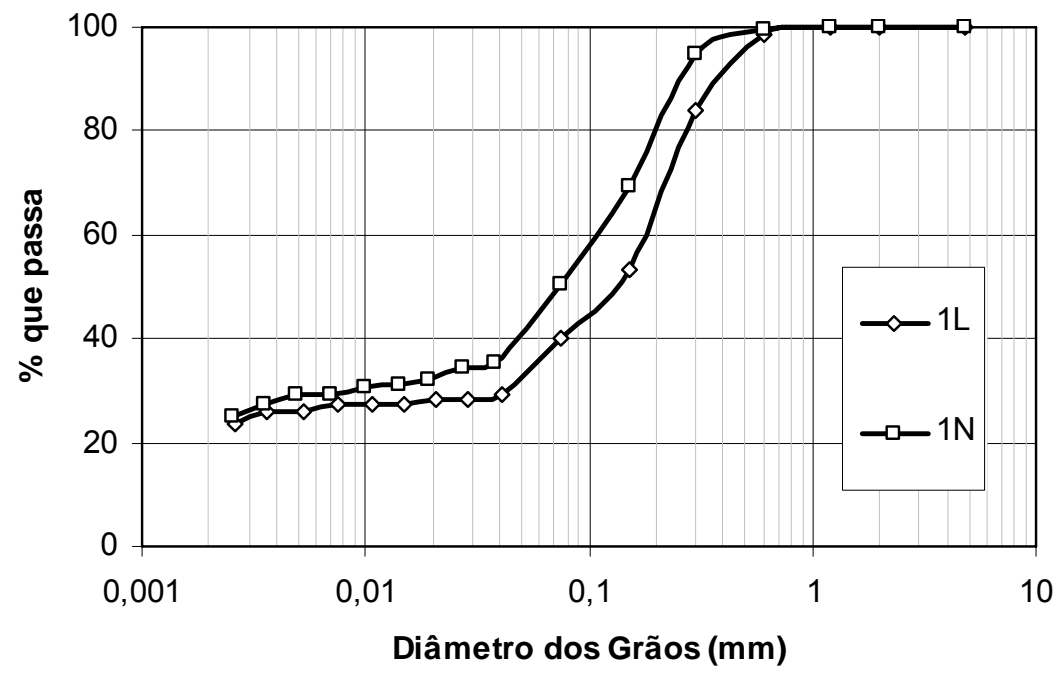

FIGURA 3.2 - Curvas granulométricas dos solos 1L e 1N

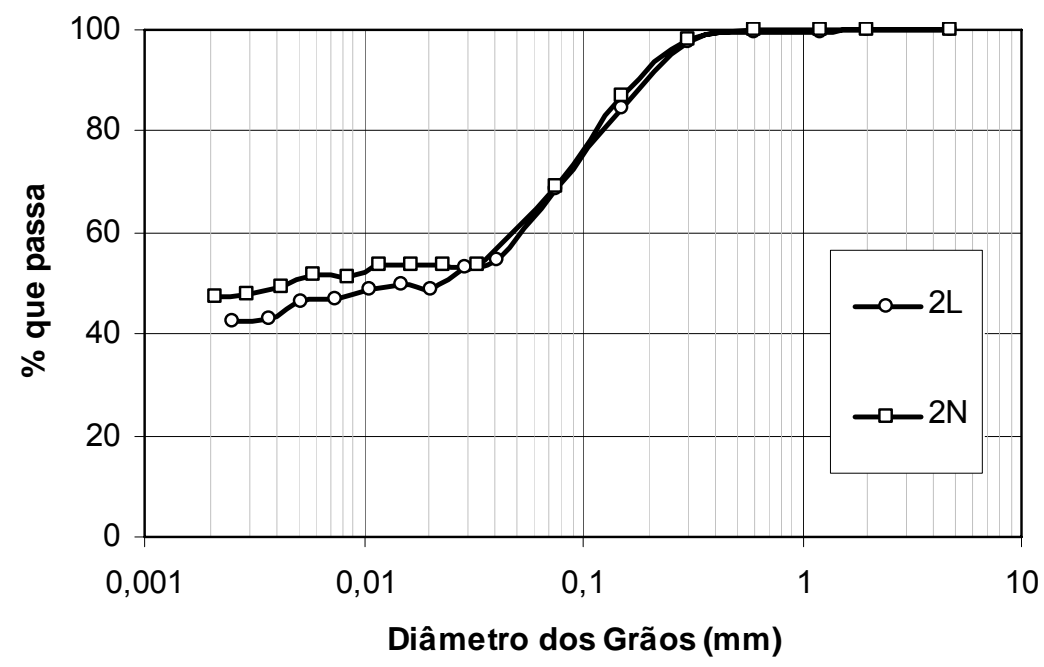

FIGURA 3.3 - Curvas granulométricas dos solos $2 \mathrm{~L}$ e $2 \mathrm{~N}$ 


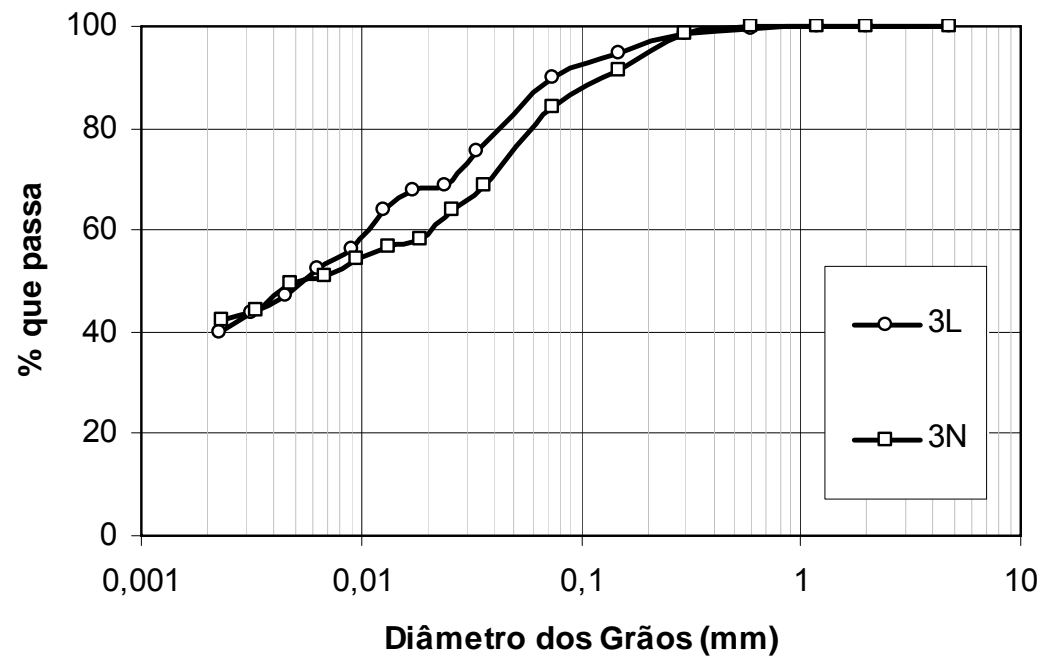

FIGURA 3.4 - Curvas granulométricas dos solos 3L e 3N

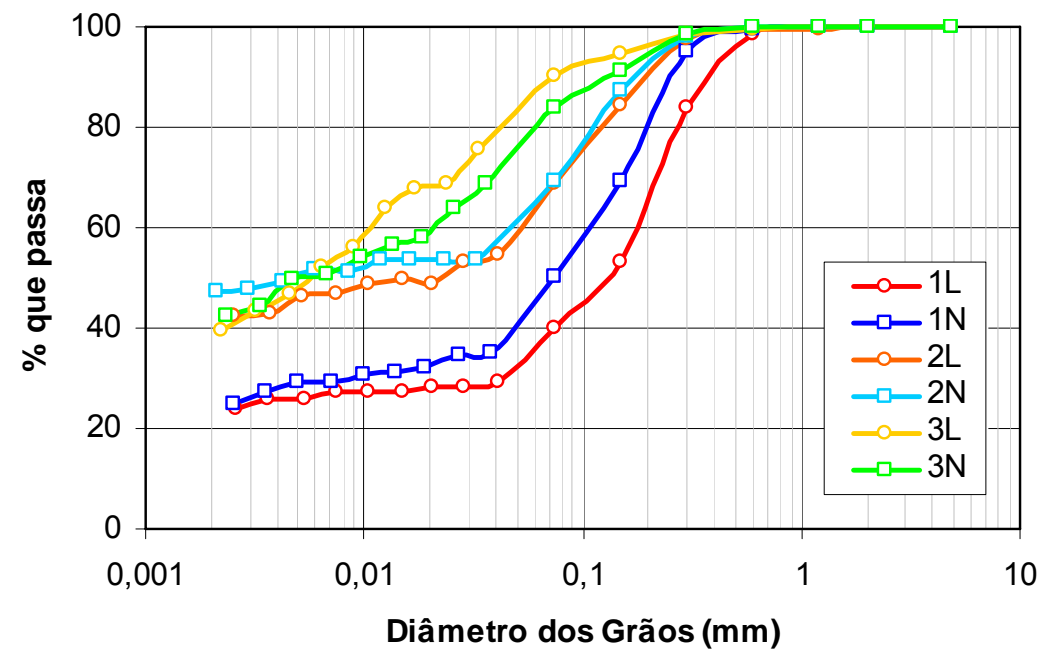

FIGURA 3.5 - Curvas granulométricas dos solos estudados

A figura 3.6 apresenta a Carta de Plasticidade de Casagrande com a posição dos solos estudados. 


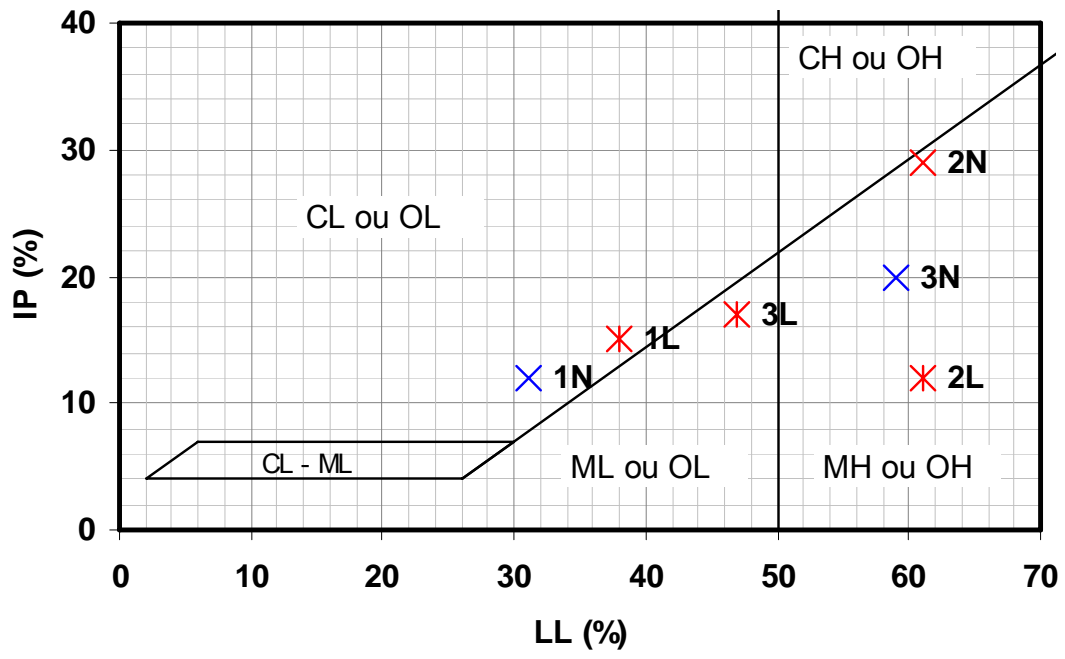

FIGURA 3.6 - Carta de Plasticidade de Casagrande

A figura 3.7 apresenta os gráficos MCT e MCT-M com as indicações dos 6 solos estudados. As figuras 3.8 a 3.13 apresentam as imagens obtidas nos ensaios de microscopia eletrônica de varredura dos solos $1 \mathrm{~N}, 1 \mathrm{~L}, 2 \mathrm{~N}, 2 \mathrm{~L}, 3 \mathrm{~N}$ e $3 \mathrm{~L}$, respectivamente. Cada amostra foi caracterizada por duas imagens com diferentes aumentos. Conforme se observa a seguir, a primeira foto tem aumento de 3000 vezes e a segunda aumento de 10000 vezes.
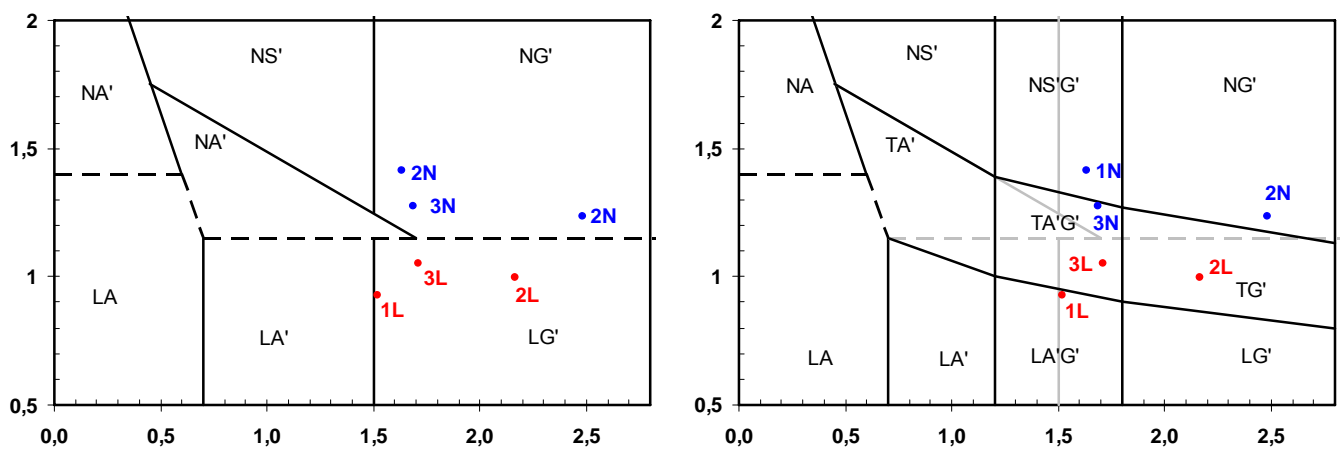

(a)

(b)

FIGURA 3.7 - Gráficos MCT e MCT-M (Vertamatti, 1988) com a indicação dos seis solos estudados. 


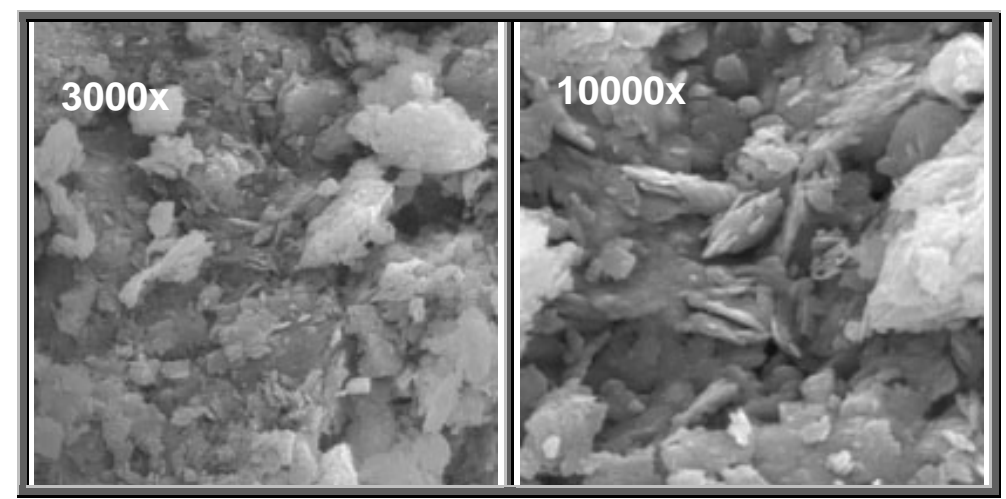

FIGURA 3.8- Imagens de microscopia eletrônica de varredura do solo 1N.

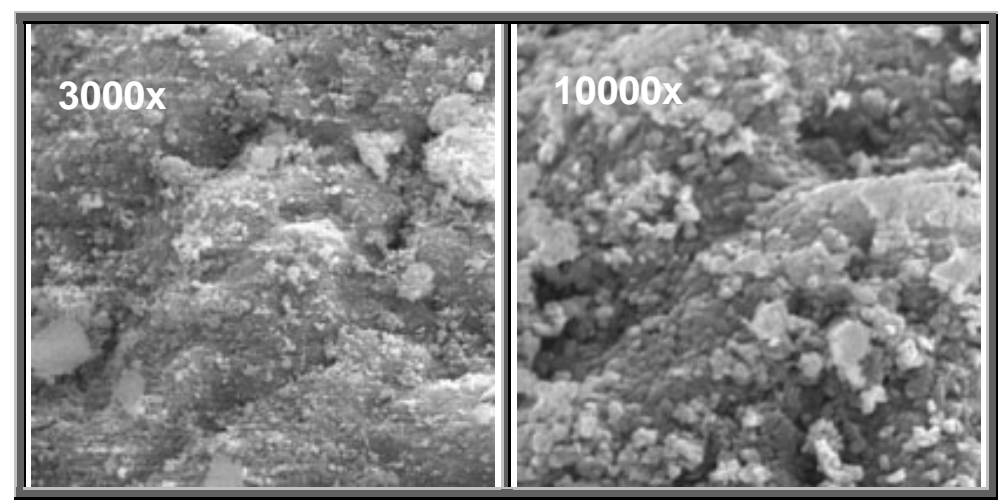

FIGURA 3.9 - Imagens de microscopia eletrônica de varredura do solo 1L.

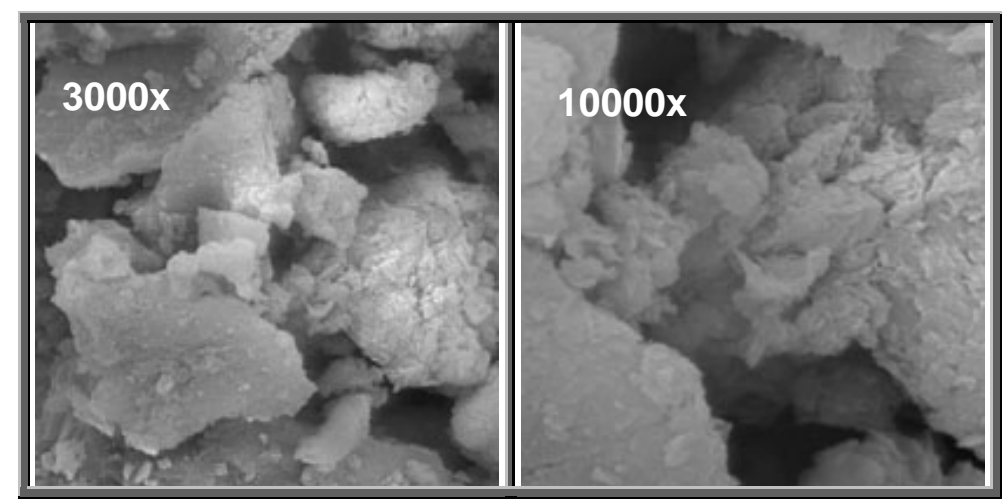

FIGURA 3.10 - Imagens de microscopia eletrônica de varredura do solo 2N. 


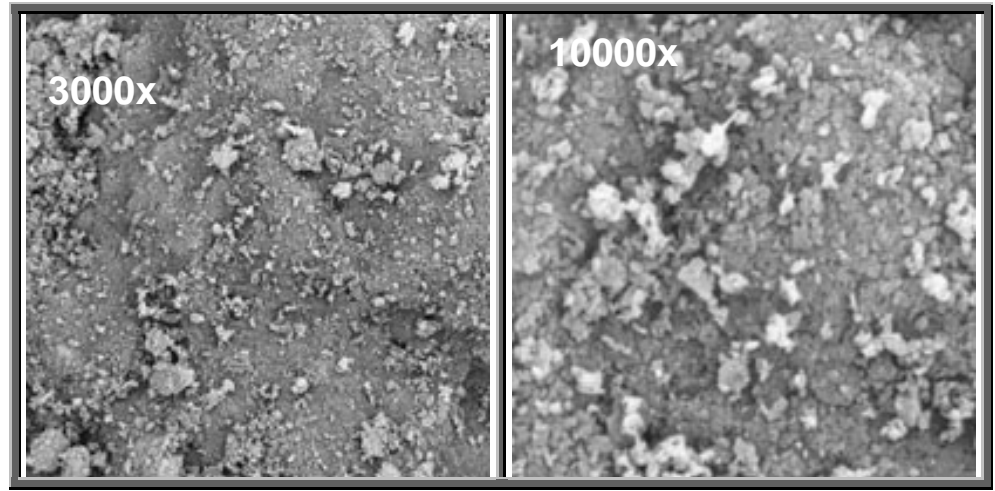

FIGURA 3.11 - Imagens de microscopia eletrônica de varredura do solo 2L.

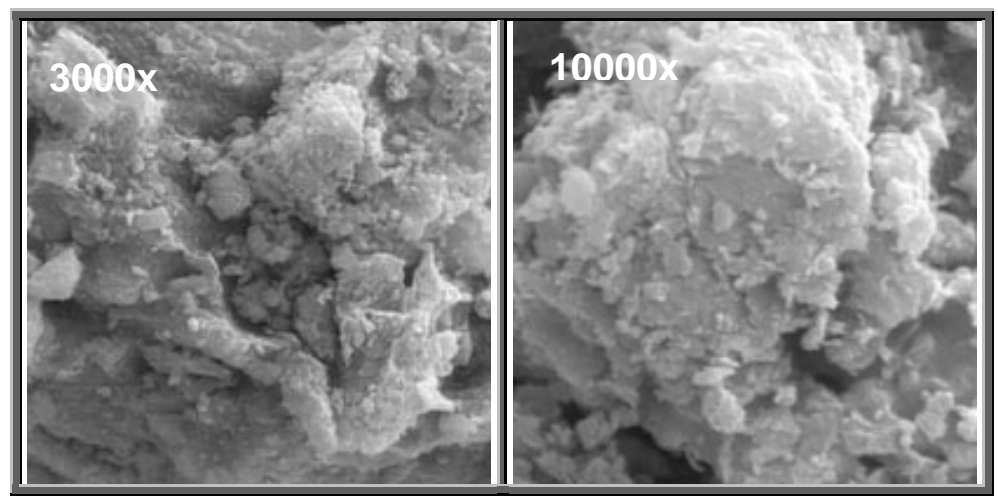

FIGURA 3.12 - Imagens de microscopia eletrônica de varredura do solo 3N.

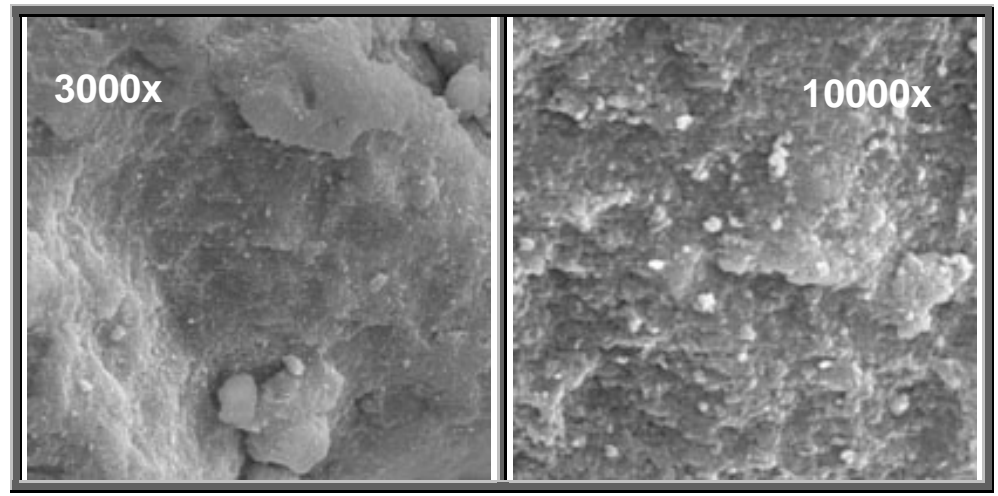

FIGURA 3.13 - Imagens de microscopia eletrônica de varredura do solo 3L.

Tabela 3.2 apresenta os resultados de caracterização e classificação para cada solo selecionado. 
TABELA 3.2 - Caracterização e classificação dos solos estudados

\begin{tabular}{cccccccc}
\hline Solo & & 1L & 1N & 2L & 2N & 3L & 3N \\
\hline \multirow{5}{*}{ Caracterização } & $\rho_{\text {s }}\left(\mathrm{g} / \mathrm{cm}^{3}\right)$ & 2,546 & 2,691 & 2,613 & 2,66 & 2,932 & 2,980 \\
& \% passa \# 200 & 40 & 49 & 69 & 69 & 84 & 90 \\
& \% argila & 24 & 25 & 43 & 47 & 42 & 40 \\
& LL & 31 & 38 & 61 & 55 & 46 & 79 \\
& IP & 12 & 15 & 29 & 20 & 13 & 26 \\
\hline \multirow{3}{*}{ Classificação } & HRB & A-6 & A-6 & A-7-5 & A-7-5 & A-7-5 & A-7-5 \\
& USCS & SC & SC & MH & MH & ML & MH \\
& MCT & LG' & NG' & LG' & NG' & LG' & NG' \\
\hline
\end{tabular}

\subsubsection{Ensaios de Compactação}

Além dos ensaios de caracterização e classificação, Takeda (2006) realizou em todas as amostras ensaios de compactação para determinação do par ordenado umidade ótima e massa específica seca máxima $\left(w_{o t} x \rho_{d m a x}\right)$ na energia normal do Ensaio de Proctor. Esses ensaios foram realizados de acordo com a norma DER M 13-71 e seus resultados encontram-se na tabela 3.3.

TABELA 3.3 - Resultados do ensaio de compactação, energia Proctor Normal

\begin{tabular}{cccccccc}
\hline Solo & & $\mathbf{1 L}$ & $\mathbf{1 N}$ & $\mathbf{2 L}$ & $\mathbf{2 N}$ & $\mathbf{3 L}$ & $\mathbf{3 N}$ \\
\hline \multirow{2}{*}{ Proctor Normal } & $\mathrm{w}_{\mathrm{ot}}(\%)$ & 12,6 & 17,0 & 20,9 & 29,1 & 24,9 & 32,0 \\
& $\rho_{\mathrm{dmax}}\left(\mathrm{g} / \mathrm{cm}^{3}\right)$ & 1,888 & 1,739 & 1,626 & 1,417 & 1,608 & 1,415 \\
\hline
\end{tabular}




\subsection{Investigação Experimental}

O comportamento mecânico dos solos estudados foi determinado a partir da análise de resultados de ensaios de compressão simples e triaxiais convencionais.

\subsubsection{Moldagem dos Corpos-de-Prova}

A Figura 3.14 apresenta a prensa utilizada para moldagem dos corpos-de-prova.

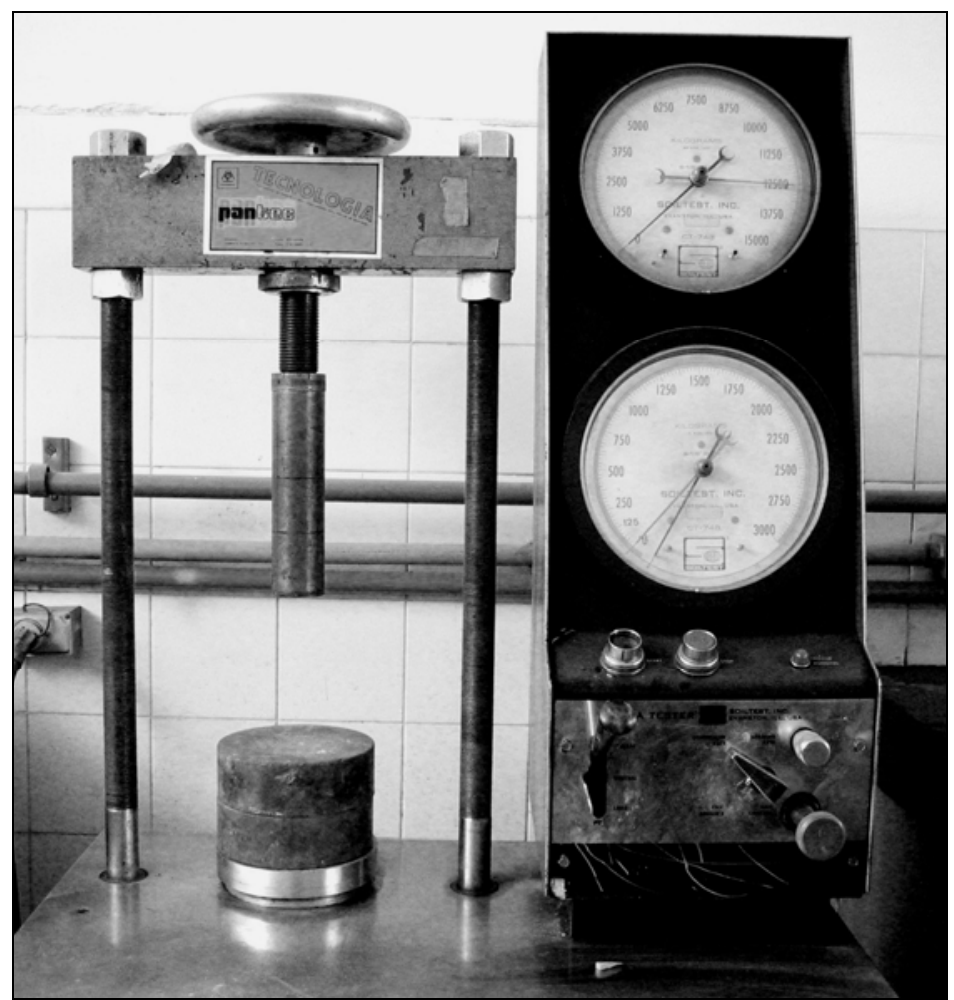

FIGURA 3.14 - Prensa Versatester utilizada para compactação estática de corpos-de-prova 
Todos os corpos-de-prova foram moldados sob a condição de umidade ótima ( $\left.w_{\mathrm{ot}}\right)$ e massa específica seca máxima ( $\left.\rho_{\mathrm{dmax}}\right)$ correspondente ao Proctor Normal.

À amostra previamente seca ao ar era adicionada água suficiente para atingir a umidade desejada, sendo então o material homogeneizado e embalado em saco plástico. Após a homogeneização, duas cápsulas do solo eram retiradas para a verificação do teor de umidade atingido. Portando, nenhum corpo-de-prova era moldado antes de 24 horas, período este usado para a determinação da umidade e também para a equalização da umidade na amostra. A moldagem era realizada apenas quando a umidade estivesse no intervalo de $\pm 0,25 \%$ da umidade alvo.

Foram utilizados corpos-de-prova cilíndricos de $50 \mathrm{~mm}$ de diâmetro e $100 \mathrm{~mm}$ de altura, moldados estaticamente em três camadas em uma prensa Versatester 30M.

\subsubsection{Ensaio Triaxial Convencional}

Para todas as amostras foram realizados ensaios triaxiais saturados do tipo adensado-drenado $(C D)$, ou seja, com permanente drenagem do corpo de prova e segundo metodologia descrita em Bishop e Henkel (1957).

Para o par 1 constituído dos solos $1 \mathrm{~L}$ e $1 \mathrm{~N}$ também foram executados ensaios não saturados sem controle de sucção. 


\subsubsection{Determinação dos Valores de Tensão Confinante}

As tensões de confinamento adotadas para os ensaios triaxiais foram obtidas de maneira a representar tensões no subleito de pavimentos.

Em uma primeira etapa, calculou-se a tensão de confinamento devido ao peso próprio do pavimento e ao tráfego decorrente do carregamento do eixo padrão (eixo simples de roda dupla e 8,2tf).

Para tal simulação considerou-se cada camada do pavimento composta por materiais de comportamento elástico-linear, caracterizados pelo módulo de elasticidade (E) e coeficiente de Poisson ( $v)$ constantes. Foram modelados dois pavimentos, um com três camadas (capa, base de solo fino e subleito) e outro com duas (base de solo fino e subleito). A Tabela 3.4 apresenta as características dos materiais adotados como camadas de cada uma das estruturas de pavimento analisadas.

O cálculo se deu com auxílio do programa ELSYM5 e determinou-se um valor de 25kPa para tensão de confinamento de ambas as estruturas analisadas.

TABELA 3.4 - Características das Camadas dos Pavimentos Modelados

\begin{tabular}{cccccc}
\hline Pavimento & Camada & $\mathrm{E}\left(10^{3} \mathrm{kPa}\right)$ & $v$ & $\mathrm{e}(\mathrm{cm})$ & $\rho(\mathrm{g} / \mathrm{cm} 3)$ \\
\hline \multirow{2}{*}{1} & 1 & 360 & 0,45 & 60 & 1,66 \\
& 2 & 158 & 0,45 & $\infty$ & 1,66 \\
\hline \multirow{2}{*}{2} & 1 & 4000 & 0,25 & 7,5 & 2,0 \\
& 2 & 360 & 0,45 & 52,5 & 1,66 \\
& 3 & 158 & 0,45 & $\infty$ & 1,66 \\
\hline
\end{tabular}


Como tensões complementares, foram adotadas ainda as tensões de $50 \mathrm{kPa}$ e $75 \mathrm{kPa}$, tensões estas compatíveis respectivamente, com tensões de confinamento preconizadas pela AASHTO T 307-99 para o ensaio de materiais de subleito e subbase de pavimento.

\subsubsection{Equipamentos}

A Figura 3.15 apresenta o equipamento utilizado para os ensaios triaxiais.

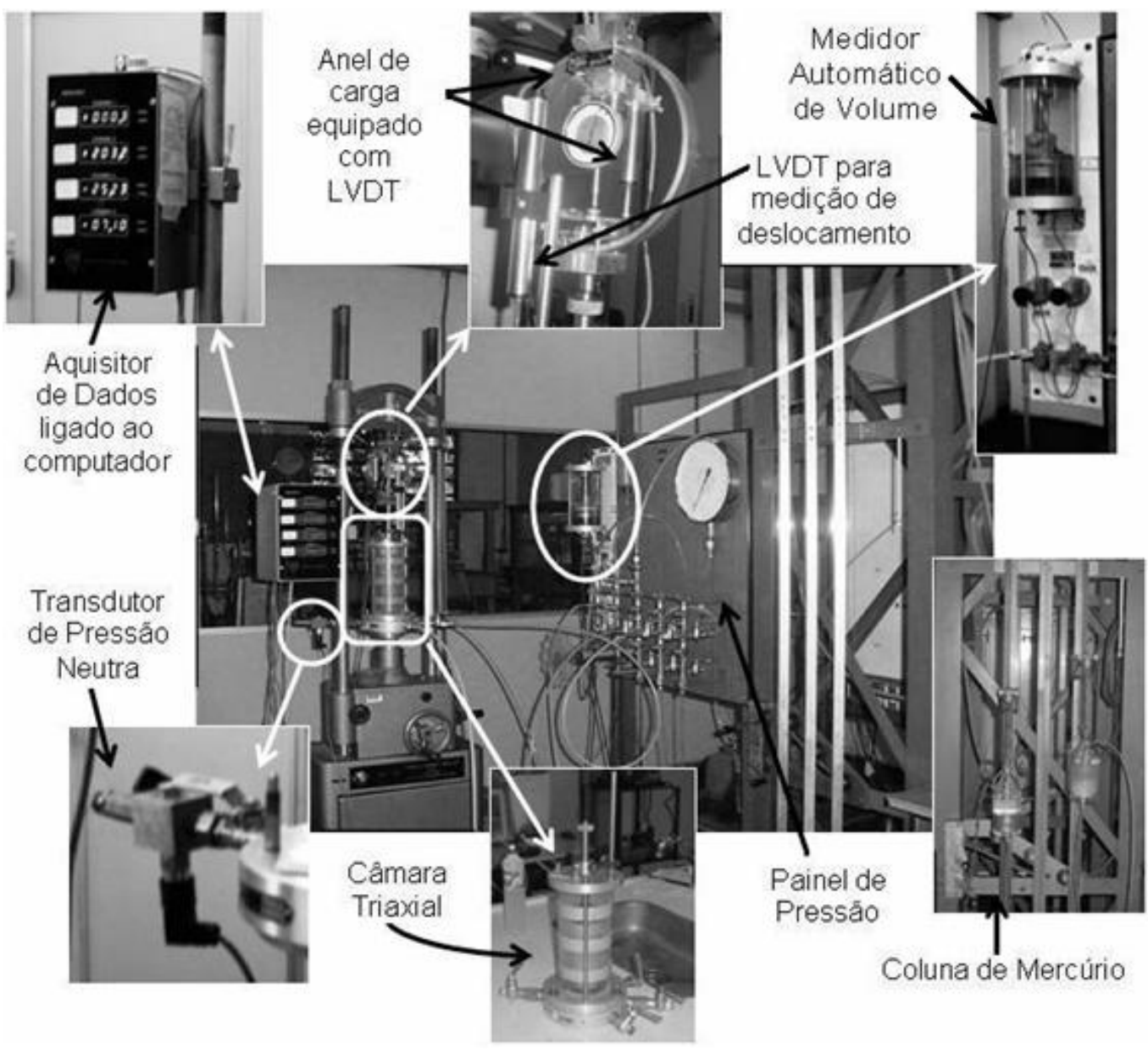

FIGURA 3.15 - Equipamentos utilizados para o ensaio Triaxial Convencional 
Utilizou-se para os ensaios triaxiais uma prensa WYKEHAM FARRANCE modelo 10051 de 5ton de capacidade, pertencente ao Departamento de Geotecnia da EESC - USP. Foram utilizados também uma câmara cintada para corpos-de-prova de no máximo 2" de diâmetro e com capacidade de 1700kPa de pressão; um anel de carga de capacidade $200 \mathrm{~kg}$ equipado com um LVDT para a aquisição eletrônica da força aplicada; um transdutor de pressão para medir a pressão neutra; um medidor automático de variação de volume e um LVDT externo a câmara para medir o deslocamento.

Foram utilizados também membranas látex para proteger o corpo-de-prova durante os ensaios e 2 pedras porosas de carborundum, uma na base e outra no topo do corpo-de-prova.

\subsubsection{Procedimento de Ensaio}

Durante a realização dos ensaios as tensões confinantes eram aplicadas por meio de água destilada através de colunas de mercúrio.

\section{a. Ensaio saturado}

Após a montagem do ensaio, o primeiro passo era a saturação. Nesta fase aplicavase uma pressão no interior da câmara e outra no interior do corpo-de-prova 
(contrapressão) com uma diferença aproximada de $10 \mathrm{kPa}$ entre elas. Elevavam-se essas pressões gradativamente, em taxas constantes de $50 \mathrm{kPa}$ até atingir-se a saturação por dissolução do ar. A condição de saturação era verificada através da medição do parâmetro B de Skempton, dado pela expressão:

$$
\mathrm{B}=\frac{\Delta \mathrm{u}}{\Delta \sigma_{3}} \cdot 100
$$

Onde: $\quad$ B = parâmetro de Skempton (\%);

$$
\begin{aligned}
& \Delta \mathrm{u}=\text { Variação de pressão neutra }(\mathrm{kPa}) \\
& \Delta \sigma_{3}=\text { Variação de tensão confinante }(\mathrm{kPa}) .
\end{aligned}
$$

Saturada a amostra, iniciava-se o adensamento aplicando-se a tensão confinante escolhida para o ensaio. O controle dessa fase era realizado através do gráfico Raiz de Tempo versus Variação de Volume $(\sqrt{\mathrm{t}} \mathrm{x} \Delta \mathrm{v})$

Em seguida, iniciava-se a ruptura da amostra. Para tal, elevava-se a tensão axial na amostra a uma taxa de $0,02 \mathrm{~mm} / \mathrm{min}$ permitindo assim a percolação da água. Dessa forma, a pressão neutra durante o ensaio permanecia praticamente nula e as tensões totais medidas eram as tensões efetivas.

Nas fases de adensamento e ruptura, realizava-se a aquisição de dados através do programa CONDRE, desenvolvido pelo Departamento de Geotecnia. 


\section{b. Ensaio não saturado}

Com os corpo-de-prova do par 1 foram montados ensaios não saturados sem medida de sucção. Os ensaios eram realizados utilizando os mesmos procedimentos descritos no item anterior excetuando-se a fase de saturação. A drenagem do corpode-prova era aberta para atmosfera.

\subsubsection{Ensaio de compressão sem tensão confinante}

\subsubsection{Equipamentos}

Estes ensaios foram realizados no equipamento triaxial descrito no item 3.3.2.2.

\subsubsection{Procedimento de Ensaio}

\section{a. Ensaio saturado}

Após a montagem do ensaio, saturava-se o corpo-de-prova de acordo com o subitem "a" do item 3.3.2.3. Em seguida, igualava-se a pressão interna e externa do corpo-de-prova e iniciava-se o cisalhamento como o descrito também sub-item "a" do item 3.3.2.3. 
b. Ensaios não saturados

Para os solos $1 \mathrm{~L}$ e $1 \mathrm{~N}$ foram realizados ensaios de compressão simples não saturado. Utilizou-se para tanto a pressa triaxial descrita no item 3.3.2.2 e velocidade $1,14 \mathrm{~mm} / \mathrm{min}$. A aquisição de dados era realizado através do programa Compsimp desenvolvido pelo Departamento de Geotecnia.

\subsection{Análise dos Resultados}

\subsubsection{Resistências Mobilizadas}

Adotou-se o modelo de Mohr-Coulomb para determinação dos parâmetros coesão (c) e ângulo de atrito interno $(\phi)$ na ruptura e em tensões correspondentes a 1/16, 1/8, 1/4 e 1/2 da deformação alcançada na ruptura.

\subsubsection{Critério de Resistência de Mohr-Coulomb}

Para o cálculo de $c$ e $\phi$ foi utilizado o gráfico $p \times q$, a partir do qual pode-se determinar os parâmetros a' e $\alpha$, que se relacionam com os primeiros através das equações:

$$
\begin{aligned}
& \operatorname{sen} \phi=\operatorname{tg} \alpha \\
& \mathrm{c}=\frac{\mathrm{a}^{\prime}}{\cos \phi}
\end{aligned}
$$


Onde: $\alpha=$ ângulo de inclinação da reta que une os pontos de máximos no gráfico $p$ x q $\left({ }^{\mathrm{O}}\right)$;

$$
\begin{aligned}
& \phi=\text { ângulo de atrito da trajetória de ruptura de Mohr-Coulomb }\left({ }^{O}\right) ; \\
& \mathrm{c}=\text { parâmetro de coesão da trajetória de ruptura de Mohr-Coulomb }(\mathrm{kPa}) ; \\
& \mathrm{a}^{\prime}=\text { Ponto de interseção da reta que une os pontos de máximos no gráfico p }
\end{aligned}
$$

x q com o eixo das ordenadas $(\mathrm{kPa})$.

\subsubsection{Deformabilidade}

Para a análise da deformabilidade foram determinados o módulo tangente inicial e os módulos secantes correspondentes a $50 \%$ e a $100 \%$ da tensão de ruptura conforme ilustra a figura 3.15.

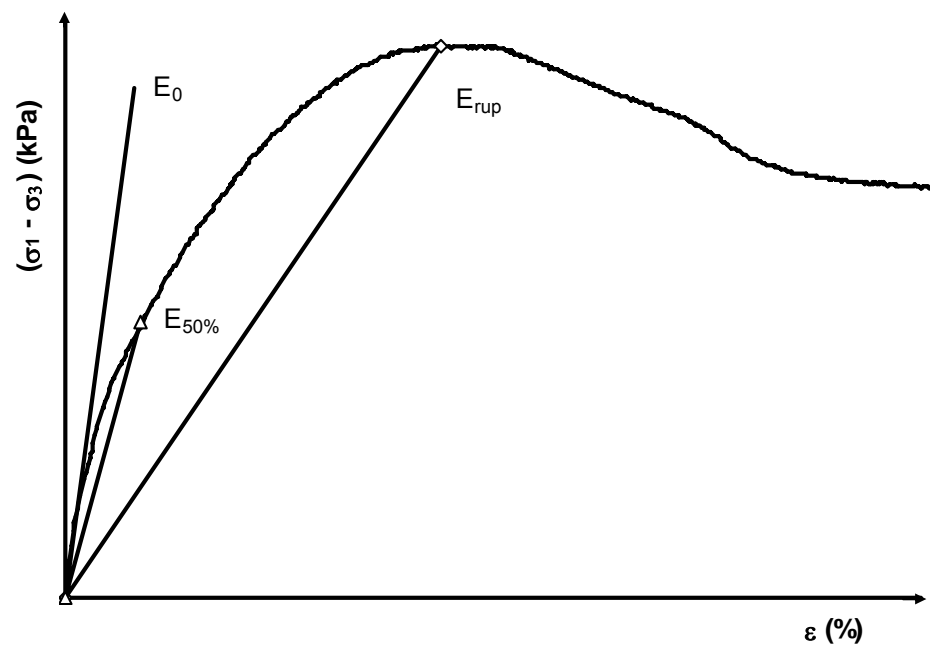

FIGURA 3.16 - Módulos de deformabilidade utilizados no estudo. 


\subsubsection{Determinação do Módulo Tangente Inicial}

Para facilitar e eliminar a subjetividade na determinação do módulo tangente inicial adotou-se o procedimento apresentado por Duncan e Chang (1970), pelo qual a curva tensão versus deformação é traçada de acordo com um modelo hiperbólico expresso pelas equações 2.3 e 2.4 .

\subsubsection{Modelagem da Variação de $E_{0}$ com a Tensão Confinante}

A variação do módulo tangente inicial com a tensão confinante foi moldada conforme proposto por Janbu (1963) através da seguinte equação:

$$
E_{0}=k \cdot P a \cdot\left(\frac{\sigma_{3}}{P a}\right)^{n}
$$

Onde $\mathrm{E}_{0}$ : Módulo tangente inicial;

$\sigma_{3}:$ tensão confinante;

Pa: Pressão atmosférica expressa na unidade que $E_{0}$ e $\sigma_{3}$;

k e n: constantes

\subsubsection{Comparação entre o Comportamento de Solos Lateríticos e Não Lateríticos}

Finalmente, comparou-se o comportamento mecânico de solos laterítico e não laterítico, para uso em pavimentação, frente às analises realizadas, procurando reconhecer diferenças e semelhanças e identificar as razões que as originaram. 


\subsubsection{Análise da Relação entre os Resultados dos Ensaios Triaxiais Convencionais e Triaxiais Cíclicos}

A partir dos valores de módulo tangente inicial e módulo de resiliência, analisou-se a deformação elástica dos materiais, procurando investigar relações nas respostas dos dois ensaios. 


\section{APRESENTAÇÃO E DISCUSSÃO DOS RESULTADOS}

\subsection{Introdução}

Neste capítulo são apresentados e analisados os resultados dos ensaios de laboratório realizados para se alcançarem os objetivos desta dissertação.

\subsection{Ensaios de Compactação}

Nas figuras 4.1, 4.2 e 4.3 são apresentadas, respectivamente, as curvas de compactação dos pares de solos 1, 2 e 3, enquanto que a figura 4.4 apresenta estas mesmas curvas conjuntamente. Esses ensaios foram realizados por Takeda (2006) na energia normal do ensaio de Proctor.

Analisando-se essas figuras, observa-se para um mesmo par, que o solo laterítico apresenta menor teor de umidade ótima e maior massa específica seca máxima quando comparado ao solo não laterítico. 


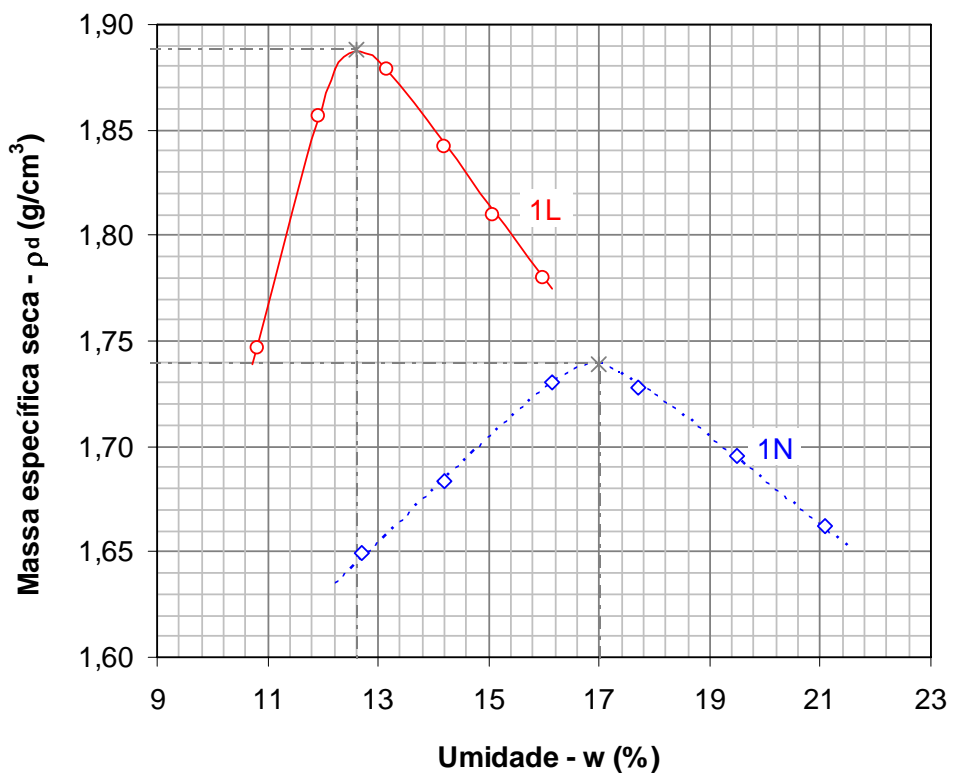

FIGURA 4.1 - Curvas de compactação do par 1

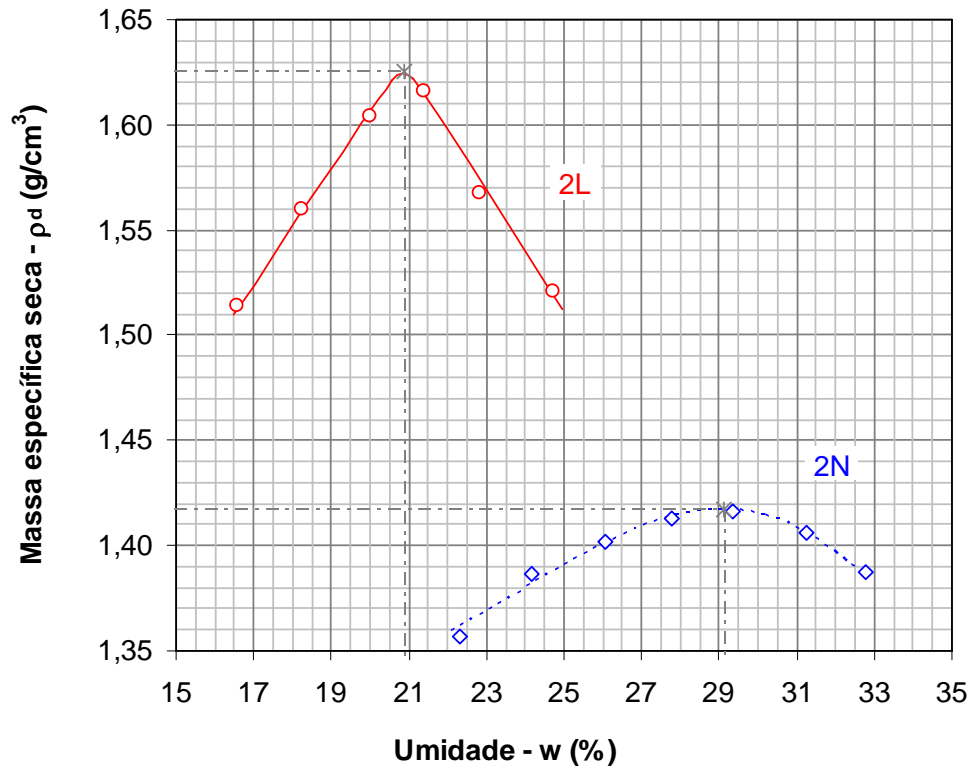

FIGURA 4.2 - Curvas de compactação do par 2 (A-7-5, MH) 


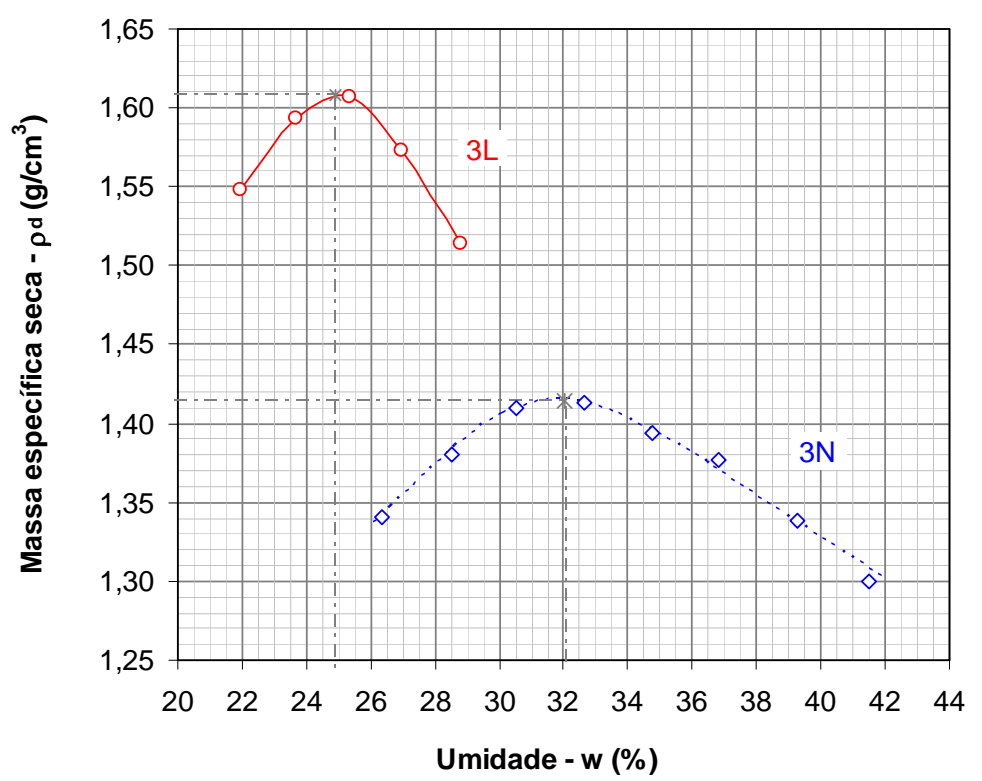

FIGURA 4.3 - Curvas de compactação do par 3 (A-7-5, MH)

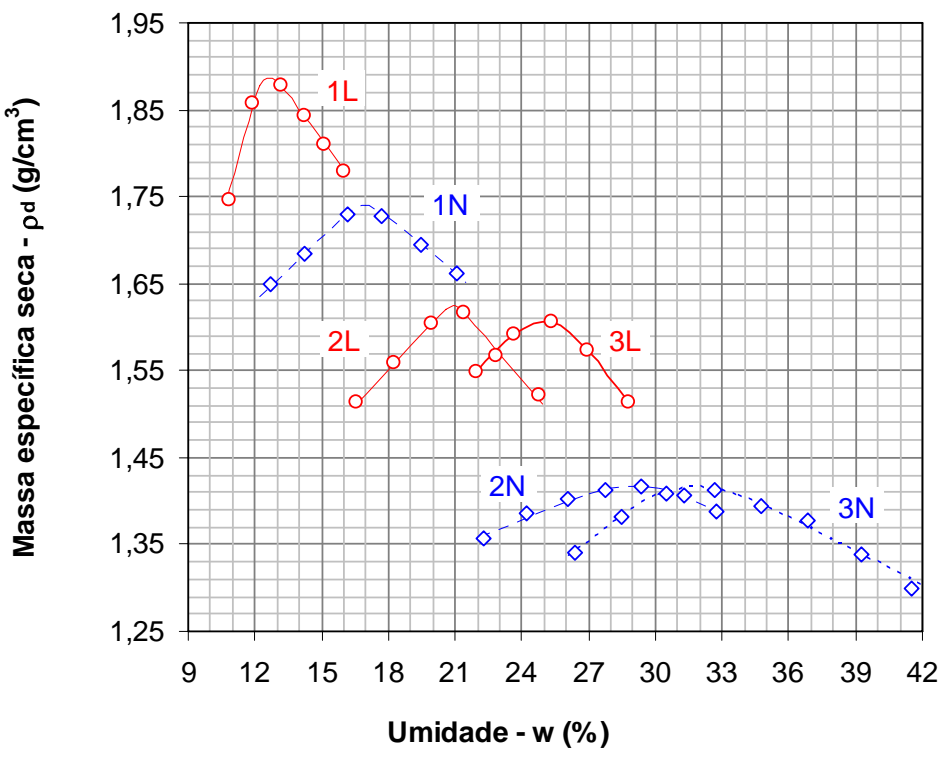

FIGURA 4.4 - Curvas de compactação dos materiais estudados 
A figura 4.5 apresenta a relação entre a variação da massa específica seca máxima e a correspondente variação de umidade para o solo laterítico e não laterítico. Analisando essa figura, observa-se que existe uma boa relação entre essas variáveis e que a massa especifica seca máxima diminui com o aumento da umidade ótima, com uma taxa variação coincidente para ambas as gêneses dos materiais, estando a curva dos solos lateríticos ligeiramente acima da curva dos solos não lateríticos.

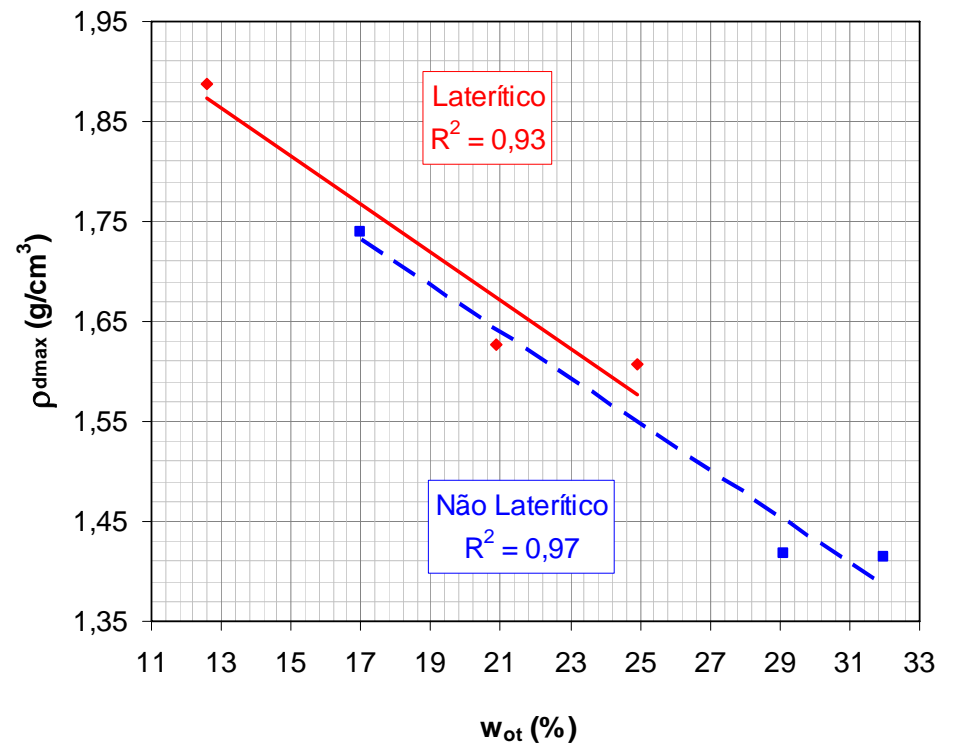

FIGURA 4.5 - $\rho_{\mathrm{dmax}}$ versus $\mathrm{w}_{\mathrm{ot}}$ para solos lateríticos e não lateríticos

Procurou-se relacionar, também, os resultados dos ensaios de compactação, massa específica seca máxima e umidade ótima, com as características granulométricas e plásticas dos materiais. As figuras 4.6 e 4.7 apresentam respectivamente a variação da umidade ótima com o teor de finos (porcentagem de material menor que 0,075mm - NBR 6505/95, ABNT) e argila (porcentagem de material menor que 0,002mm - NBR 6505/95, ABNT), respectivamente. 


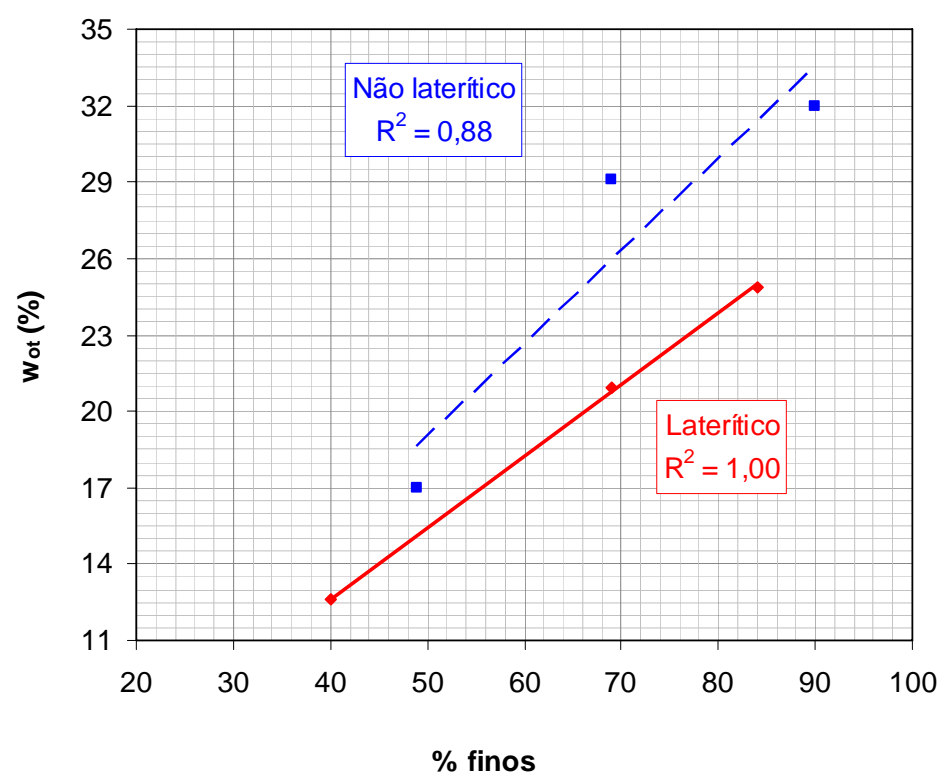

FIGURA 4.6 - Porcentagem de finos versus umidade ótima

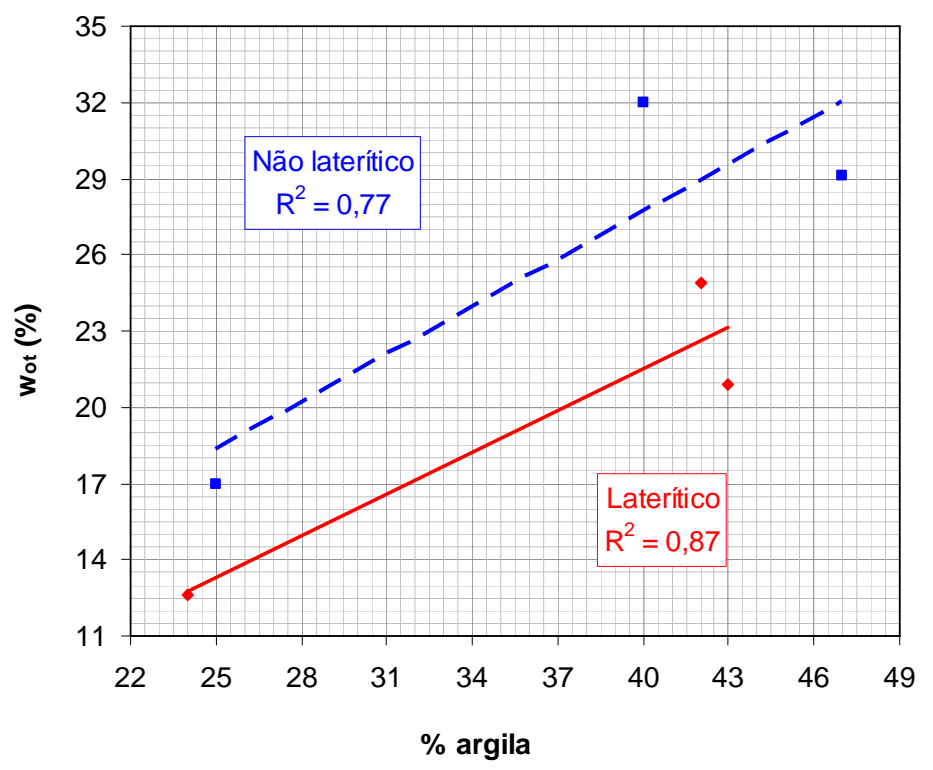

FIGURA 4.7 - Porcentagem de argila versus umidade ótima 
Analisando as figuras 4.6 e 4.7 observa-se que é possível relacionar a umidade ótima com o teor de finos e com o teor de argila, sendo que a correlação obtida a partir do teor de finos mostra-se um pouco superior à obtida a partir do teor de argila. Conforme era esperado, a umidade ótima cresce com o aumento dos teores de finos e de argila. Com relação a gênese dos solos, observa-se que para iguais porcentagens de argila ou de finos, os solos lateríticos apresentam menores valores de umidade ótima quando comparados aos solos não lateríticos.

As figuras 4.8 e 4.9 apresentam respectivamente a variação da massa específica seca máxima com o teor de finos (porcentagem de material menor que 0,075mm NBR 6505/95, ABNT) e argila (porcentagem de material menor que 0,002mm - NBR 6505/95, ABNT), respectivamente.

Analisando essas figuras observa-se que é possível relacionar a massa específica seca máxima com o teor de finos e com o teor de argila, sendo que a correlação obtida a partir do teor de argila mostra-se um pouco superior à obtida a partir do teor de finos. Conforme era esperado, a massa específica seca máxima decresce com o aumento dos teores de finos e de argila. Com relação a gênese dos solos, observase que para iguais porcentagens de argila ou de finos, os solos lateríticos apresentam maiores valores de massa específica seca máxima quando comparados aos solos não lateríticos. 


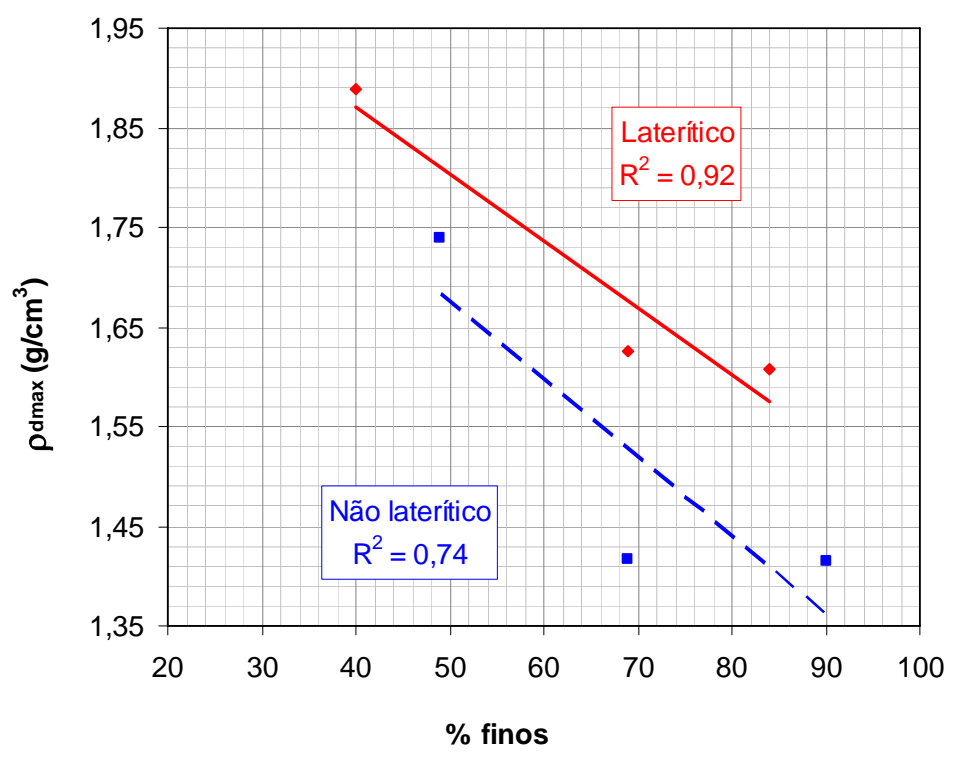

FIGURA 4.8 - Porcentagem de finos versus massa específica seca máxima

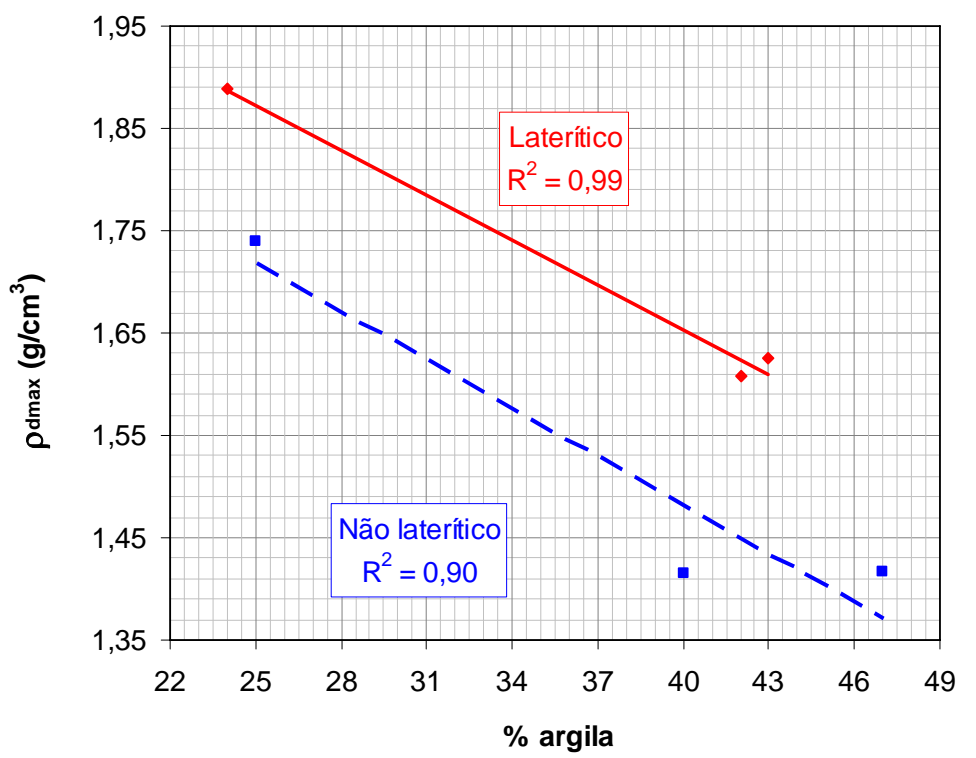

FIGURA 4.9 - Porcentagem de argila versus massa específica seca máxima 


\subsection{Ensaios Confinados e Não-Confinados}

\subsubsection{Ensaios Saturados}

As figuras 4.10, 4.11 e 4.12 apresentam as curvas tensão versus deformação axial e deformação volumétrica versus deformação axial para os pares de solos 1, 2 e 3, respectivamente.

Analisando-se essas figuras, e observando-se o desenvolvimento das curvas tensão desvio e variação volumétrica com a deformação axial, constata-se que os pares 1 e 2 têm comportamento semelhante, ou seja, solos lateríticos (1L e 2L) apresentam um comportamento frágil se comparados aos solos não lateríticos (1N e $2 \mathrm{~N})$, com uma resistência residual menor que a resistência de pico. No tocante à variação volumétrica, esta é compressiva até próximo à ruptura para ambas as gêneses, seguindo-se uma dilatância pronunciada para os solos lateríticos, que não se repete para os solos não lateríticos. Destaca-se que para os ensaios sem confinamento, a dilatância é observada para solos lateríticos e não lateríticos, sendo que para estes últimos ela é menos pronunciada.

Ainda para os pares 1 e 2, observa-se que solos lateríticos rompem com aproximadamente $1 \%$ de deformação axial, com um pico bem delineado, enquanto que para os solos não lateríticos não é possível estabelecer claramente o pico de ruptura. Quando se comparam as tensões de ruptura, os solos lateríticos apresentam valores superiores às dos solos não lateríticos. 

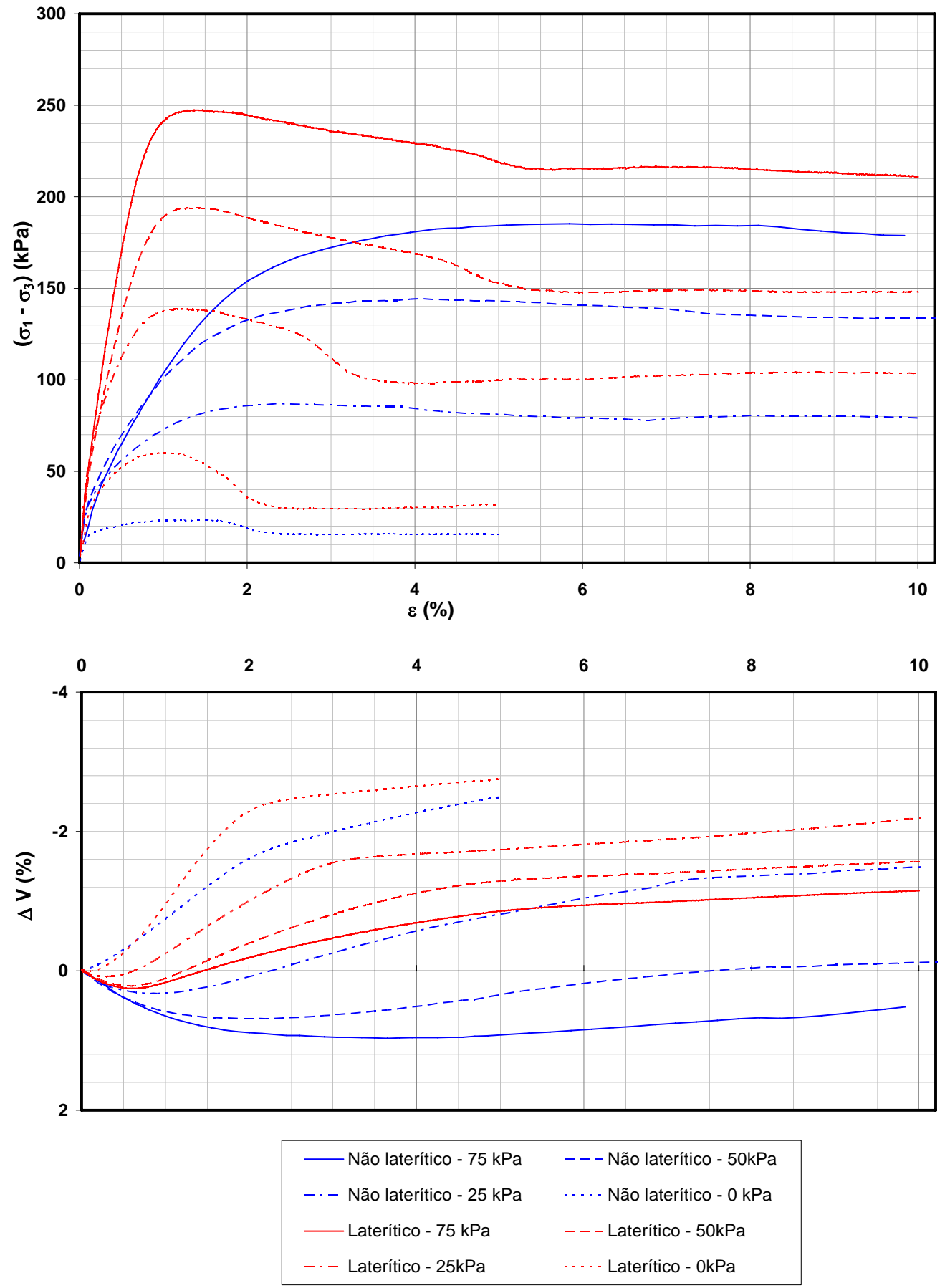

FIGURA 4.10 - Curvas tensão desvio versus deformação axial e variação volumétrica versus deformação axial para os solos do Par 1 

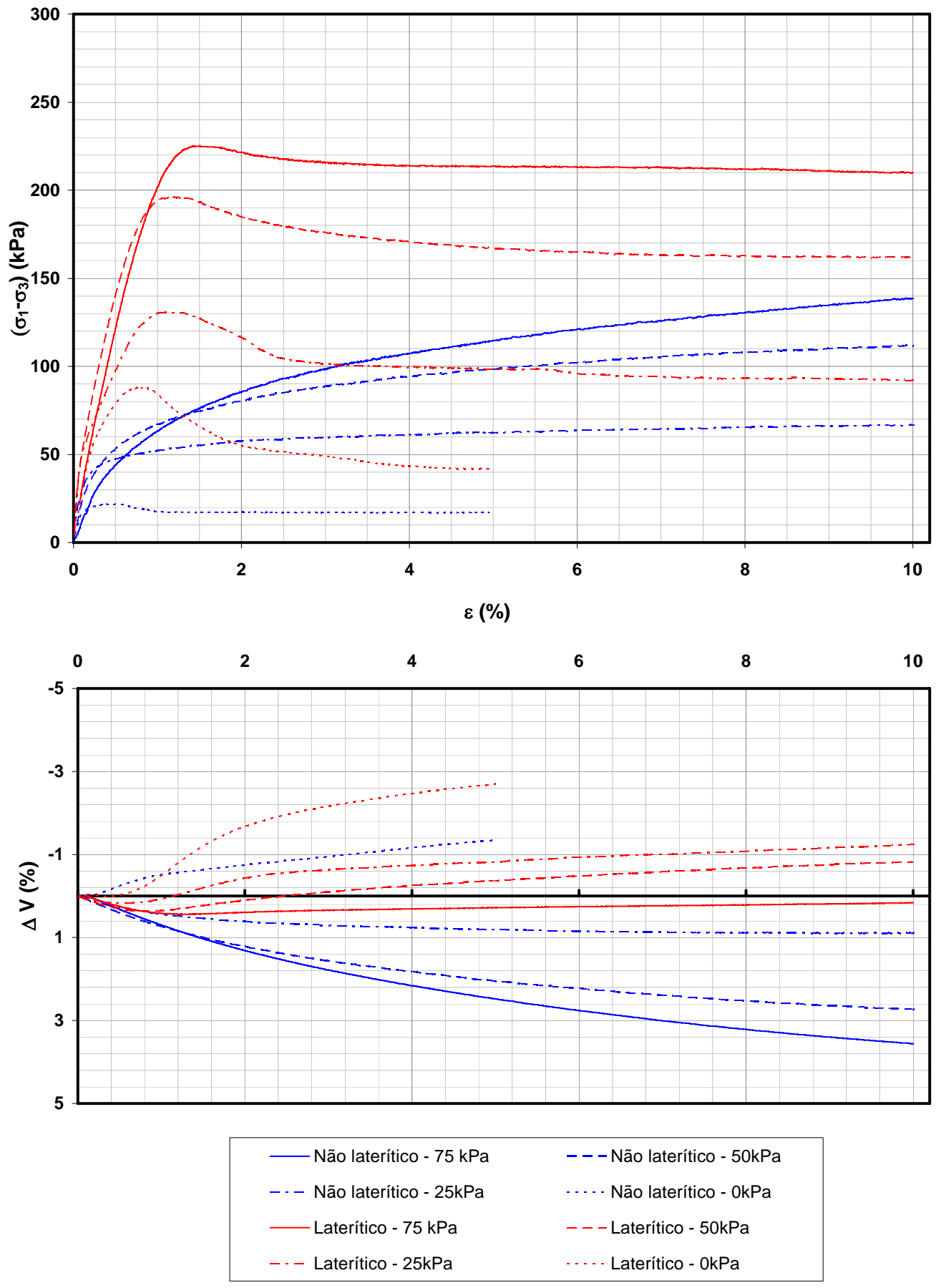

FIGURA 4.11 - Curvas tensão desvio versus deformação axial e variação volumétrica versus deformação axial para os solos do Par 2 

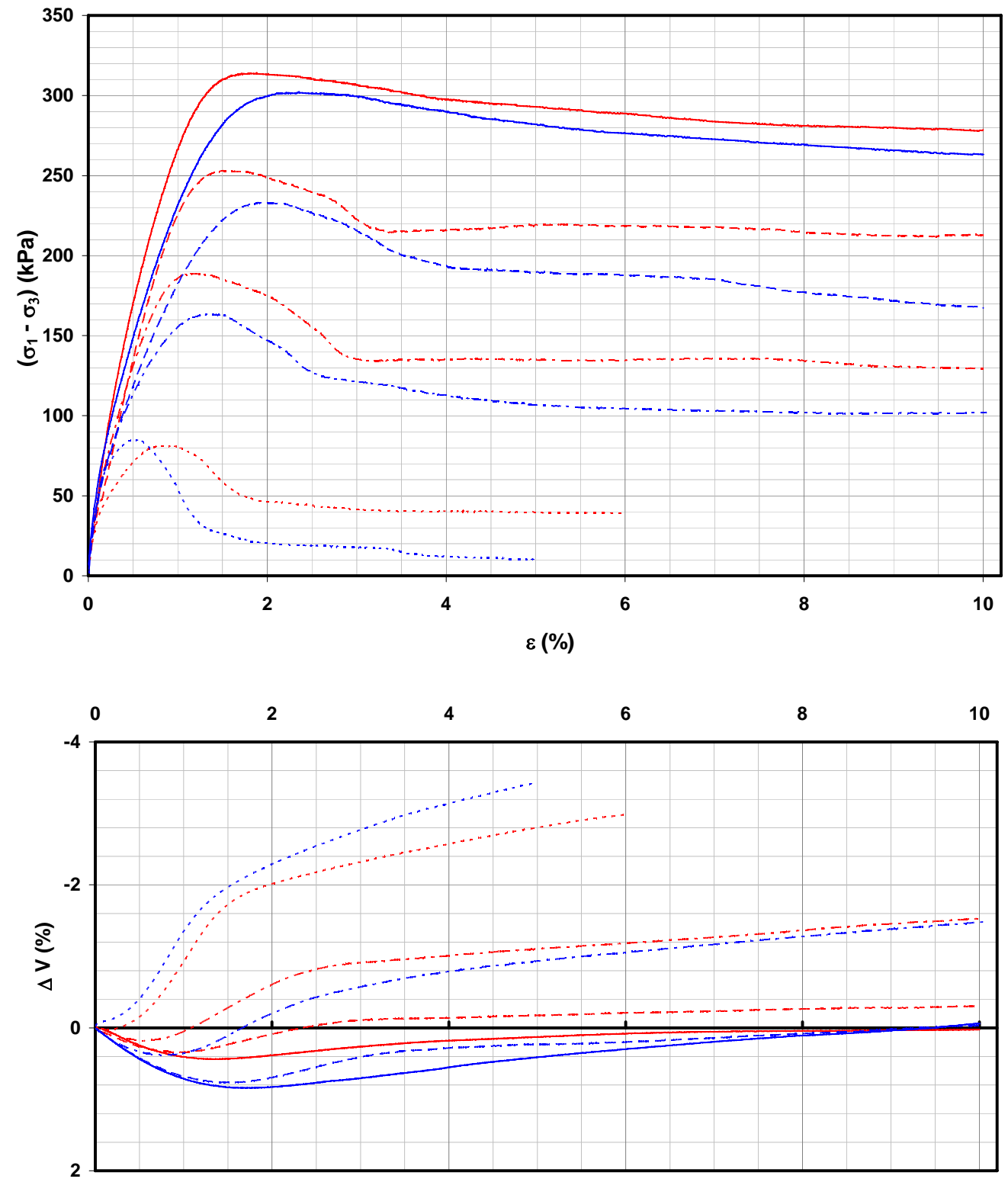

FIGURA 4.12 - Curvas tensão desvio versus deformação axial e variação volumétrica versus deformação axial para os solos do Par 3 
Analisando-se o desenvolvimento das curvas tensão desvio e variação volumétrica com a deformação axial para os solos do par 3, constata-se que a diferença existente entre solos lateríticos e não lateríticos observada para os pares 1 e 2 não se repete. Neste caso, ambos os solos apresentaram um comportamento frágil, podendo-se delinear o pico de ruptura, que se dá para deformações entre 0,5\% a 2,5\%. Observa-se também que o solo laterítico apesar de apresentar resistência superior a do solo não laterítico, esta diferença é pequena se comparada às observadas para os pares 1 e 2. No tocante à variação volumétrica, observa-se dilatância após a ruptura para os dois solos.

\subsubsection{Resistência à Ruptura}

Foram calculadas as diferenças relativas de tensão de ruptura para cada um dos pares de solos segundo a equação 4.1:

$$
\Delta \sigma=\frac{\left(\sigma_{\text {rupL }}-\sigma_{\text {rupN }}\right)}{\sigma_{\text {rup } N}}
$$

Onde: $\Delta \sigma=$ Diferença relativa de tensão de ruptura (\%);

$\sigma_{\text {rupN }}=$ Tensão desvio de ruptura para o solo não laterítico $(\mathrm{kPa})$;

$\sigma_{\text {rupL }}=$ Tensão desvio de ruptura para o solo laterítico $(\mathrm{kPa})$.

A tabela 4.1 apresenta os valores da tensão de ruptura para os solos estudados e a diferença relativa de tensão de ruptura $(\Delta \sigma)$ para cada tensão de confinamento $\left(\sigma_{c}\right)$, 
calculadas conforme a equação 4.1. A figura 4.8 ilustra a variação de $\Delta \sigma$ com as tensões de confinamento.

TABELA 4.1 - Tensão de ruptura das amostras e diferença relativa de tensão de ruptura para cada tensão de confinamento

\begin{tabular}{ccccc} 
Par & $\begin{array}{c}\sigma_{\mathrm{c}} \\
(\mathrm{kPa})\end{array}$ & $\begin{array}{c}\sigma_{\text {rupL }} \\
(\mathrm{kPa})\end{array}$ & $\begin{array}{c}\sigma_{\text {rupN }} \\
(\mathrm{kPa})\end{array}$ & $\begin{array}{c}\Delta \sigma \\
(\%)\end{array}$ \\
\hline \multirow{3}{*}{1} & 0 & 60 & 24 & $156 \%$ \\
& 25 & 139 & 87 & $60 \%$ \\
& 50 & 194 & 144 & $35 \%$ \\
& 75 & 248 & 185 & $34 \%$ \\
\hline \multirow{3}{*}{2} & 0 & 88 & 22 & $299 \%$ \\
& 25 & 131 & 68 & $92 \%$ \\
& 50 & 196 & 117 & $67 \%$ \\
3 & 75 & 225 & 153 & $47 \%$ \\
\hline & 0 & 81 & 85 & $-4 \%$ \\
& 25 & 189 & 164 & $16 \%$ \\
& 50 & 253 & 233 & $9 \%$ \\
& 75 & 314 & 302 & $4 \%$ \\
\hline
\end{tabular}

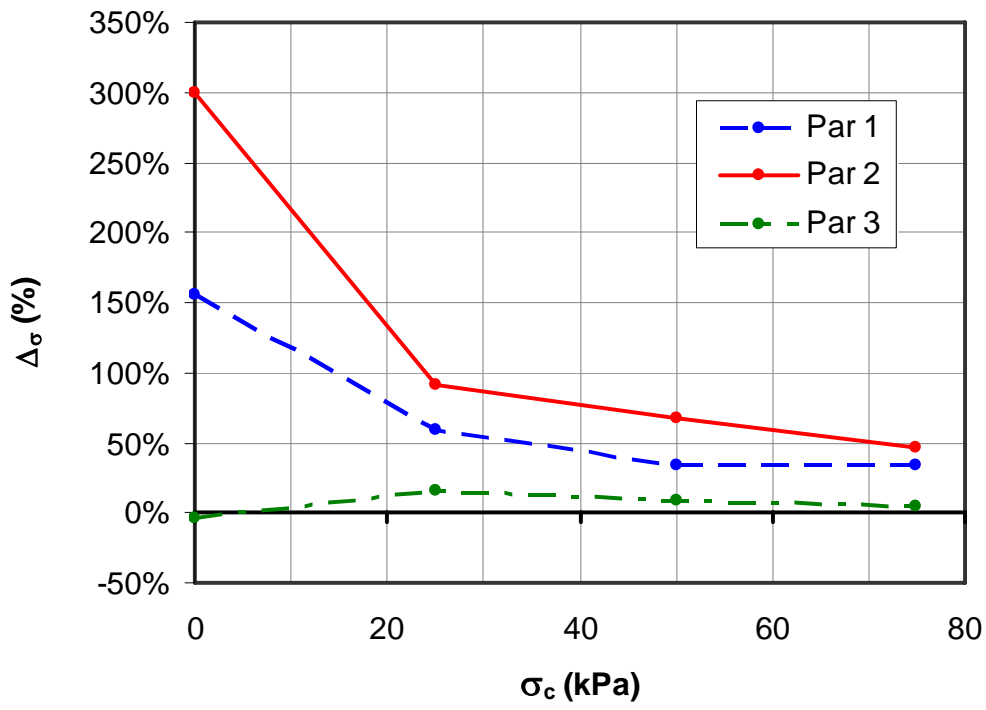

FIGURA 4.13 - Variação da diferença relativa de tensão de ruptura com a tensão confinante 
Analisando-se os valores da tabela 4.1, observa-se que, excetuando-se os ensaios sem confinamento do par 3, os solos lateríticos alcançaram resistências maiores que os solos não lateríticos. Observa-se ainda, através da tabela 4.1 e da figura 4.13, que para os pares 1 e 2 existe uma grande diferença relativa de tensão de ruptura entre os solos lateríticos e não lateríticos, destacando-se os resultados dos ensaios sem confinamento que apresentaram diferença superior a 150\%. Para o par 3, essa diferença apresenta-se pequena, sendo que para os ensaios sem confinamento, o solo não laterítico apresentou resistência ligeiramente maior que a do solo laterítico.

Considerando-se que os ensaios realizados sem confinamento conduziram a valores de diferença relativa de tensões de ruptura muito discrepantes quando comparados aos ensaios confinados, para as análises que se seguem, serão consideradas apenas os resultados desses últimos ensaios. Assim, a figura 4.14 apresenta a variação das diferenças relativas de tensão de ruptura com a tensão confinante apenas para os ensaios triaxiais.

Analisando-se essa figura e considerando-se os valores de $\mathrm{R}^{2}$ destacados, pode-se afirmar que a variação de $\Delta_{\sigma}$ com $\sigma_{c}$ é aproximadamente linear e que a mesma decresce com o aumento de $\sigma_{c}$. Observa-se, também, que a inclinação da reta correspondente ao par 2 é maior que a do par 1, que por sua vez é maior que a do par 3. A granulometria poderia explicar este fato, visto que os solos do par 3 são os mais finos e portanto, menos sujeitos ao efeito da tensão confinante. 


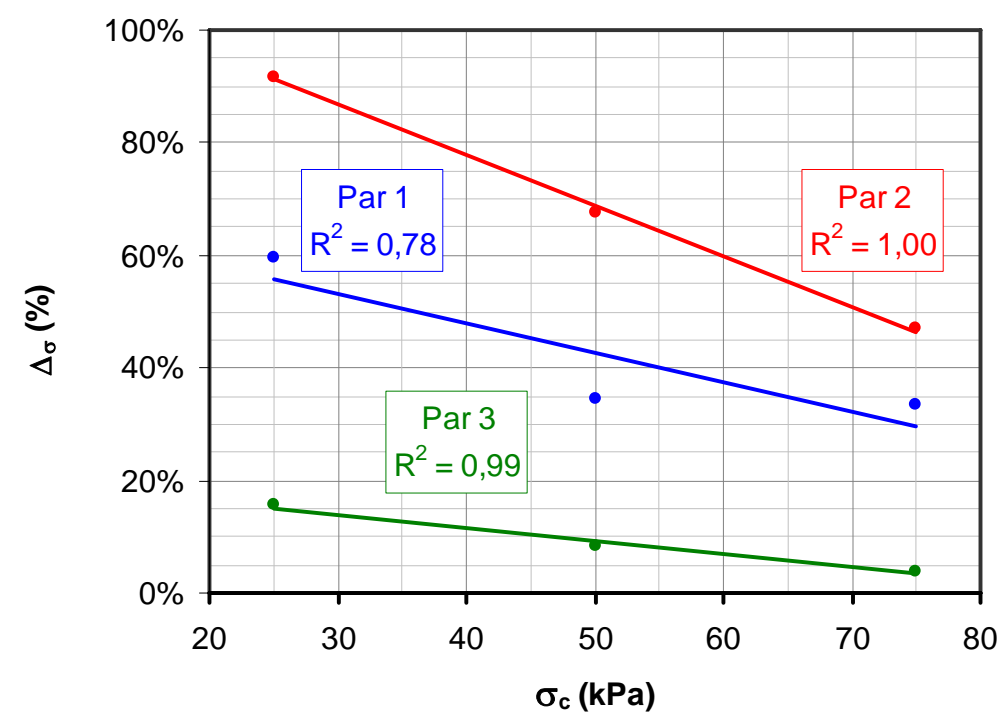

FIGURA 4.14 - Variação da diferença relativa de tensão de ruptura com a tensão confinante para os ensaios triaxiais

Ainda para a figura 4.14, as diferenças relativas de tensão de ruptura médias calculadas a partir das 3 tensões de confinamento são 43\%, $69 \%$ e $9 \%$, respectivamente, para os pares de solos 1, 2 e 3.

\section{Envoltória de Ruptura de Mohr-Coulomb}

A tabela 4.2 apresenta os valores dos parâmetros ф' (ângulo de atrito interno efetivo) e c' (coesão efetiva) da envoltória de ruptura de Mohr-Coulomb, calculados para os ensaios realizados a partir de amostras saturadas. Para o cálculo destes valores, foram considerados apenas os ensaios confinados, visto que os ensaios não confinados apresentaram resultados discrepantes dos demais, conforme discutido anteriormente. A ilustração das envoltórias de ruptura obtidas a partir dos círculos de Mohr é apresentada no Apêndice A. 
TABELA 4.2 - Valores de $\phi$ ' e c' para a envoltória de ruptura de Mohr-Coulomb dos solos estudados

\begin{tabular}{ccccccc}
\hline & $\mathbf{1 L}$ & $\mathbf{1 N}$ & $\mathbf{2 L}$ & $\mathbf{2 N}$ & $\mathbf{3 L}$ & $\mathbf{3 N}$ \\
\hline $\boldsymbol{\phi}^{\prime}\left({ }^{\mathbf{0}}\right)$ & 31 & 30 & 29 & 27 & 34 & 36 \\
\hline $\mathbf{c}^{\prime}(\mathbf{k P a})$ & 24 & 12 & 25 & 8 & 34 & 24 \\
\hline
\end{tabular}

As figuras 4.15, 4.16 e 4.17 apresentam as envoltórias de ruptura de Mohr-Coulomb respectivamente para os solos dos pares 1, 2 e 3 representadas em diagramas de tensão p'x q'. Analisando-se essas figuras, podem-se considerar as envoltórias como retilíneas para as tensões confinantes estudadas.

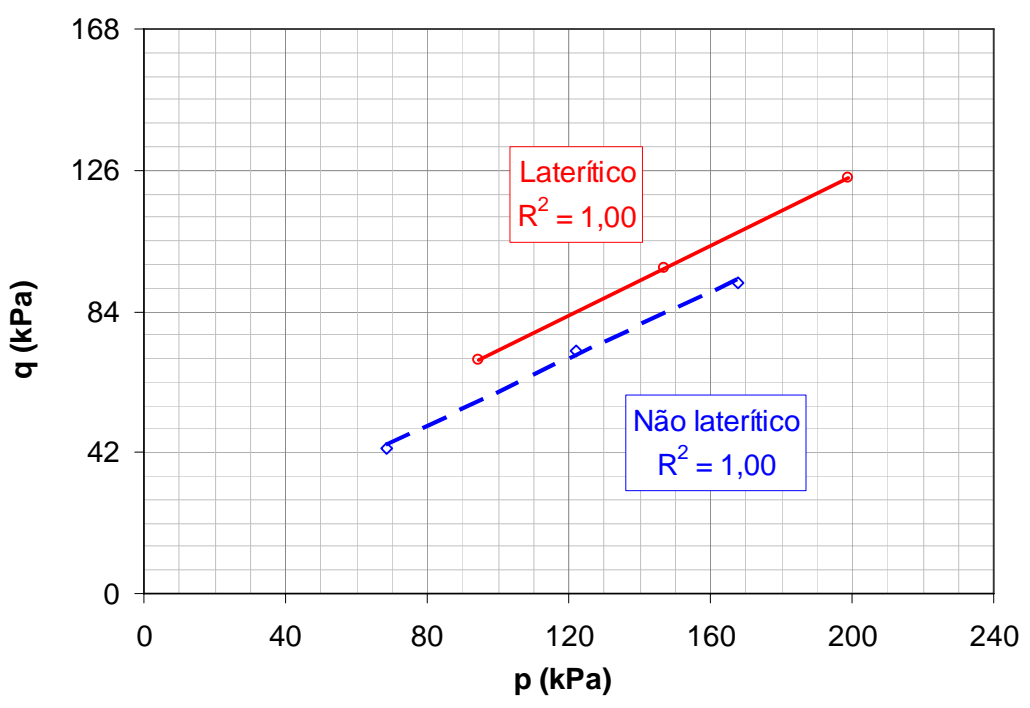

FIGURA 4.15 - Envoltória de resistência das amostras 1L e 1N 


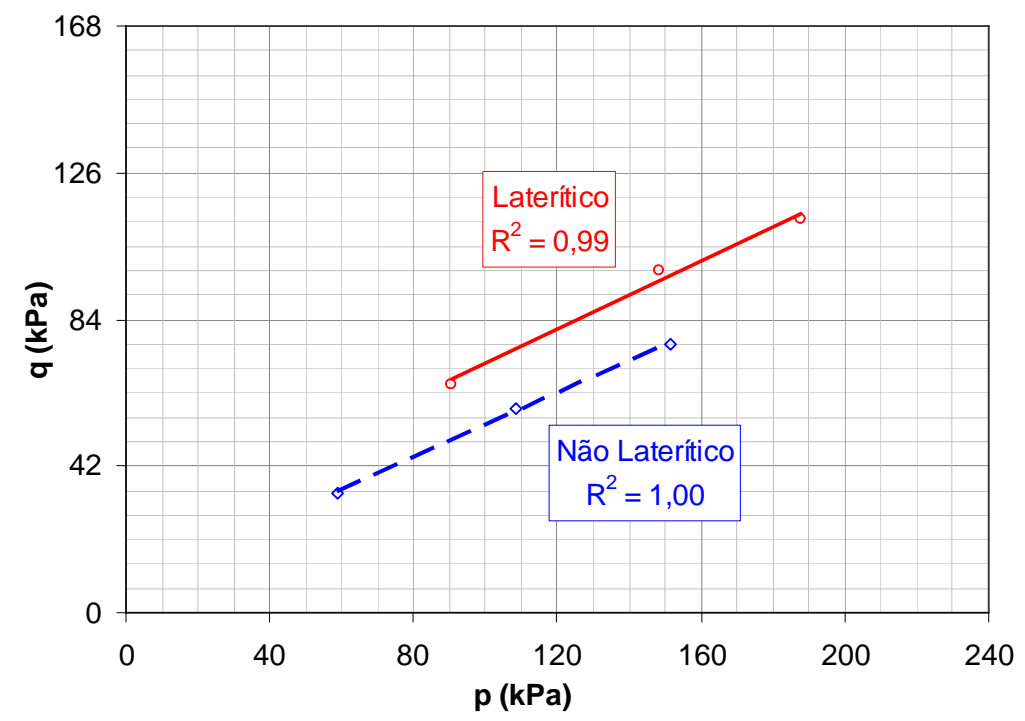

FIGURA 4.16 - Envoltória de resistência das amostras 2L e 2N

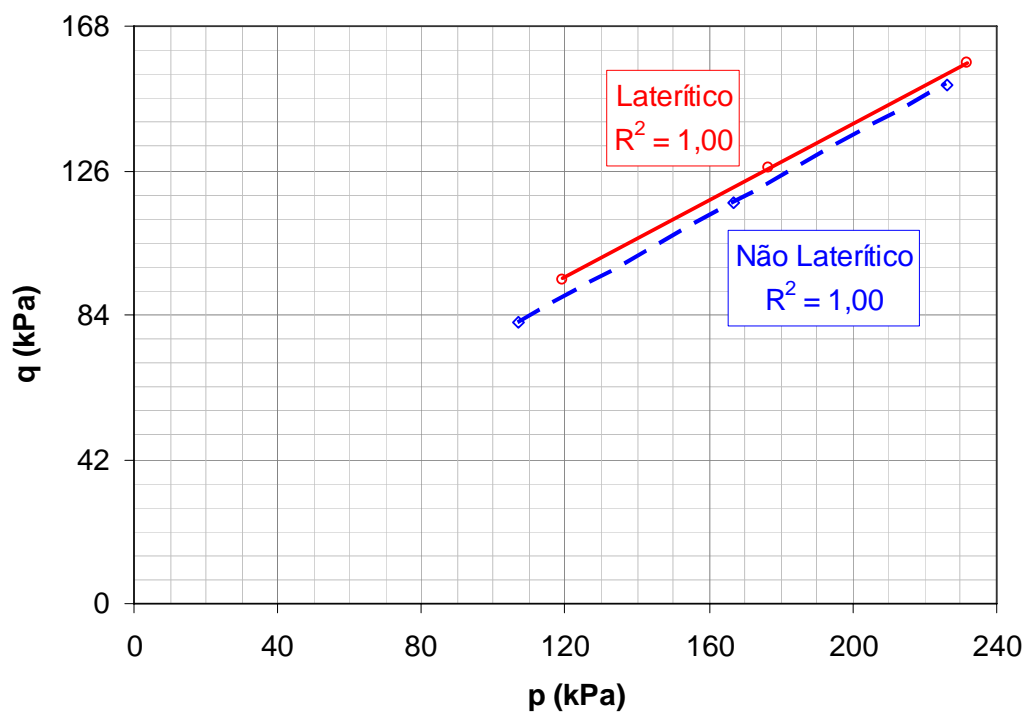

FIGURA 4.17 - Envoltória de resistência das amostras 3L e 3N 
Analisando-se os valores da tabela 4.2 e as figuras $4.15,4.16$ e 4.17 , observa-se que os solos lateríticos e não lateríticos apresentam valores de ângulos de atrito interno efetivo muito próximos entre si se considerados um mesmo par, fato também verificado pelo paralelismo entre as envoltórias obtidas para solos lateríticos e não lateríticos. Essa sobreposição de valores indica que a gênese do solo não influencia o valor deste parâmetro.

Analisando a coesão efetiva das amostras estudadas na tabela 4.2, observa-se que os solos lateríticos apresentam valores de c' maiores que os não lateríticos. Esse resultado indica que a gênese do material exerce uma forte influência no valor da coesão. Essa influencia poderia ser explicada pela presença de óxidos e hidróxidos de ferro e alumínio nos solos lateríticos, que promovem a cimentação entre partículas, contribuindo para o aumento do valor da coesão desses solos.

Observa-se ainda na tabela 4.2 que os solos lateríticos apresentam valores de coesão efetiva superiores aos solos não lateríticos da ordem de 100\%, 213\% e 42\%, respectivamente, para os pares 1, 2 e 3, indicando comportamento semelhante entre os solos do par 3 se comparado com os solos dos pares 1 e 2 . 


\section{> Análise Geral}

Conforme observado nas análises anteriores, os solos pertencentes aos pares 1 e 2 tiveram um comportamento coincidente com o esperado, ou seja, os solos lateríticos apresentaram maiores resistências e menores deformabilidades na ruptura que os solos não lateríticos. No entanto, para os solos do par 3, observou-se que os solos laterítico e o não laterítico apresentaram comportamento muito próximos entre si. Essa semelhança poderia ser explicada pela classificação MCT-M (Vertamatti, 1988) conforme ilustrada a figura 3.6 (b), onde se observa que ambos os solos pertencem à classe TAG', indicando que teriam comportamentos geotécnicos coincidentes.

\subsubsection{Resistência mobilizada}

Em seguida serão analisadas as resistências em termos de ângulo de atrito mobilizado e coesão mobilizada para os níveis de deformação de 1/16, 1/8, 1/4 e 1/2 da deformação alcançada na ruptura do material.

As figuras 4.18, 4.19 e 4.20 ilustram a variação de $\phi$ e de c mobilizados com a deformação axial para os solos dos pares 1, 2 e 3, respectivamente. 

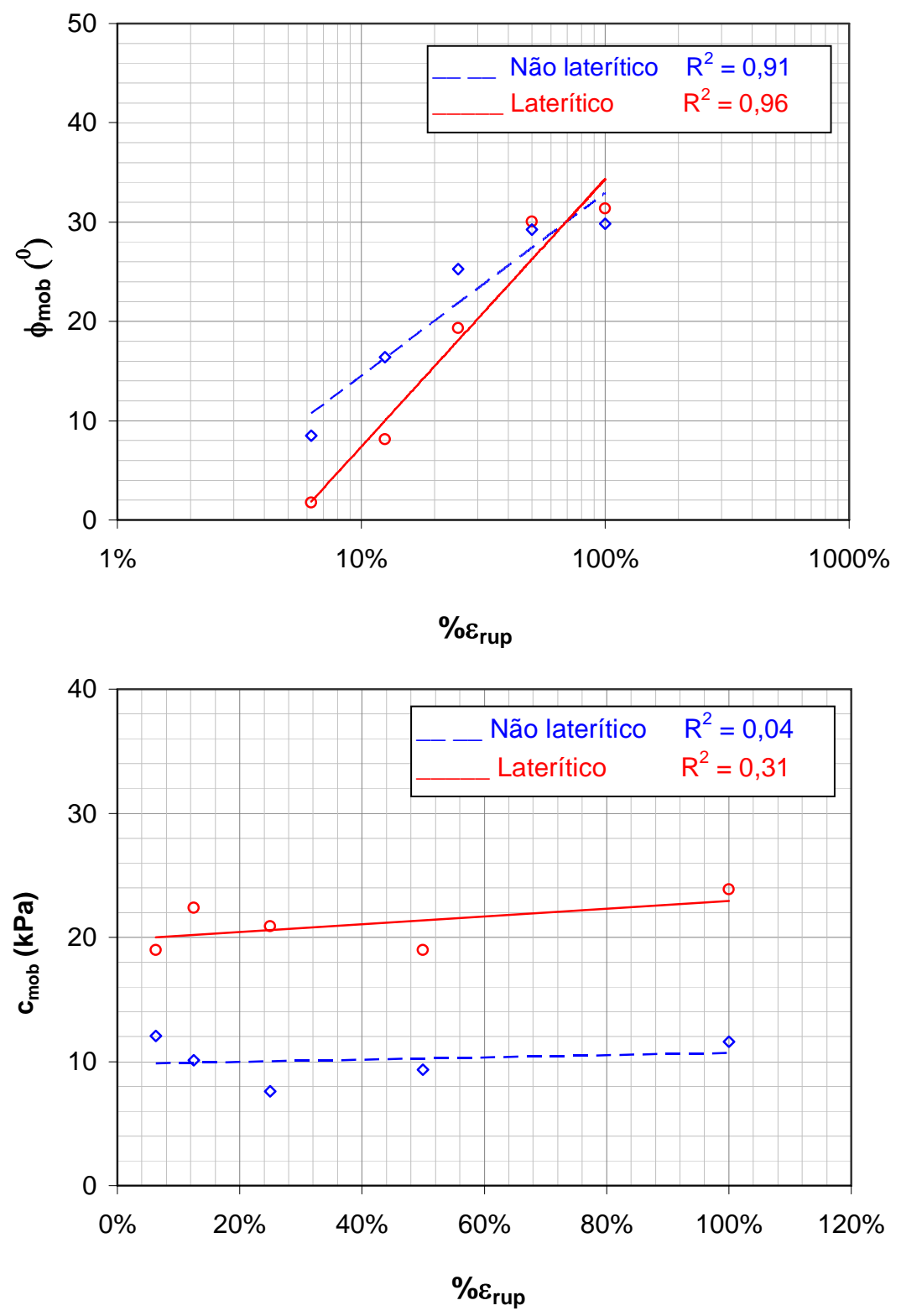

FIGURA 4.18 - Variação do atrito interno mobilizado e da coesão mobilizada em função da \% $\varepsilon_{\text {rup }}$ para o Par 1 

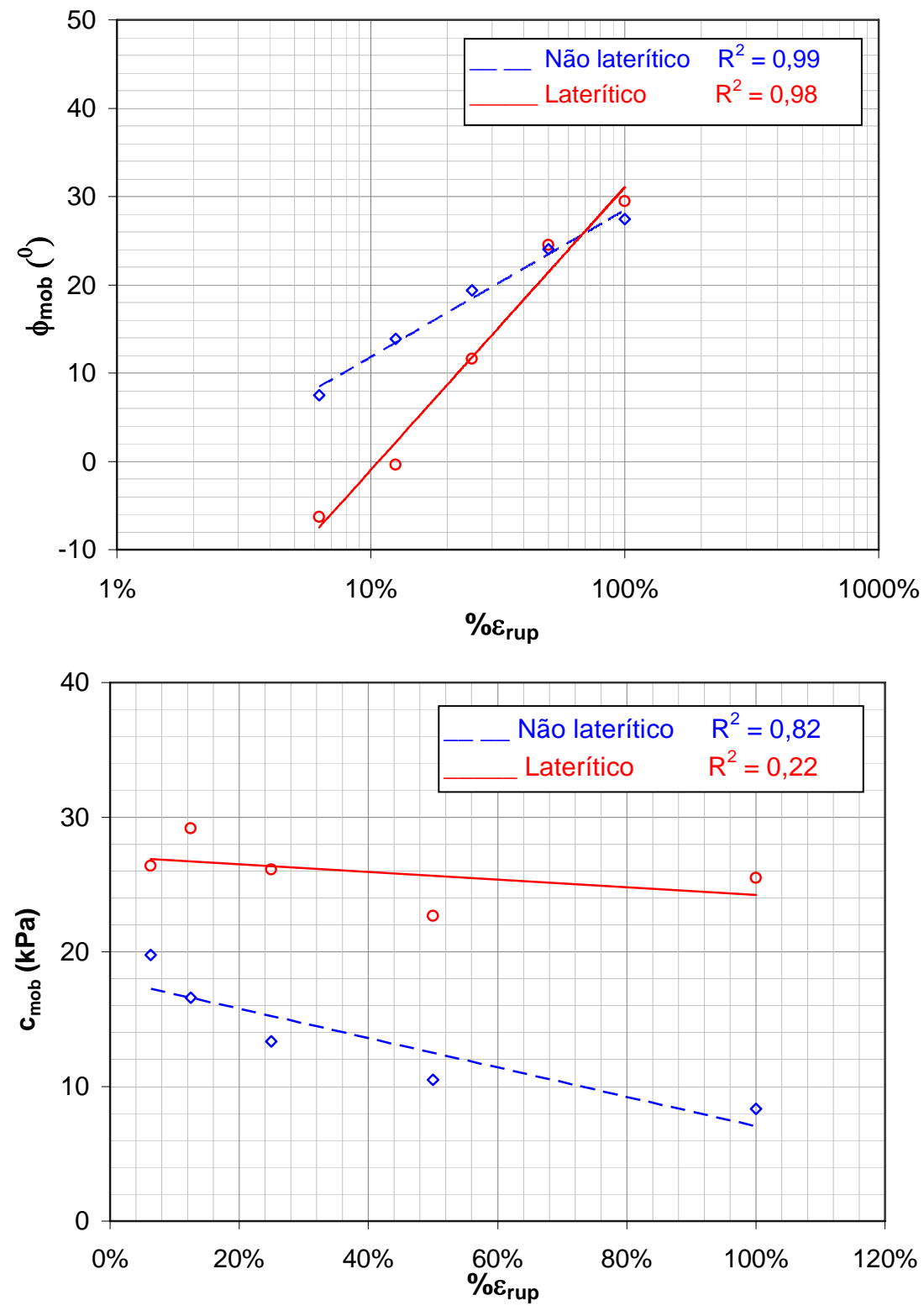

FIGURA 4.19 - Variação do atrito interno mobilizado e da coesão mobilizada em função da \% $\%$ rup para o Par 2 

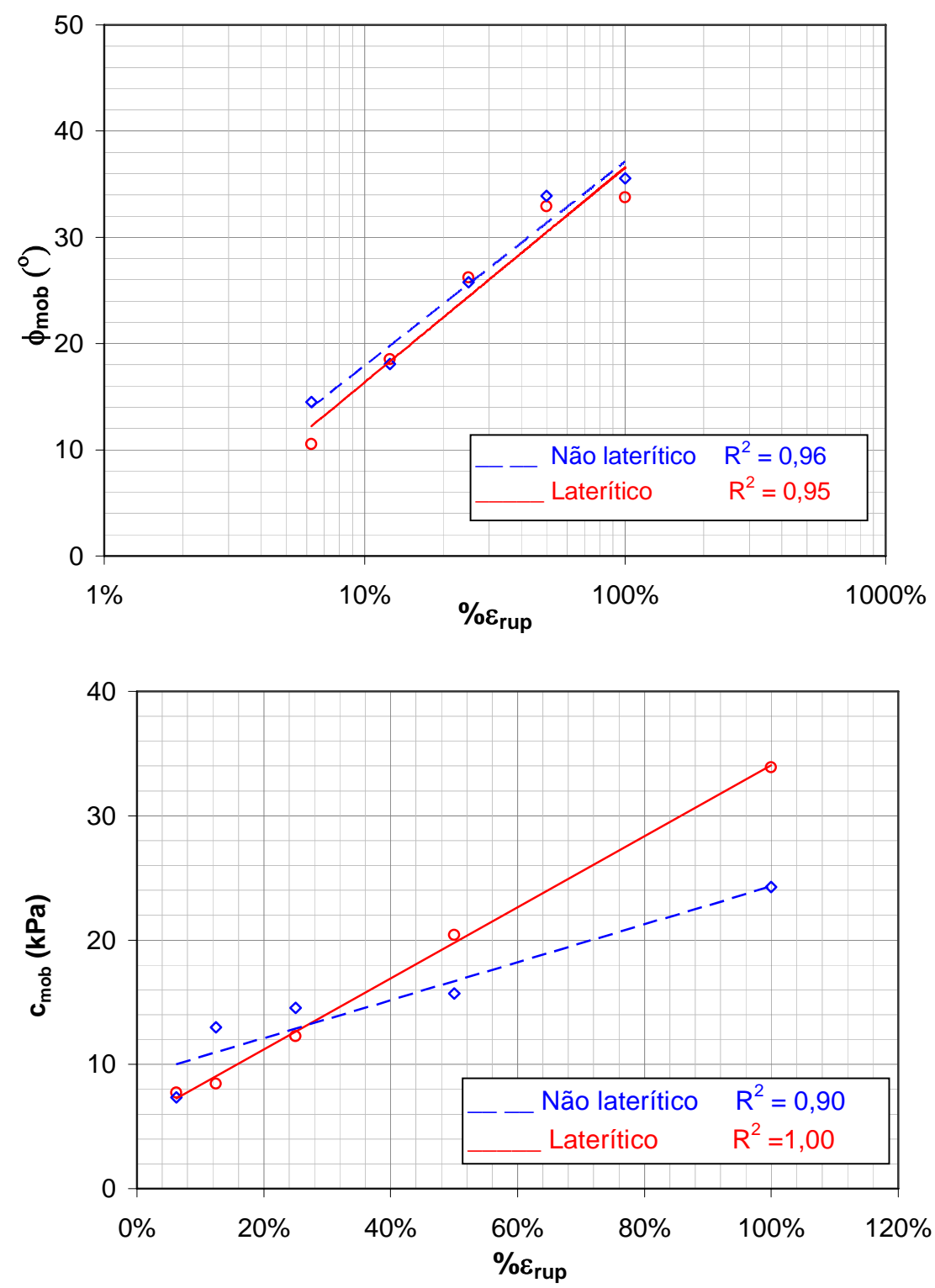

FIGURA 4.20 - Variação do atrito interno mobilizado e da coesão mobilizada em função da \% $\varepsilon_{\text {rup }}$ para o Par 3 
Analisando-se as figuras 4.18, 4.19 e 4.20, observa-se que o atrito interno mobilizado apresenta valores muito pequenos para as menores deformações, crescendo à medida que se aproxima da deformação de ruptura, quando alcançam o seu valor máximo. Esse fato indica que o atrito interno entre as partículas aumenta com o crescimento do nível de tensão e com o desenvolvimento das deformações. Observa-se ainda que para as pares 1 e 2, o atrito interno mobilizado dos solos lateríticos é mais sensível ao nível de deformação que o dos solos não lateríticos. No caso do par 3, os dois solos comportam-se de maneira muito semelhante, confirmando o destacado anteriormente, ou seja, que seriam solos pertencentes a uma mesma classe segundo a classificação MCT-M (Vertamitti, 1988).

No tocante à coesão, os diferentes pares apresentam comportamento distintos entre si, conforme discutido em seguida.

Se comparada ao ângulo de atrito interno mobilizado, a coesão mobilizada para os solos dos pares 1 e 2 varia muito pouco no decorrer de todo o ensaio triaxial. Esse fato indicaria que o efeito das ligações entre partículas decorrentes de eventuais cimentações depende pouco do estado de tensão ou da deformação desenvolvida, sendo mobilizada, praticamente na sua totalidade, desde o início do ensaio. Dos solos constituintes desses dois pares, apenas o solo $2 \mathrm{~N}$ apresenta uma variação mais significativa do $c_{m o b}$, sendo que sua diminuição com o desenvolvimento de maiores deformações poderia ser conseqüência de uma quebra de ligações entre partículas. 
Quanto ao aumento de $\mathrm{c}_{\mathrm{mob}}$ de ambos os solos do par 3 com o desenvolvimento das deformações, esse comportamento seria inusitado e não pôde ser explicado no contexto desse estudo.

\subsubsection{Deformabilidade}

Para a comparação entre a deformabilidade dos solos lateríticos e não lateríticos, foram determinadas e analisadas a deformação na ruptura, os módulos de deformação tangente inicial e os módulos de deformação secantes a 50\% da tensão de ruptura e na ruptura.

\section{Deformação na ruptura}

Para a análise comparativa da deformabilidade na ruptura dos solos lateríticos e não lateríticos, foram calculadas as diferenças relativas de deformação axial de ruptura para cada um dos pares de solos segundo a equação 4.2:

$$
\Delta \varepsilon=\frac{\left(\varepsilon_{\text {rupL }}-\varepsilon_{\text {rupN }}\right)}{\varepsilon_{\text {rupN }}} \cdot 100
$$

Onde: $. \Delta \varepsilon=$ Diferença relativa de deformação axial de ruptura (\%);

$\varepsilon_{\text {rupN }}=$ Deformação axial de ruptura para o solo não laterítico (\%);

$\varepsilon_{\text {rupL }}=$ Deformação axial de ruptura para o solo laterítico (\%). 
A tabela 4.3 apresenta os valores de $\varepsilon_{\text {rupN }}$ e $\varepsilon_{\text {rupL }}$ para os solos estudados e os valores de diferença absoluta e relativa de deformação axial de ruptura para cada tensão de confinamento $\left(\sigma_{c}\right)$, calculadas conforme a equação 4.2. A figura 4.21 ilustra a variação de $\Delta \varepsilon$ com $\sigma_{\mathrm{c}}$.

TABELA 4.3 - Deformação axial de ruptura das amostras e diferença relativa de deformação axial de ruptura para cada tensão de confinamento

\begin{tabular}{cccccc}
\hline Par & $\begin{array}{c}\sigma_{3} \\
(\mathrm{kPa})\end{array}$ & $\begin{array}{c}\varepsilon_{\text {rupL }} \\
(\%)\end{array}$ & $\begin{array}{c}\varepsilon_{\text {rupN }} \\
(\%)\end{array}$ & $\begin{array}{c}\left(\varepsilon_{\text {rupL }}-\varepsilon_{\text {rupN }}\right) \\
(\%)\end{array}$ & $\Delta \varepsilon(\%)$ \\
\hline \multirow{3}{*}{1} & 25 & 1,16 & 2,35 & 1,19 & 51 \\
& 50 & 1,36 & 4,10 & 2,74 & 67 \\
& 75 & 1,47 & 5,85 & 4,38 & 75 \\
\hline \multirow{3}{*}{2} & 25 & 1,08 & 14,53 & 13,44 & 93 \\
& 50 & 1,16 & 14,79 & 13,63 & 92 \\
& 75 & 1,51 & 16,70 & 15,20 & 91 \\
\hline \multirow{3}{*}{3} & 25 & 1,10 & 1,30 & 0,20 & 16 \\
& 50 & 1,48 & 1,90 & 0,41 & 22 \\
& 75 & 1,89 & 2,35 & 0,46 & 20 \\
\hline
\end{tabular}

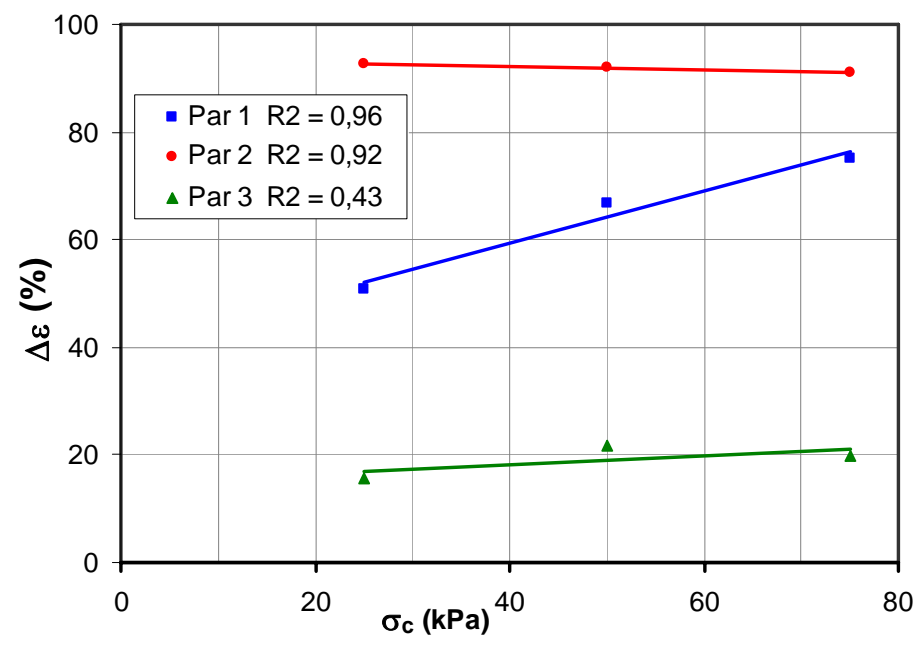

FIGURA 4.21 - Variação da diferença relativa de deformação axial de ruptura com a tensão confinante para os ensaios triaxiais. 
Analisando-se os valores da tabela 4.3, pode-se observar que a deformação de ruptura para todos os pares é menor para os solos lateríticos quando comparados aos não lateríticos. Observa-se também que a variação entre as deformações de ruptura dos solos lateríticos e não lateríticos para os pares 1 e 2, com médias de $64 \%$ e $92 \%$, respectivamente, é maior que para o par 3, com média de $19 \%$. O fato de $\Delta \varepsilon$ correspondente ao par 3 ser significativamente menor que as dos demais pares confirma a hipótese desses solos apresentarem comportamentos semelhantes entre si por pertencerem a uma mesma classe conforme a classificação MCT-M (Vertamatti, 1988).

Analisando a figura 4.21, observa-se que, para os pares 2 e 3 , a variação de $\Delta \varepsilon$ não depende de $\sigma_{c}$, enquanto que para o par $1, \Delta \varepsilon$ cresce linearmente com o aumento de $\sigma_{c}$. A granulometria poderia explicar este fato, visto que os solos do par 1 são os mais grossos e portanto estão mais sujeitos ao efeito da tensão confinante.

> Módulo tangente inicial

Para a determinação do módulo tangente inicial $\left(E_{0}\right)$ foram observados dois procedimentos: o traçado da tangente diretamente a partir do gráfico tensão versus deformação e o modelo hiperbólico preconizado por Duncan e Chang (1970). Analisando-se os resultados obtidos por este último procedimento, observou-se que, para uma parcela significativa dos ensaios, o modelo hiperbólico não reproduzia com fidelidade a curva tensão versus deformação, conforme pode ser visto no Apêndice 
B. Assim, decidiu-se utilizar nas análises que se seguem apenas os módulos tangentes iniciais determinados a partir do primeiro procedimento.

Calculados os valores de $E_{0}$, esses foram modelados em função da tensão confinante conforme a equação 3.5 sugerida por Janbu (1963). A tabela 4.4 apresenta os valores de módulo tangente inicial dos solos estudados e de $\mathrm{K}, \mathrm{n}$ e $\mathrm{R}^{2}$ da equação 3.5 para cada solo estudado. A figura 4.22 apresenta a curva de variação de $\mathrm{E}_{0}$ com $\sigma_{\mathrm{c}}$ para o conjunto de solos.

TABELA 4.4 - Módulos tangente inicial das amostras e parâmetros $\mathrm{K}$, n e $\mathbf{R}^{2}$ da equação 3.5 para cada tensão de confinamento

\begin{tabular}{cccccc}
\hline Solo & $\sigma_{3}(\mathrm{kPa})$ & $\mathrm{E}_{0}(\mathrm{MPa})$ & $\mathrm{k}$ & $\mathrm{n}$ & $\mathrm{R}^{2}$ \\
\hline \multirow{2}{*}{$1 \mathrm{~L}$} & 25 & 60 & & & \\
& 50 & 46 & 439 & $-0,1888$ & 0,6088 \\
& 75 & 50 & & & \\
\hline \multirow{2}{*}{$1 \mathrm{~N}$} & 25 & 50 & & & \\
& 50 & 46 & 193 & $-0,7567$ & 0,6861 \\
& 75 & 20 & & & \\
\hline \multirow{2}{*}{$2 \mathrm{~L}$} & 25 & 59 & & & \\
& 50 & 64 & 319 & $-0,5169$ & 0,5071 \\
& 75 & 31 & & & \\
\multirow{2}{*}{$2 \mathrm{~N}$} & 25 & 57 & & & \\
& 50 & 25 & 79 & $-1,4303$ & 0,9805 \\
& 75 & 11 & & & \\
\hline \multirow{2}{*}{$3 \mathrm{~L}$} & 25 & 46 & & & \\
& 50 & 48 & 480 & 0,038 & 0,5079 \\
& 75 & 47 & & & \\
\hline \multirow{2}{*}{$3 \mathrm{~N}$} & 25 & 85 & & & \\
& 50 & 59 & 696 & $-0,0689$ & 0,0346 \\
& 75 & 83 & & &
\end{tabular}




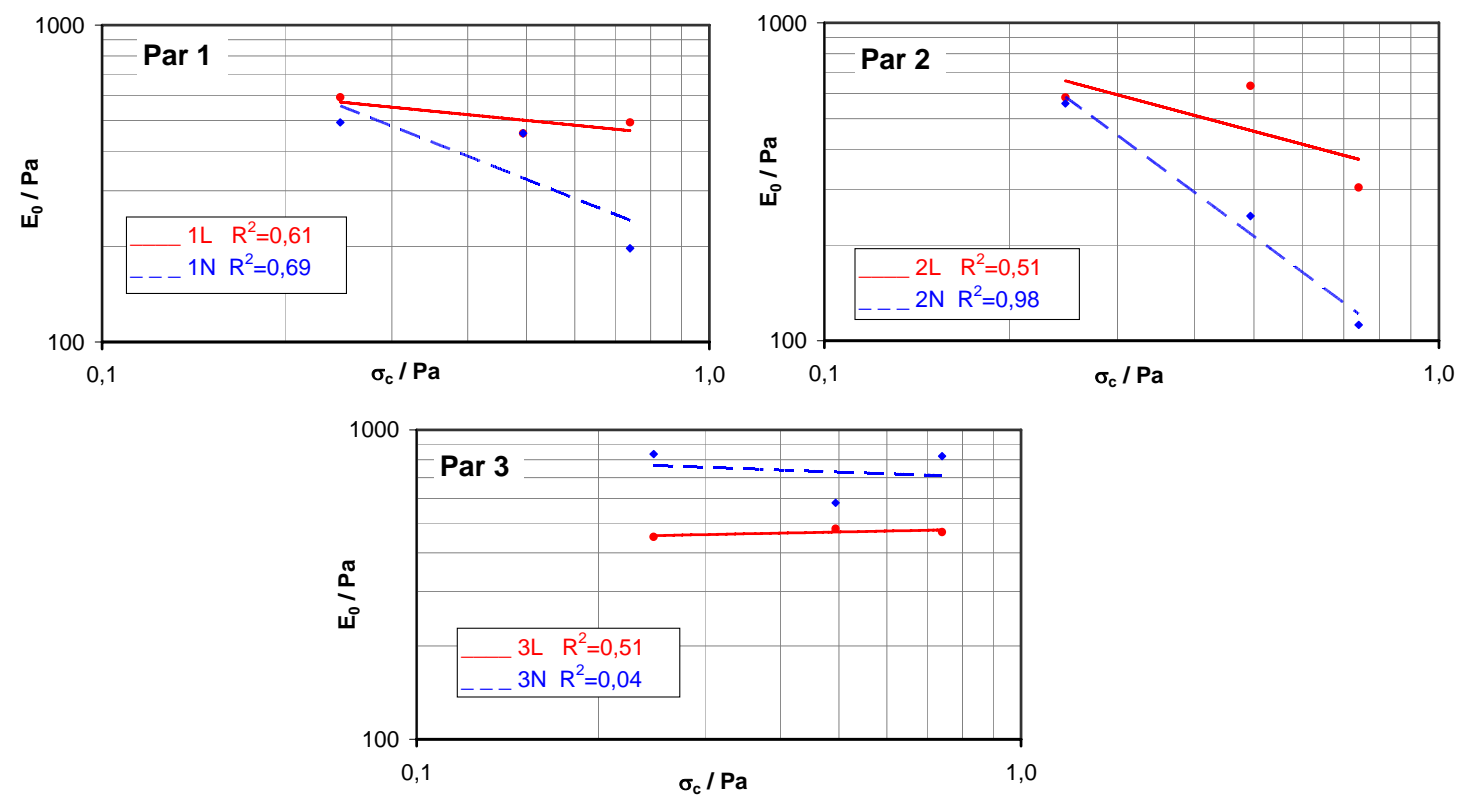

FIGURA 4.22 - Variação de $E_{0}$ com $\sigma_{c}$ para cada solo estudado.

Analisando-se a tabela 4.4 observa-se que, como exceção do solo $2 \mathrm{~N}$, a relação entre o módulo tangente inicial e a tensão confinante apresenta valores poucos elevados de $\mathrm{R}^{2}$, comportamento contrario ao relatado em inúmeros artigos para ensaios triaxiais. Este fato repete-se para os ensaios não saturados, conforme será apresentado no item 4.3.2.2. Neste sentido, a tabela 4.5 apresenta a variação do módulo de resiliência determinado para ensaios cíclicos não saturados dos solos em questão e os respectivos modelos determinados em função das tensões desvio e confinante e dessas duas tensões tomadas conjuntamente. 
Analisando essa tabela, observa-se que a variação de Mr depende principalmente da tensão desvio, visto que os modelos que consideram essa tensão apresentam $\mathrm{R}^{2}$ elevados, ao contrário do modelo que leva em conta apenas a tensão confinante que apresenta valores muito pequenos de $\mathrm{R}^{2}$ para todos os solos analisados.

TABELA 4.5 - Modelos para cálculo do módulo de resiliência calibrados por Takeda (2006) para os solos estudados

\begin{tabular}{|c|c|c|c|c|c|c|c|c|c|c|}
\hline \multirow{2}{*}{ Solo } & \multicolumn{3}{|c|}{ Modelo $\left(\mathrm{Mr}=\mathrm{k}_{1}{ }^{*} \sigma_{\mathrm{d}}{ }^{\mathrm{k} 2}\right)$} & \multicolumn{3}{|c|}{ Modelo $\left(\mathrm{Mr}=\mathrm{k}_{1}{ }^{*} \sigma_{3}{ }^{\mathrm{k} 2}\right)$} & \multicolumn{4}{|c|}{ Modelo $\left(\mathrm{Mr}=\mathrm{k}_{1}{ }^{*} \sigma_{\mathrm{d}}{ }^{\left.\mathrm{k}{ }^{2}{ }_{\sigma_{3}}{ }^{\mathrm{k} 3}\right)}\right.$} \\
\hline & $\mathrm{K}_{1}$ & $\mathrm{~K}_{2}$ & $\mathbf{R}^{2}$ & $\mathrm{~K}_{1}$ & $\mathrm{~K}_{2}$ & $\mathbf{R}^{2}$ & $\mathrm{~K}_{1}$ & $\mathrm{~K}_{2}$ & $\mathrm{~K}_{3}$ & $\mathbf{R}^{2}$ \\
\hline $1 \mathrm{~L}$ & 1523 & $-0,031$ & 0,84 & 309 & 0,162 & 0,14 & 864 & $-0,304$ & 0,167 & 0,97 \\
\hline $1 \mathrm{~N}$ & 1340 & $-0,159$ & 0,96 & 792 & $-0,006$ & 0,00 & 1365 & $-0,157$ & 0,008 & 0,96 \\
\hline $2 \mathrm{~L}$ & 1275 & $-0,319$ & 0,91 & 297 & 0,112 & 0,07 & 853 & $-0,326$ & 0,131 & 0,99 \\
\hline $2 \mathrm{~N}$ & 390 & $-0,122$ & 0,89 & 254 & 0,005 & 0,00 & 376 & $-0,119$ & 0,008 & 0,88 \\
\hline $3 \mathrm{~L}$ & 1661 & $-0,421$ & 0,97 & 322 & 0,071 & 0,02 & 1275 & $-0,423$ & 0,084 & 0,99 \\
\hline $3 \mathrm{~N}$ & 1500 & $-0,246$ & 0,98 & 695 & $-0,020$ & 0,00 & 974 & $-0,124$ & $-0,054$ & 0,95 \\
\hline
\end{tabular}

Ainda analisando-se a tabela 4.4 e a figura 4.22 observa-se que, para os pares 1 e 2, os solos lateríticos apresentam módulo tangente inicial superior aos dos solos não lateríticos. Observa-se ainda que, para esses pares, considerando os valores de $\mathrm{R}^{2}$, os solos não lateríticos apresentam uma relação melhor com a tensão confinante, quando comparado aos solos lateríticos. No entanto, para os solos desses pares há uma tendência de decréscimo de $\mathrm{E}_{0}$ com o aumento da tensão confinante, sendo que os solos não lateríticos apresentam queda mais acentuada que os solos lateríticos. Este fato provoca um acréscimo na diferença entre o $E_{0}$ dos solos lateríticos e dos solos não lateríticos com o aumento de $\sigma_{\mathrm{c}}$.

Considerando-se que tensões elevadas aumentam o atrito intergranular, o aumento de tensão confinante agiria no sentido de aumentar a rigidez dos solos, entretanto, 
um efeito contrário seria possível se for considerado solos com alguma cimentação, ou então solos compactados, onde o aumento da tensão confinante provocaria um desarranjo granular. Assim, o nível de tensões utilizados nos ensaios saturados dessa dissertação, podem estar provocando nesses solos quebra em pequenas ligações obtidas durante a compactação, sendo que, possivelmente se esses níveis de tensões fossem elevados se obteria valores de $E_{0}$ crescentes com o aumento de $\sigma_{\mathrm{c}}$

Ao se observar o comportamento dos solos do par 3, detecta-se uma discrepância com os demais pares, pois o solo não laterítico $3 \mathrm{~N}$ apresenta $\mathrm{E}_{0}$ maior que o solo $3 \mathrm{~L}$ e, para ambos os solos, $E_{0}$ varia pouco com a tensão confinante. Essa discrepância com os demais pares vem se mostrando em todas as análises e dificultando a identificação de comportamentos típicos de solos lateríticos e não lateríticos entre esses solos. Assim confirma-se mais uma vez que eles apresentam comportamentos semelhantes por pertencerem a uma mesma classe conforme indica a classificação MCT-M.

Comparando os solos dos 3 pares estudados pode-se observar que, os solos do par 3, além de apresentarem comportamento semelhante entre si, esse comportamento assemelha-se ao comportamento dos solos lateríticos dos pares 1 e 2 .

\section{Módulos secantes}

A tabela 4.6 apresenta os valores dos módulos de deformação secante a $50 \%$ da tensão de ruptura $\left(E_{50}\right)$ e na ruptura $\left(E_{\text {rup }}\right)$ e valores dos módulos de deformação 
tangente inicial $\left(E_{0}\right)$ para cada valor de tensão confinante para todos os solos estudados. As figuras 4.23, 4.24 e 4.25 apresentam as variações desses módulos com $\sigma_{c}$ para os pares 1, 2 e 3 , respectivamente.

TABELA 4.6 - Módulos de deformação secante a $50 \%$ da tensão de ruptura, módulos de deformação secante na ruptura e módulos de deformação tangente inicial dos solos estudados

\begin{tabular}{ccccc}
\hline \multirow{2}{*}{ Solo } & $\sigma_{3}(\mathrm{kPa})$ & $E_{\text {rup }}(\mathrm{MPa})$ & $E_{50}(\mathrm{MPa})$ & $E_{0}(\mathrm{MPa})$ \\
\hline \multirow{3}{*}{$1 \mathrm{~L}$} & 25 & 12 & 40 & 60 \\
& 50 & 14 & 31 & 46 \\
& 75 & 17 & 38 & 50 \\
\hline \multirow{3}{*}{$1 \mathrm{~N}$} & 25 & 4 & 17 & 50 \\
& 50 & 4 & 13 & 46 \\
& 75 & 3 & 11 & 20 \\
\hline \multirow{2}{*}{$2 \mathrm{~L}$} & 25 & 12 & 30 & 59 \\
& 50 & 17 & 33 & 64 \\
& 75 & 15 & 25 & 31 \\
\hline \multirow{3}{*}{$2 \mathrm{~N}$} & 25 & 0 & 24 & 56 \\
& 50 & 1 & 9 & 25 \\
& 75 & 1 & 5 & 11 \\
\hline \multirow{2}{*}{$3 \mathrm{~L}$} & 25 & 17 & 30 & 46 \\
& 50 & 17 & 28 & 48 \\
& 75 & 17 & 36 & 47 \\
\hline \multirow{2}{*}{$3 \mathrm{~N}$} & 25 & 13 & 30 & 67 \\
& 50 & 12 & 24 & 59 \\
& 75 & 13 & 30 & 83 \\
\hline
\end{tabular}



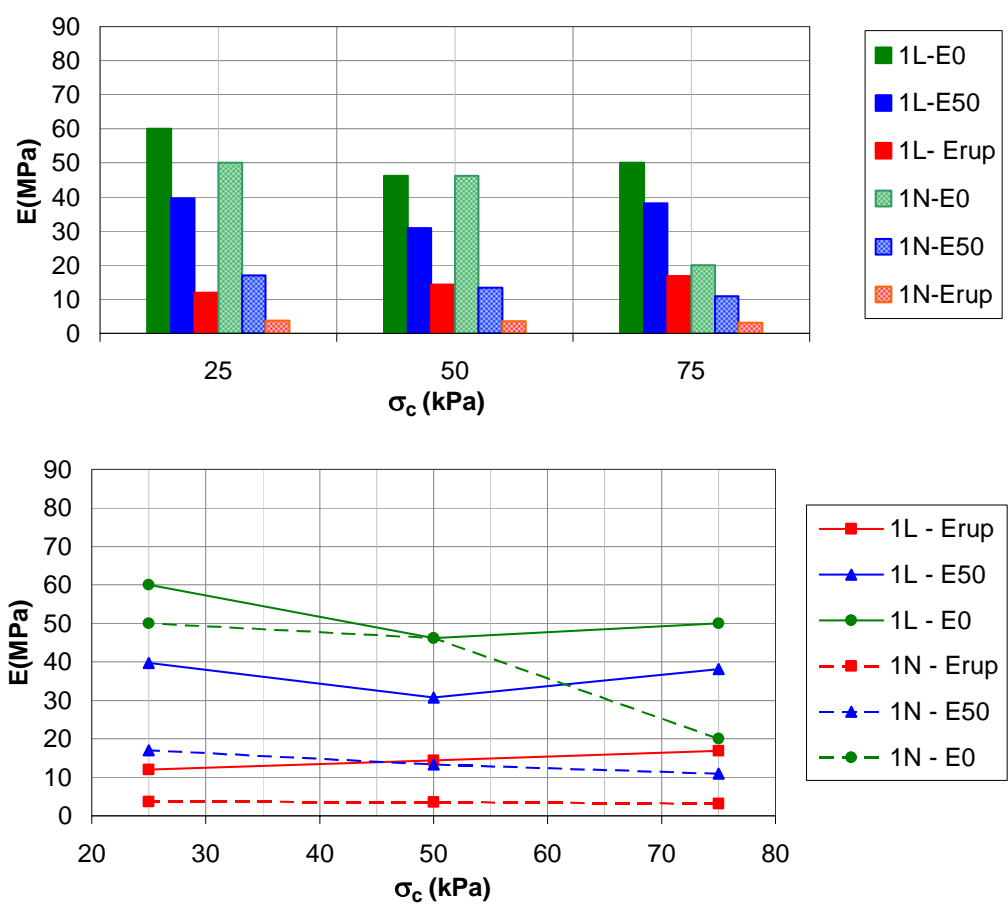

FIGURA 4.23 - Variação de $E_{0}, E_{50}$ e $E_{\text {rup }}$ com $\sigma_{c}$ para cada solo do par 1
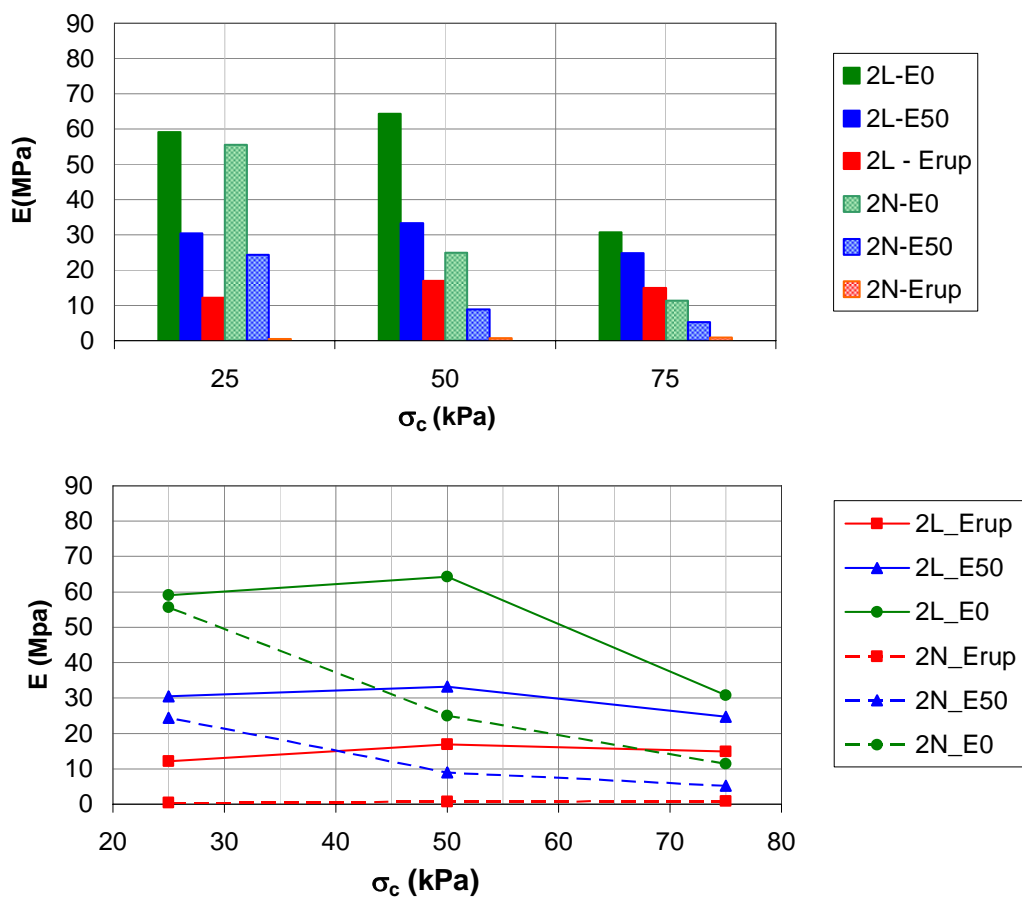

FIGURA 4.24 - Variação de $E_{0}, E_{50}$ e $E_{\text {rup }}$ com $\sigma_{c}$ para cada solo do par 2 

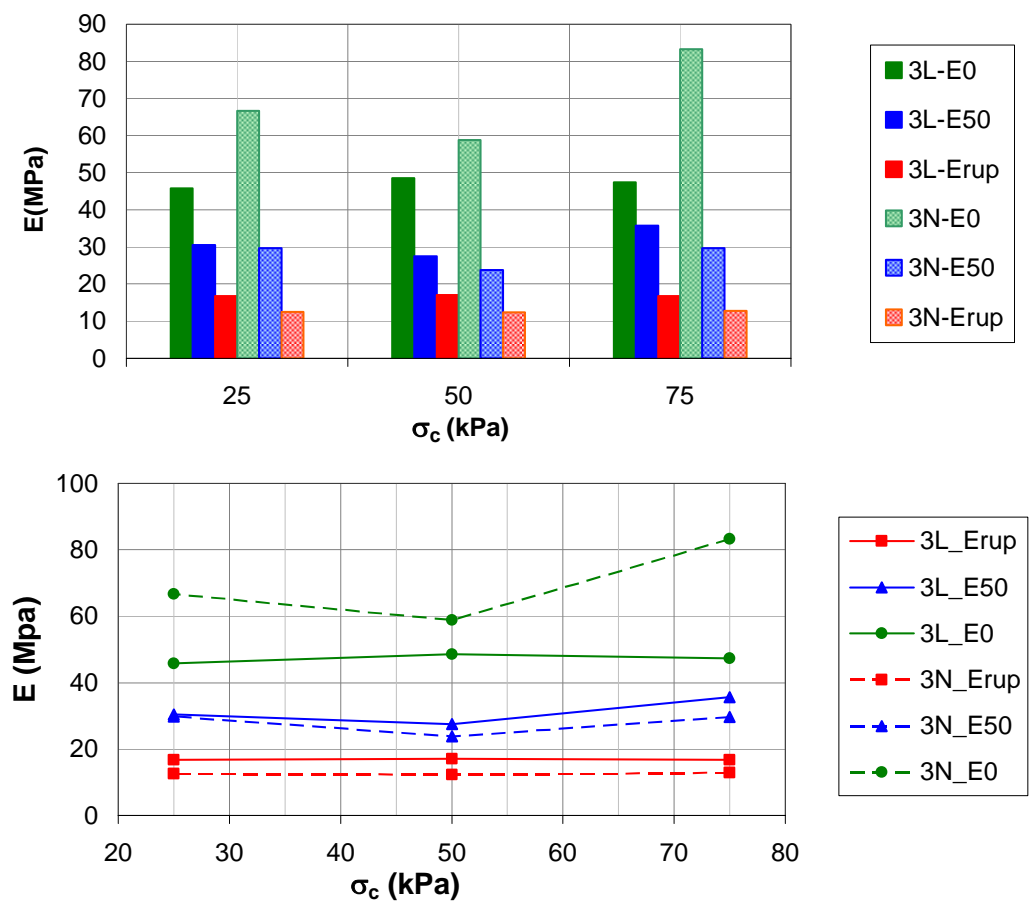

FIGURA 4.25 - Variação de $E_{0}, E_{50}$ e $E_{\text {rup }}$ com $\sigma_{c}$ para cada solo do par 3

Analisando-se a tabela 4.6 e as figuras 4.23 e 4.24 observa-se que, para os solos dos pares 1 e 2, todos os valores de módulos de deformação calculados para os solos lateríticos são maiores que os dos não lateríticos. Observa-se ainda que, os solos desses pares apresentam $E_{\text {rup }}$ praticamente constantes, independentes de $\sigma_{c}$. Quanto ao comportamento de $E_{50}$ observa-se que, os solos do par 1 apresentam uma variação maior que a do $E_{\text {rup, }}$ porém ainda pouco expressiva, enquanto que, para o par 2, apenas o solo laterítico comporta-se conforme destacado anteriormente e o solo $2 \mathrm{~N}$ mostra uma diminuição de $\mathrm{E}_{50}$ com o aumento de $\sigma_{\mathrm{c}}$.

Quando comparadas as diferenças entre os módulos $E_{0}$ e $E_{50}$ e entre os módulos $E_{50}$ e $E_{\text {rup }}$ observa-se que essas diferenças diminuem com o aumento da tensão confinante, diminuição esta mais expressiva para os solos não lateríticos. 
Analisando-se a figura 4.25 e a tabela 4.6 observa-se que, para os solos do par 3, os módulos secantes apresentam valores semelhantes para os solos lateríticos e não lateríticos. Observa-se ainda que, assim como nos outros pares estudados $E_{\text {rup }}$ é praticamente constante para os solos do par 3, ou seja, independe de $\sigma_{\mathrm{c}}$. Quanto ao comportamento de $E_{50}$, nota-se uma semelhança entre o solos $3 \mathrm{~L}$ e $3 \mathrm{~N}$, e para ambos $E_{50}$ apresenta uma variação maior que a do $E_{\text {rup, porém ainda pouco }}$ expressiva.

Tomando-se os valores médios de $\mathrm{E}_{50}$, de 17 e 13MPa, respectivamente, para os

solos $3 \mathrm{~L}$ e $3 \mathrm{~N}$, e os valores médios de $\mathrm{E}_{\text {rup, }}$ de 31 e $29 \mathrm{MPa}$, respectivamente, para os solos $3 \mathrm{~L}$ e $3 \mathrm{~N}$, observa-se que ambos os solos do par 3 apresentam comportamentos semelhantes entre si. Além disso, comparando-se esses valores com os valores médios de $E_{50}$, de 14 e $15 \mathrm{MPa}$, respectivamente, para os solos $1 \mathrm{~L}$ e 2L, e os valores médios de $\mathrm{E}_{\text {rup }}$, de 36 e $29 \mathrm{MPa}$, respectivamente, para os solos $1 \mathrm{~L}$ e 2L, observa-se que, os solos do par 3 apresentam comportamento muito próximo aos dos solos lateríticos dos pares 1 e 2 .

\subsubsection{Ensaios Não Saturados}

Como destacado no capítulo 3 apenas os solos do par 1 foram submetidos aos ensaios na umidade de compactação, sem a saturação dos corpos-de-prova.

A figura 4.26 apresenta as curvas de tensão versus deformação axial e deformação volumétrica versus deformação axial do par 1, para os ensaio não saturados. 

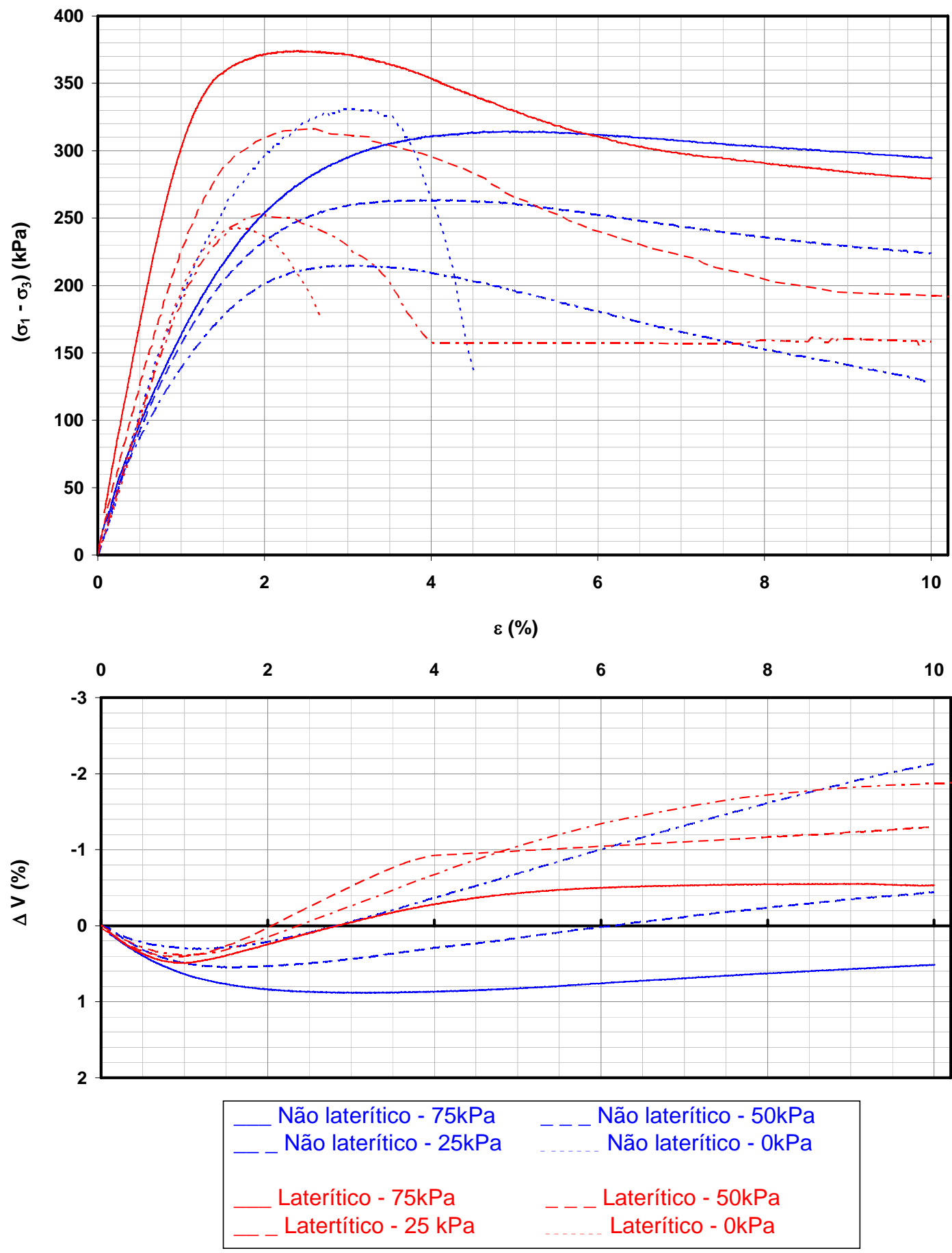

FIGURA 4.26 - Curvas tensão desvio versus deformação axial e variação volumétrica versus deformação axial dos solos do Par 1 relativos aos ensaios não saturados 
Analisando-se a figura 4.26, e observando o desenvolvimento das curvas tensão desvio e variação volumétrica com a deformação axial, constata-se que as curvas dos ensaios não saturados realizados com confinamento apresentam comportamento semelhante às curvas dos ensaios triaxiais saturados (figura 4.10), ou seja, o solo laterítico (1L) apresenta um comportamento frágil se comparado ao solo não laterítico $(1 \mathrm{~N})$, com uma resistência residual menor que a resistência de pico. Observa-se, também, que para os ensaios triaxiais não saturados, os corposde-prova do solo $1 \mathrm{~L}$ rompem com aproximadamente $2,5 \%$ de deformação axial, com um pico bem delineado, enquanto os ensaios do solo $1 \mathrm{~N}$ rompem com deformação axial entre $3 \%$ e $5 \%$ sem pico de ruptura claramente estabelecido. Quando se comparam as tensões de ruptura, o solo laterítico apresenta valores superiores aos do solo não laterítico.

No tocante à variação volumétrica, esta é compressiva até próximo à ruptura, seguindo-se uma dilatância para ambas as gêneses, diferente dos ensaios saturados, onde apenas o solo laterítico apresenta dilatância (vide figura 4.10).

Ainda analisando-se o desenvolvimento das curvas tensão desvio com a deformação axial, mas considerando-se apenas os ensaios sem confinamento, constata-se que ambos os solos apresentaram um comportamento frágil, podendo-se delinear o pico de ruptura, que se dá para deformações entre 2\% e 4\% da deformação axial. Observa-se também que o solo laterítico apresenta resistência inferior ao solo não laterítico, fato inesperado e não evidenciado em nenhum dos outros ensaios realizados. 
Além disso, para o solo $1 \mathrm{~N}$, a tensão de ruptura obtida no ensaio sem confinamento é superior às correspondentes aos ensaios confinados, fato que contraria a expectativa para este tipo de ensaio. Esse fato pode ter sido provocado pela perda de umidade para o ambiente, uma vez que durante os ensaios sem confinamento os corpos-de-prova ficavam expostos. Assim, tendo em vista estas discrepâncias, resolveu-se não considerar os resultados dos ensaios sem confinamento nas análises que se seguem.

\subsubsection{Resistência à Ruptura}

A tabela 4.7 apresenta os valores da tensão de ruptura para os solos do par 1 e as diferenças absolutas e relativas de tensão de ruptura, $\Delta \sigma$, calculadas através da equação 4.1, para cada tensão de confinamento, para os ensaios saturados e não saturados. A figura 4.27 ilustra a variação de $\Delta \sigma$ com a tensão de confinamento.

TABELA 4.7 - Tensões de ruptura e diferenças absolutas e relativas de tensão de ruptura para cada tensão de confinamento dos ensaios saturados e não saturados dos solos $1 \mathrm{~L}$ e $1 \mathrm{~N}$

\begin{tabular}{cccccc}
\hline \multirow{6}{*}{ Não Sat } & $\begin{array}{c}\sigma_{3} \\
(\mathrm{kPa})\end{array}$ & $\begin{array}{c}\sigma_{\text {rupL }} \\
(\mathrm{kPa})\end{array}$ & $\begin{array}{c}\sigma_{\text {rupN }} \\
(\mathrm{kPa})\end{array}$ & $\begin{array}{c}\left(\sigma_{\text {rupL }}-\sigma_{\text {rupN }}\right) \\
(\mathrm{kPa})\end{array}$ & $\Delta_{\sigma}(\%)$ \\
\hline \multirow{4}{*}{ Sat } & 25 & 254 & 215 & 39 & $18 \%$ \\
& 50 & 316 & 264 & 53 & $20 \%$ \\
& 75 & 374 & 314 & 60 & $19 \%$ \\
\hline & 25 & 139 & 87 & 52 & $60 \%$ \\
& 50 & 194 & 144 & 50 & $35 \%$ \\
& 75 & 248 & 185 & 62 & $34 \%$ \\
\hline
\end{tabular}




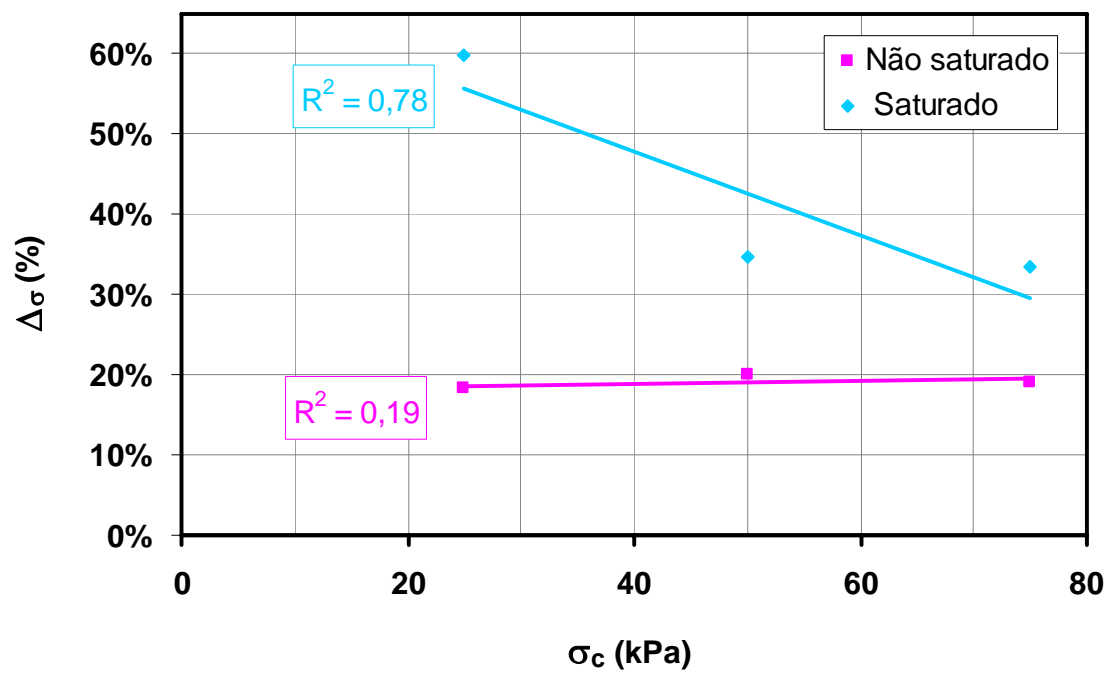

FIGURA 4.27 - Variação da diferença relativa de tensão de ruptura com tensão de confinamento para os ensaios triaxiais saturados e não saturados do par 1

Analisando-se a tabela 4.7 e a figura 4.27 observa-se que, as diferenças de tensão de ruptura dos solos laterítico e não laterítico em termos absolutos, determinadas a partir dos ensaios saturados e não saturados, são praticamente coincidentes. No entanto, em termos relativos, para os ensaios não saturados, o solo laterítico comporta-se ligeiramente melhor que o solo não laterítico, sendo que a resistência do primeiro é, em média, 19\% superior à determinada para o solo não laterítico, e essa diferença não depende da tensão de confinamento. Observa-se também que, para os ensaios saturados, o comportamento do solo $1 \mathrm{~L}$ é pronunciadamente melhor que a do solo $1 \mathrm{~N}$, sendo que a diferença relativa de resistência entre os mesmos varia de $60 \%$ a 34\%, conforme a tensão de confinamento aplicada. 
No tocante à influencia da tensão de confinamento, a diferença de resistência entre o solo laterítico e o solo não laterítico diminui com o aumento desta variável, sendo que $\Delta \sigma$ para esses ensaios converge para valores coincidentes aos dos ensaios não saturados para tensões de confinamento superiores a $75 \mathrm{kPa}$.

Com base nas tensões de ruptura determinadas nos ensaios saturados e não saturados, determinou-se também a porcentagem de queda de resistência decorrente da saturação conforme a equação 4.4:

$$
P_{q}=\frac{\left(\sigma_{\text {rupNS }}-\sigma_{\text {rups }}\right)}{\sigma_{\text {rupNS }}} \bullet 100
$$

Onde: . $P_{q}=$ Porcentagem de queda de tensão de ruptura devida à saturação (\%);

$$
\begin{aligned}
& \sigma_{\text {rupNS }}=\text { Tensão desvio de ruptura não saturado }(\mathrm{kPa}) \\
& \sigma_{\text {rups }}=\text { Tensão desvio de ruptura saturado }(\mathrm{kPa}) .
\end{aligned}
$$

A tabela 4.8 apresenta os valores da tensão de ruptura para dos solos $1 \mathrm{~L}$ e $1 \mathrm{~N}$ e a porcentagem de queda de resistência devido à saturação para cada tensão de confinamento $\left(\sigma_{c}\right)$. A figura 4.28 ilustra a variação do $P_{q}$ com as tensões de confinamento. 
TABELA 4.8 - Tensões de ruptura e porcentagem de queda de resistência devido à saturação, para cada tensão de confinamento dos ensaios saturados e não saturados dos solos 1L e 1N

\begin{tabular}{|c|c|c|c|c|c|}
\hline & $\begin{array}{c}\sigma_{3} \\
(\mathrm{kPa})\end{array}$ & $\begin{array}{l}\sigma_{\text {rupNS }} \\
(\mathrm{kPa})\end{array}$ & $\begin{array}{r}\sigma_{\text {rups }} \\
(\mathrm{kPa})\end{array}$ & $\begin{array}{c}\left(\sigma_{\text {rupNs }}-\sigma_{\text {rups }}\right) \\
(\mathrm{kPa})\end{array}$ & $P_{q}(\%)$ \\
\hline \multirow{3}{*}{$1 \mathrm{~L}$} & 25 & 254 & 139 & 115 & $45 \%$ \\
\hline & 50 & 316 & 194 & 122 & $39 \%$ \\
\hline & 75 & 374 & 248 & 127 & $34 \%$ \\
\hline \multirow{3}{*}{$1 \mathrm{~N}$} & 25 & 215 & 87 & 128 & $60 \%$ \\
\hline & 50 & 264 & 144 & 120 & $45 \%$ \\
\hline & 75 & 314 & 185 & 129 & $41 \%$ \\
\hline
\end{tabular}

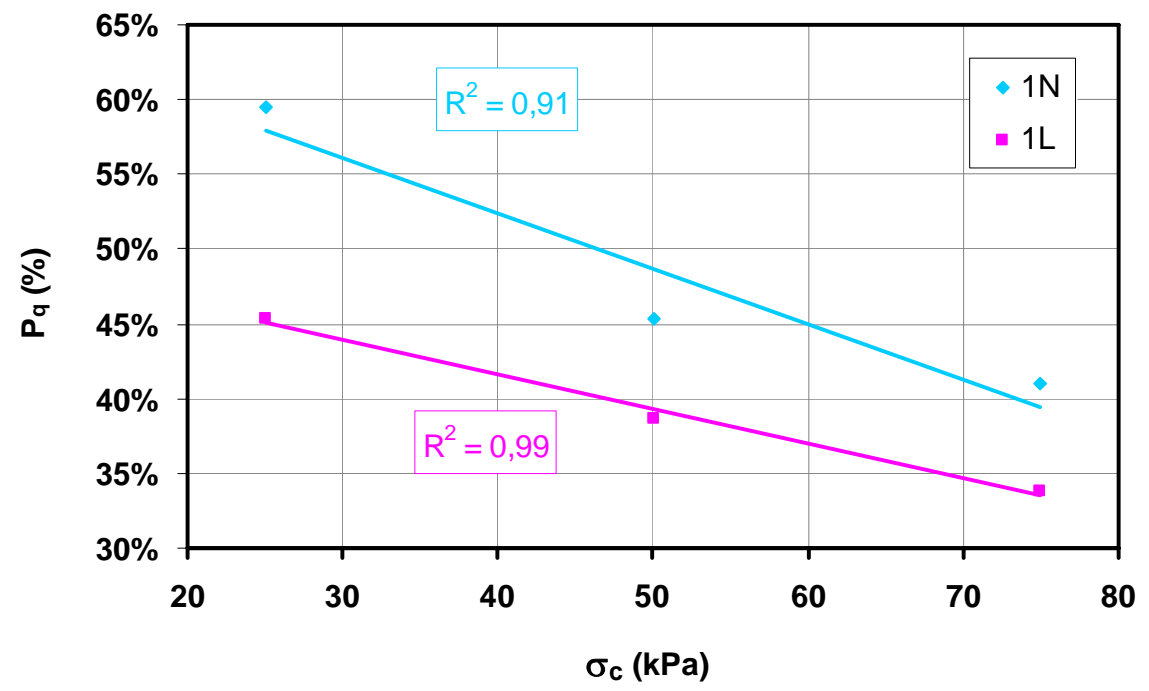

FIGURA 4.28 - Variação da porcentagem de queda de resistência devido à saturação com tensão de confinamento para os ensaios triaxiais dos solos do par 1

Analisando-se a tabela 4.8 e a figura 4.28, observa-se que para as tensões de confinamento estudadas, o solo $1 \mathrm{~L}$ apresenta porcentagem de queda de tensão de ruptura menor que o solo $1 \mathrm{~N}$, ou seja, a saturação deste último resultou em quedas maiores de resistência que a saturação do solo $1 \mathrm{~L}$. Em média o solo $1 \mathrm{~L}$ apresenta $\mathrm{P}_{\mathrm{q}}$ de $39 \%$ e o solo $1 \mathrm{~N}$ de $49 \%$. Observa-se ainda, que ambos os solos apresentam redução de $P_{q}$ com o aumento da tensão de confinamento, fato semelhante ao já 
observado para $\Delta \sigma$ e ilustrado na figura 4.27, e que existe uma tendência dos valores de $\mathrm{P}_{\mathrm{q}}$ de solos lateríticos e não lateríticos convergirem para valores próximos entre si para tensões de confinamento mais elevadas.

Ainda analisando-se a tabela 4.8, quando são comparadas as perdas de resistência absolutas $(\Delta \mathrm{w})$ decorrentes da saturação das amostras, observa-se que estes valores são, na media, muito próximos para as duas gêneses, 121 kPa e 126kPa, respectivamente para os solos laterítico e não laterítico.

Para auxiliar na análise da variação de resistência dos solos com a saturação, a tabela 4.9 apresenta para os solos $1 \mathrm{~L}$ e $1 \mathrm{~N}$, as umidades de compactação dos corpos de prova utilizados nos ensaios triaxiais não saturados, os correspondentes graus de saturação, as umidades calculadas para a condição saturada e os valores de sucção na umidade de compactação determinados pelo método do papel de filtro.

Analisando-se a tabela 4.9 observa-se que o solo laterítico apesar de apresentar uma umidade ótima menor que a do solo não laterítico, sua sucção nessa condição é menor que a deste solo. E ainda se observa que, em média, a variação de umidade e grau de saturação entre as condições "ótima" e saturada é menor para o solo laterítico.

Assim considerando-se os aspectos levantados anteriormente, pode-se concluir que a maior variação de resistência com a saturação dos solos não lateríticos, quando comparados aos lateríticos, é provocada pela perda da parcela de resistência devida a sucção que se dá ao se saturar o corpo-de-prova, que é maior para os solos não lateríticos. 
TABELA 4.9 - Valores umidades e graus de saturação para os corpos-de-prova ensaiados sob as condições saturadas e não saturadas e valores de sucção dos solos $1 \mathrm{~L}$ e $1 \mathrm{~N}$

\begin{tabular}{|c|c|c|c|c|c|c|c|}
\hline Solo & $\begin{array}{c}\text { Sucção } \\
\text { inicial } \\
\text { (kPa) }\end{array}$ & $c p$ & $\begin{array}{c}\mathbf{W}_{\text {compactação }} \\
(\%)\end{array}$ & $\begin{array}{c}\mathrm{S}_{\text {compactação }} \\
(\%)\end{array}$ & $W_{\text {sat }}(\%)$ & $\Delta \mathrm{w}(\%)$ & $\Delta \mathrm{S}(\%)$ \\
\hline \multirow{4}{*}{$1 \mathrm{~L}$} & \multirow{4}{*}{67} & 1 & 12,6 & 92,5 & 13,5 & & \\
\hline & & 2 & 12,6 & 91,2 & 13,5 & & \\
\hline & & 3 & 12,5 & 92,1 & 13,4 & & \\
\hline & & Média & 12,6 & 91,9 & 13,5 & 0,9 & 8,1 \\
\hline \multirow{4}{*}{$1 \mathrm{~N}$} & \multirow{4}{*}{99} & 1 & 16,9 & 82,8 & 20,0 & & \\
\hline & & 2 & 16,9 & 82,9 & 19,5 & & \\
\hline & & 3 & 17,0 & 82,3 & 19,4 & & \\
\hline & & Média & 16,9 & 82,7 & 19,6 & 2,7 & 17,3 \\
\hline
\end{tabular}

$\Delta \mathrm{W}=\mathrm{W}_{\text {sat }}-\mathrm{W}_{\text {compactação }} \quad \Delta \mathrm{S}=100-\mathrm{S}_{\text {compactação }}$

Envoltória de Ruptura de Mohr-Coulomb

A tabela 4.10 apresenta os valores de ângulo de atrito interno e coesão das envoltórias de ruptura de Mohr-Coulomb determinadas a partir dos resultados dos ensaios saturados e não saturados do par 1. Para o cálculo destes valores, foram considerados apenas os ensaios confinados pelas razões já apontadas anteriormente. As ilustrações das envoltórias de ruptura obtidas a partir dos círculos de Mohr são apresentadas no Apêndice A. 
TABELA 4.10 - Valores de $\phi$ e c para as envoltórias de ruptura de MohrCoulomb saturada e não saturada dos solos 1L e 1N

Saturado Não saturado

\begin{tabular}{ccccc} 
& $\phi\left({ }^{\circ}\right)$ & $\mathbf{c ~ ( k P a )}$ & $\phi\left({ }^{\circ}\right)$ & $\mathbf{c ~ ( k P a )}$ \\
\hline $\mathbf{1 L}$ & 31 & 24 & 33 & 53 \\
\hline 1N & 30 & 12 & 30 & 48 \\
\hline
\end{tabular}

A figura 4.29 apresenta as envoltórias de ruptura de Mohr-Coulomb para os ensaios saturados e não saturados dos solos do par 1, representadas em diagramas de tensão $\mathrm{p} \times \mathrm{q}$. Considerando os valores elevados dos coeficientes de regressão $\mathrm{R}^{2}$, pode-se afirmar que as envoltórias são retilíneas para as tensões de confinamento utilizadas.

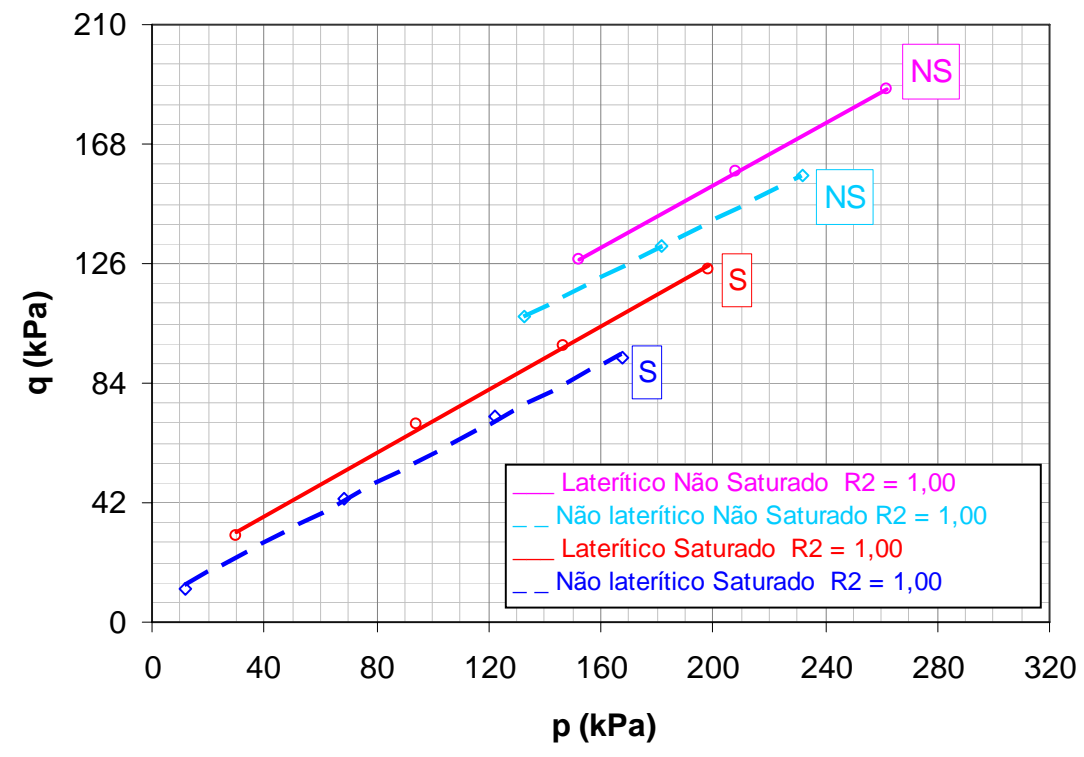

FIGURA 4.29 - Envoltória de resistência das amostras 1L e 1N para corpos-deprova saturados e não saturados

Analisando-se a tabela 4.10 e a figura 4.29, observa-se que para o solo $1 \mathrm{~N}$, o ângulo de atrito interno determinado para os ensaios saturados e não saturados 
apresentaram o mesmo valor $\left(30^{\circ}\right)$, enquanto que para o solo $1 \mathrm{~L}$, esses valores são respectivamente, $31^{\circ}$ e $33^{\circ}$. Assim, pode-se afirmar que para ambos os solos, o ângulo de atrito interno é pouco influenciado pela condição do ensaio.

No tocante à coesão, ainda com base na tabela 4.10 e na figura 4.29 , observa-se que, para o solo $1 \mathrm{~L}$ o valor desse parâmetro determinado a partir dos ensaios não saturados é da ordem de 2,2 vezes maior que o determinado a partir dos ensaios saturados. Para o solo 1N, essa relação é da ordem de 4 vezes.

E ainda, a maior diminuição da coesão com saturação observada para o solo $1 \mathrm{~N}$ indicaria que este material é mais sensível ao efeito da saturação que o solo $1 \mathrm{~L}$, confirmando análise realizada anteriormente.

No campo de estudos de resistência ao cisalhamento de solos não saturados destaca-se a atuação da variável sucção, definida como a diferença entre a pressão no ar e a pressão na água nos vazios $\left(u_{\mathrm{a}}-\mathrm{u}_{\mathrm{w}}\right)$, no comportamento dos solos. Considerando-se os dois modelos, o de Fredlund et al (1978) e o de Rohm e Vilar (1995), descritos no capitulo 2 dessa dissertação, conclui-se que, para ensaios não saturados, a coesão obtida poderia ser descrita como a soma de uma parcela correspondente à coesão efetiva com outra parcela oriunda da sucção. Quanto ao ângulo de atrito interno, esse mantém-se constante independente da existência ou não de sucção.

Analisando-se os valores da coesão e do ângulo de atrito interno para os solos do par 1 obtidos para os ensaios saturados e não saturados e considerando-se os modelos propostos para a representação do comportamento dos solos não 
saturados, observa-se que o valor de $\phi^{\prime}$ apresenta pequena variação, podendo ser considerado constante para cada um dos solos. No tocante à coesão, os valores determinados para os ensaios não saturados corresponderiam à coesão aparente e, portanto incluiriam o efeito da sucção. Assim, justificam-se os valores superiores de coesão determinados nos ensaios não saturados quando comparados aos ensaios saturados.

\subsubsection{Deformabilidade}

Assim como para os ensaios saturados, para se efetuar numa análise comparativa entre a deformação dos solos lateríticos e não lateríticos na condição não saturada, foram determinadas a deformação na ruptura, os módulos de deformação tangente inicial e os módulos de deformação secantes a $50 \%$ da tensão de ruptura e na ruptura para os solos do par 1.

\section{> Deformação na ruptura}

A tabela 4.11 apresenta os valores de $\varepsilon_{\text {rupN }}$ e $\varepsilon_{\text {rupL }}$ para os solos do par 1 e os valores da diferença absoluta e relativa de deformação axial de ruptura, respectivamente, $\left(\varepsilon_{\text {rup }}-\varepsilon_{\text {rupN }}\right)$ e $\Delta \varepsilon$, esta última calculada conforme a equação 4.2 , para cada tensão de confinamento $\left(\sigma_{c}\right)$, para os ensaios saturados e não saturados. A figura 4.31 ilustra a variação de $\Delta \varepsilon \operatorname{com} \sigma_{\mathrm{c}}$. 
TABELA 4.11 - Deformação axial de ruptura das amostras e diferença relativa de deformação axial de ruptura para cada tensão de confinamento

\begin{tabular}{cccccc}
\hline Par & $\begin{array}{c}\sigma_{3} \\
(\mathrm{kPa})\end{array}$ & $\begin{array}{c}\varepsilon_{\text {rupL }} \\
(\%)\end{array}$ & $\begin{array}{c}\varepsilon_{\text {rupN }} \\
(\%)\end{array}$ & $\begin{array}{c}\left(\varepsilon_{\text {rupL }}-\varepsilon_{\text {rupN }}\right) \\
(\%)\end{array}$ & $\Delta \varepsilon(\%)$ \\
\hline \multirow{3}{*}{ Não Sat } & 25 & 2,01 & 3,06 & 1,06 & 35 \\
& 50 & 2,60 & 4,11 & 1,51 & 37 \\
& 75 & 2,39 & 4,97 & 2,58 & 52 \\
\hline \multirow{3}{*}{ Sat } & 25 & 1,16 & 2,35 & 1,19 & 51 \\
& 50 & 1,36 & 4,10 & 2,74 & 67 \\
& 75 & 1,47 & 5,85 & 4,38 & 75 \\
\hline
\end{tabular}

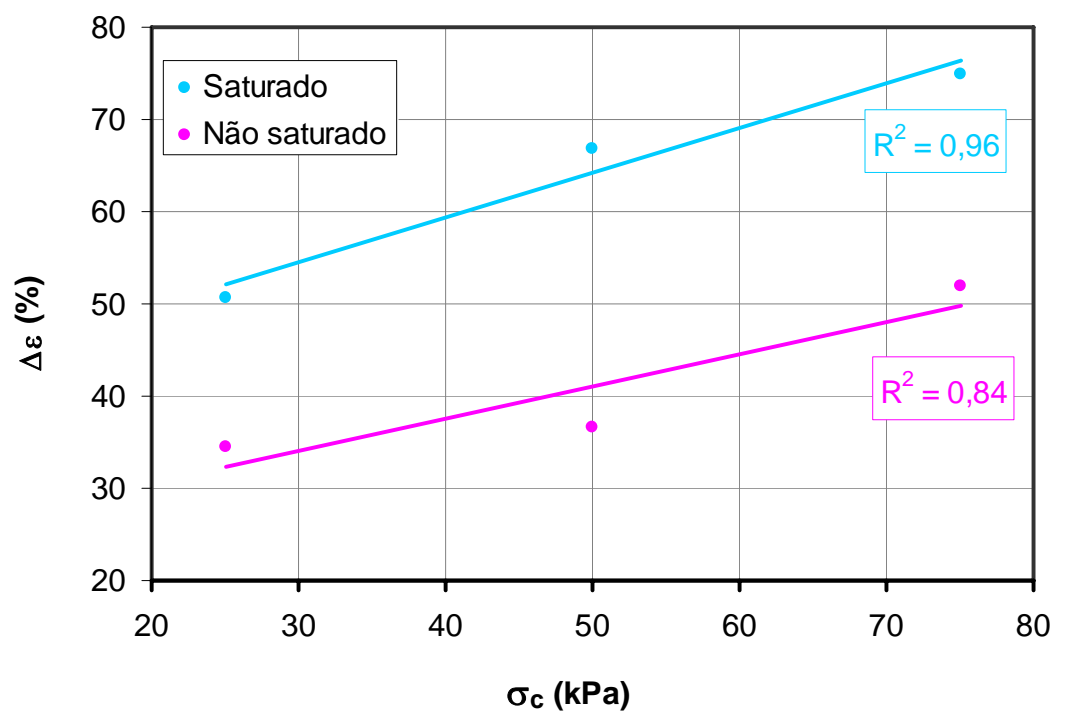

FIGURA 4.30 - Variação da diferença relativa de deformação axial de ruptura com a tensão confinante para os ensaios triaxiais saturados e não saturados do par 1.

Analisando-se os valores da tabela 4.11 e a figura 4.31 observa-se que, os solos lateríticos apresentam deformação de ruptura menor que as dos solos não lateríticos, assim como foi observado nos ensaios saturados. Tomando-se os valores médios, observa-se que, para os solos lateríticos, os ensaios saturados apresentam deformações axiais de ruptura menores que as dos ensaios não saturados. Diferente 
dos solos não lateríticos, que apresentam, para os ensaios saturados, valores médios de deformação axial de ruptura semelhantes às encontradas nos ensaios não saturados.

Observa-se também que, apesar da diferença relativa de deformação de ruptura ser menor para os ensaios não saturados, $\Delta \varepsilon$ aumenta linearmente com o aumento de $\sigma_{c}$ a taxas semelhantes para ambas as condições de ensaio.

\section{Módulo tangente inicial}

Assim como para os ensaios saturados, para as análises que se seguem foram utilizados os módulos tangentes iniciais $\left(E_{0}\right)$ determinados a partir do traçado da tangente diretamente no gráfico tensão versus deformação.

Calculados os valores de $E_{0}$, esses foram modelados em função da tensão confinante através da equação 3.5 de Janbu (1963). A tabela 4.12 apresenta os valores de módulo tangente inicial e de $\mathrm{K}, \mathrm{n}$ e $\mathrm{R}^{2}$ da equação 3.5 para os ensaios saturados e não saturados dos solos do par 1. A figura 4.32 apresenta a curva de variação de $E_{0}$ com $\sigma_{c}$ para cada solo. 
TABELA 4.12 - Módulos tangente inicial e parâmetros $K$, n e $R^{2}$ da equação 3.5 para cada tensão de confinamento dos ensaios saturados e não saturados do par 1.

\begin{tabular}{|c|c|c|c|c|c|c|}
\hline & & $\sigma_{3}(\mathrm{kPa})$ & $\mathrm{E}_{0}(\mathrm{MPa})$ & $\mathrm{k}$ & $\mathrm{n}$ & $\mathrm{R}^{2}$ \\
\hline \multirow{6}{*}{ Não Sat } & \multirow{3}{*}{$1 \mathrm{~L}$} & 25 & 21 & \multirow{3}{*}{450} & \multirow{3}{*}{0,5619} & \multirow{3}{*}{0,9964} \\
\hline & & 50 & 30 & & & \\
\hline & & 75 & 39 & & & \\
\hline & \multirow{3}{*}{$1 \mathrm{~N}$} & 25 & 29 & \multirow{3}{*}{202} & \multirow{3}{*}{$-0,197$} & \multirow{3}{*}{0,3766} \\
\hline & & 50 & 20 & & & \\
\hline & & 75 & 24 & & & \\
\hline \multirow{6}{*}{ Sat } & \multirow{3}{*}{$1 \mathrm{~L}$} & 25 & 60 & \multirow{3}{*}{439} & \multirow{3}{*}{$-0,1888$} & \multirow{3}{*}{0,6088} \\
\hline & & 50 & 46 & & & \\
\hline & & 75 & 50 & & & \\
\hline & \multirow{3}{*}{$1 \mathrm{~N}$} & 25 & 50 & \multirow{3}{*}{193} & \multirow{3}{*}{$-0,7567$} & \multirow{3}{*}{0,6861} \\
\hline & & 50 & 46 & & & \\
\hline & & 75 & 20 & & & \\
\hline
\end{tabular}

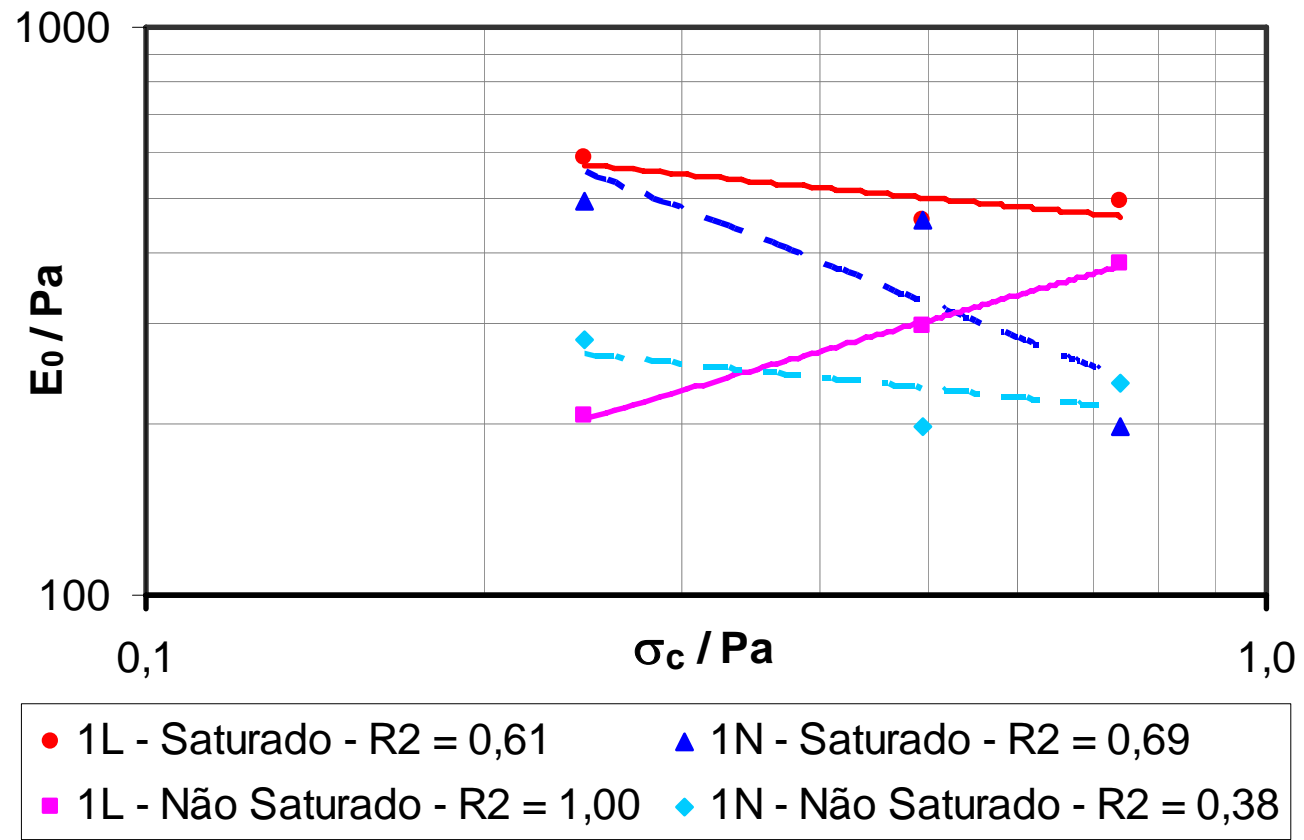

FIGURA 4.31 - Variação de $E_{0} \operatorname{com} \sigma_{c}$ para ensaios saturados e não saturados do par 1. 
Analisando-se a tabela 4.12 e a figura 4.32 observa-se que, para os ensaios não saturados, para todas as tensões confinantes, excetuando-se os ensaios de $\sigma_{c}$ $25 \mathrm{kPa}$, o solo $1 \mathrm{~L}$ apresenta $\mathrm{E}_{0}$ maior que o solo $1 \mathrm{~N}$. Observa-se ainda que, para os ensaios não saturados, o solo não laterítico apresenta tendência de variação de $\mathrm{E}_{0}$ semelhante ao dos ensaios saturados, ou seja, decrescente com o aumento de $\sigma_{\mathrm{c}}$. Enquanto que, o solo laterítico apresenta $E_{0}$ não saturado com variação contraria ao de $E_{0}$ saturado, ou seja, para os ensaios não saturados $E_{0}$ cresce com o aumento de $\sigma_{\mathrm{c}}$ e para os ensaios saturados $\mathrm{E}_{0}$ decresce com o aumento de $\sigma_{\mathrm{c}}$.

Para os dois solos, observa-se que na condição não saturada o módulo $E_{0}$ apresenta valores menores que para a condição saturada, fator inesperado e inexplicável no âmbito desta dissertação.

\section{Módulos secantes}

A tabela 4.13 apresenta os valores dos módulos de deformação secante a $50 \%$ da tensão de ruptura $\left(E_{50}\right)$ e na ruptura $\left(E_{\text {rup }}\right)$ e valores dos módulos de deformação tangente inicial $\left(E_{0}\right)$ para cada valor de tensão confinante para os ensaios saturados e não saturados dos solos do par 1. A figura 4.33 apresenta as variações desses módulos com $\sigma_{\mathrm{c}}$ para os ensaios não saturados do par 1, enquanto que as figuras 4.34 e 4.35 apresentam essas mesmas variações para ensaios saturados e não saturados dos solos $1 \mathrm{~L}$ e $1 \mathrm{~N}$ respectivamente. 
TABELA 4.13 - Módulos de deformação secante a $50 \%$ da tensão de ruptura, módulos de deformação secante na ruptura e módulos de deformação tangente inicial para as condições saturada e não saturada dos solos do par 1

\begin{tabular}{|c|c|c|c|c|c|}
\hline \multicolumn{2}{|c|}{ Solo } & $\sigma_{3}(\mathrm{kPa})$ & $\mathrm{E}_{\text {rup }}(\mathrm{MPa})$ & $\mathrm{E}_{50}(\mathrm{MPa})$ & $\mathrm{E}_{0}(\mathrm{MPa})$ \\
\hline \multirow{6}{*}{ NÃO SAT } & \multirow{3}{*}{$1 \mathrm{~L}$} & 25 & 13 & 20 & 21 \\
\hline & & 50 & 12 & 20 & 30 \\
\hline & & 75 & 16 & 34 & 39 \\
\hline & \multirow{3}{*}{$1 \mathrm{~N}$} & 25 & 7 & 15 & 29 \\
\hline & & 50 & 6 & 17 & 20 \\
\hline & & 75 & 6 & 17 & 24 \\
\hline \multirow{6}{*}{ SAT } & \multirow{3}{*}{$1 \mathrm{~L}$} & 25 & 12 & 40 & 60 \\
\hline & & 50 & 14 & 31 & 46 \\
\hline & & 75 & 17 & 38 & 50 \\
\hline & \multirow{3}{*}{$1 \mathrm{~N}$} & 25 & 4 & 17 & 50 \\
\hline & & 50 & 4 & 13 & 46 \\
\hline & & 75 & 3 & 11 & 20 \\
\hline
\end{tabular}
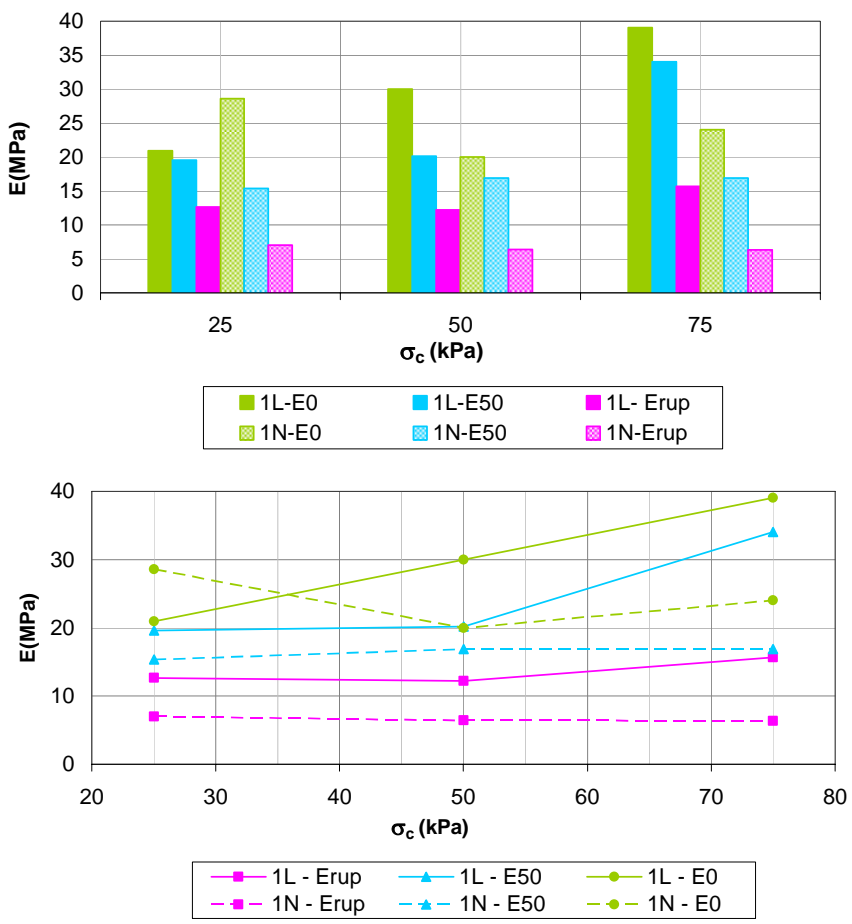

FIGURA 4.32 - Variação de $E_{0}, E_{50}$ e $E_{\text {rup }} \operatorname{com} \sigma_{c}$ para os ensaios não saturados do par 1 

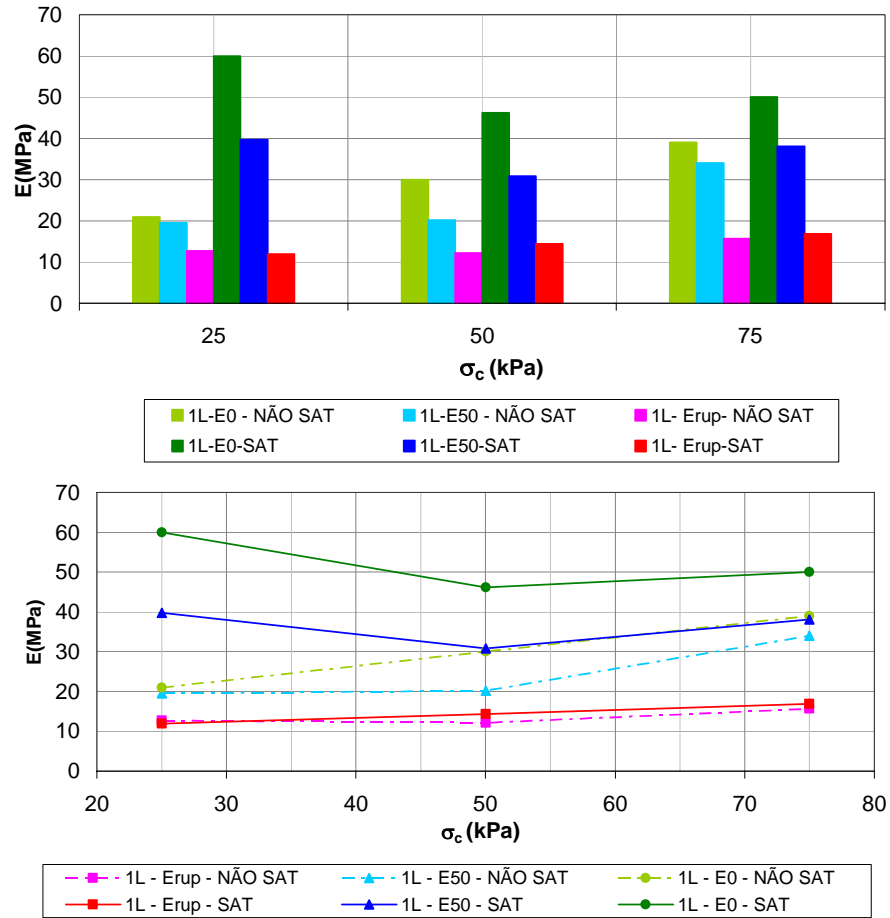

FIGURA 4.33 - Variação de $E_{0}, E_{50}$ e $E_{\text {rup }} \operatorname{com} \sigma_{c}$ para os ensaios saturados e não saturados do solo $1 \mathrm{~L}$
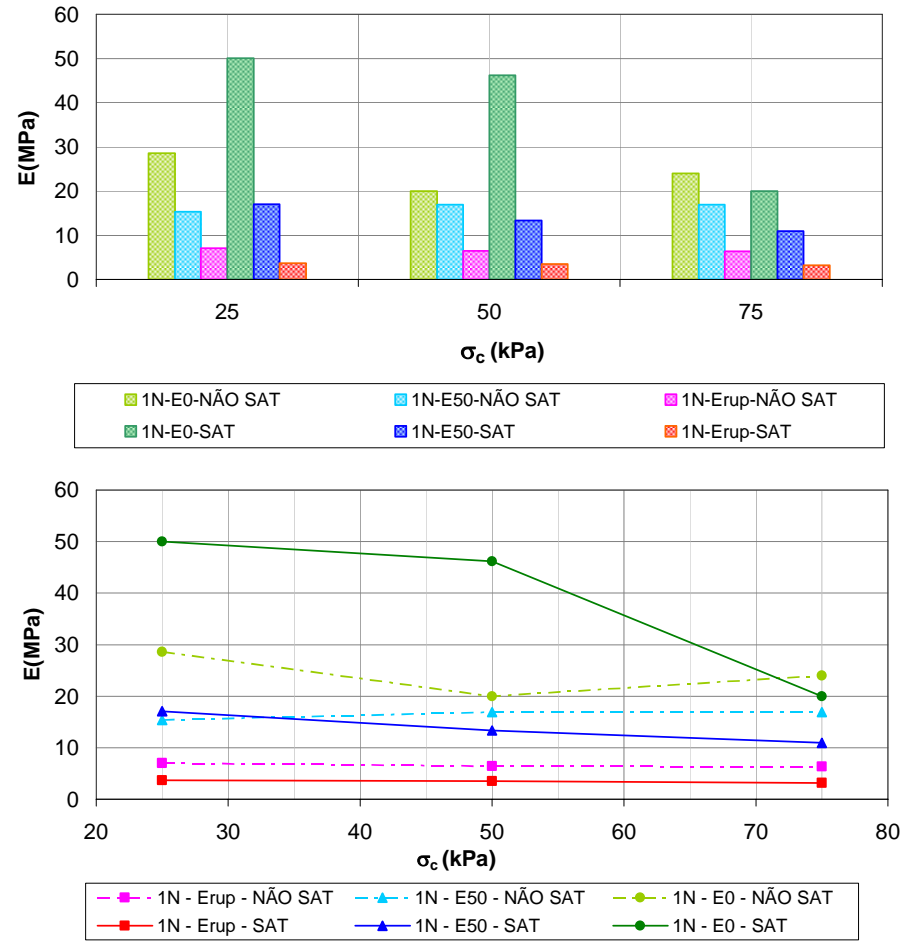

FIGURA 4.34 - Variação de $E_{0}, E_{50}$ e $E_{\text {rup }} \operatorname{com} \sigma_{c}$ para os ensaios saturados e não saturados do solo $1 \mathrm{~N}$ 
Analisando-se a tabela 4.13 e as figuras $4.33,4.34$ e 4.35 observa-se que, assim como para os ensaios não saturados, todos os valores de módulos de deformação secante calculados para o solo laterítico $1 \mathrm{~L}$ são maiores que os correspondentes do não laterítico $1 \mathrm{~N}$.

Observa-se ainda que, assim como para os ensaios saturados, para os ensaios não saturados, ambos os solos desse par apresentam $E_{\text {rup }}$ praticamente independente de $\sigma_{c}$. Comparando os ensaios saturados aos não saturados pode-se observar que as curvas de variação de $\mathrm{E}_{\text {rup }} \operatorname{com} \sigma_{\mathrm{c}}$ são muito semelhantes tanto para o solo $1 \mathrm{~L}$ quanto para o solo $1 \mathrm{~N}$.

Tomando-se a variação de deformação $E_{50}$, observa-se que, para a condição não saturada, o solo $1 \mathrm{~N}$ apresenta deformação $E_{50}$, independente de $\sigma_{c}$, enquanto que o solo $1 \mathrm{~L}$ mostra um acréscimo de valores de deformação $E_{50}$ com o aumento de $\sigma_{\mathrm{c}}$. 


\section{CONCLUSÕES E RECOMENDAÇÕES}

\subsection{Introdução}

Neste capítulo são apresentadas as principais conclusões deste trabalho, que teve por objetivo principal analisar o comportamento mecânico de solos tropicais para uso em pavimentação por meio de ensaios triaxiais convencionais. Ressalta-se que todas as conclusões apresentadas estão restritas ao universo dos solos estudados.

\subsection{Conclusões}

A partir das análises realizadas nesse trabalho conclui-se que os solos do par 3 , apesar de pertencerem a classes diferentes pela classificação MCT, têm comportamentos semelhantes entre si e próximos ao comportamento dos solos lateríticos pertencentes aos pares 1 e 2. A semelhança entre os solos desse par poderia ser explicada pela classificação MCT-M (Vertamatti 1988), onde se observa que ambos os solos pertencem a uma mesma classe, TAG', o que indica que teriam comportamentos geotécnicos coincidentes. Assim, as conclusões que se seguem sobre as diferenças e semelhanças no comportamento dos solos lateríticos e não lateríticos foram realizadas a partir exclusivamente das análises dos solos dos pares 1 e 2. 


\subsubsection{Ensaios Saturados}

A análise da resistência à ruptura dos solos mostra que, solos de comportamento laterítico alcançam resistências maiores que solos não lateríticos, sendo que essa diferença de resistência diminui com o aumento da tensão de confinamento. Analisando a resistência à ruptura desses solos através da envoltória de MohrCoulomb conclui-se que, quando se comparam solos de granulometrias semelhantes, a diferença de resistência entre solos lateríticos e não lateríticos se encontra no intercepto coesivo, sendo o ângulo de atrito interno semelhante para ambas as gêneses e em média igual a $29^{\circ}$. O intercepto coesivo dos solos lateríticos chegaram a alcançar valores superiores a 3 vezes os dos solos não lateríticos. Esse resultado poderia ser explicado pela presença de óxidos e hidróxidos de ferro e alumínio nos solos lateríticos, que promovem a cimentação entre partículas, contribuindo para o aumento do valor da coesão desses solos.

Analisando a resistência mobilizada pode-se concluir que, para ambas as gêneses, à medida em que se aumenta o nível de tensão, o ângulo de atrito mobilizado cresce e a coesão mobilizada apresenta variação muito pequena. Para níveis de tensão muito pequenos, os solos não lateríticos apresentam maiores ângulos de atrito mobilizado que os lateríticos, no entanto, esses últimos apresentam maior sensibilidade ao aumento do nível de tensão e próximo à ruptura, o ângulo de atrito interno desses solos se assemelha ao dos não lateríticos.

Quando se analisa a deformação dos solos, observa-se que os solos lateríticos rompem a deformações menores que os solos não lateríticos, não sendo possível 
determinar uma tendência de comportamento para a diferença entre as deformações de ruptura dos solos lateríticos e não lateríticos em função da tensão confinante.

Com relação ao módulo de deformação tangente inicial, os solos lateríticos apresentam rigidez maior que os não lateríticos, em média 52 e 35MPa, respectivamente. Para ambas as gêneses, a rigidez diminui com o aumento da tensão confinante, sendo essa diminuição mais acentuada para os solos não lateríticos. A diferença entre a rigidez dos solos lateríticos e não lateríticos aumenta com o aumento da tensão confinante.

Quanto às analises dos módulos de deformação secantes, pode-se concluir que o aumento do nível de tensões provoca, tanto nos solos lateríticos como nos não lateríticos, a diminuição da dependência dessa variável com a tensão confinante, sendo que os solos lateríticos apresentam valores de rigidez maiores que os não lateríticos para todos os níveis de tensão.

\subsubsection{Ensaios Não Saturados}

Pela análise da resistência à ruptura dos solos, conclui-se que, assim como na condição saturada, os solos de comportamento laterítico alcançam resistências maiores que os solos não lateríticos, sendo que a diferença de resistência é menor para a condição não saturada. Observa-se ainda que, para ambas as gêneses, a diferença entre a resistência saturada e não saturada diminui com o aumento da tensão confinante, sendo essa queda mais acentuada para os solos não lateríticos. 
Comparando-se ensaios saturados e não saturados, conclui-se que o efeito da saturação na diminuição da resistência é menor para os solos lateríticos. Supõe-se que isto deva-se ao fato de que os solos não lateríticos apresentam na umidade de compactação níveis de sucção superior às dos solos lateríticos.

As análises mostram também que, para ambas as gêneses, a saturação dos solos não influencia os valores de ângulo de atrito. No entanto, no tocante à coesão, a saturação conduz a uma redução desse parâmetro, sendo que o solo não laterítico é mais sensível ao efeito da saturação do que o solo laterítico.

Quando se analisa a deformação axial na ruptura observa-se que, assim como na condição saturada, na condição não saturada, os solos lateríticos rompem a deformações menores que os solos não lateríticos.

A análise do módulo tangente inicial na condição não saturada mostra que, semelhante aos ensaios saturados, os solos lateríticos apresentam rigidez maior que os não lateríticos. No tocante à variação do $E_{0}$ com o confinamento, o solo não laterítico apresenta uma diminuição da rigidez com o aumento de tensão a taxas menores que na condição saturada, enquanto que para o solo laterítico, constata-se uma inversão no comportamento observado nos ensaios saturados, sendo que a rigidez aumenta com o crescimento da tensão de confinamento.

A análise do módulo tangente inicial mostra ainda que, na condição não saturada, este apresenta valores menores que na condição saturada, fato inesperado e que não foi possível explicar no contexto deste trabalho. 
Nas análises dos módulos de deformação secantes determinados na condição não saturada, observa-se que assim como na condição saturada, o aumento do nível de tensões provoca, tanto nos solos lateríticos como nos não lateríticos, a diminuição da dependência dessa variável com a tensão confinante. No entanto, para a condição não saturada, a variação da rigidez ao longo do ensaio é menor que na condição saturada.

\subsection{Recomendações e sugestões para trabalhos futuros}

Sugere-se que, em trabalhos futuros, sejam desenvolvidos os seguintes aspectos:

- Aumentar o número de amostras estudadas, considerando solos de diferentes granulometrias, independente de constituirem pares granulométricos;

- Ampliar os estudos com ensaios triaxiais com medida interna de deslocamento para assegurar maior confiabilidade nos resultados obtidos para pequenas deformações;

- Avaliar as influências do processo, energia, umidade e grau de compactação e variação da umidade pós-compactação no comportamento dos solo;

- Ampliar os estudos do comportamento mecânico realizando ensaios triaxiais estáticos não saturados com controle de sucção e determinar a curva característica desses solos. 


\section{REFERÊNCIAS BIBLIOGRÁFICAS}

ARANOVICH, L.A.S.; OGURTSOVA, J. (1987). Estabilização de Solos Lateríticos Argilosos com e sem Aditivos. In 22a REUNIÃO DE PAVIMENTAÇÃO, Maceió. Anais. ABPV, Rio de Janeiro. V.1, p. 709-733.

BERNUCCI, L.L.B.; SERRA, P.R.M. (1990). Mistura Argila Laterítica-Brita como Base de Pavimentos Econômicos Urbanos - Segmento Experimental de Diadema, SP. In 24 ${ }^{\mathrm{a}}$ REUNIÃO DE PAVIMENTAÇÃO, Belém. Anais. ABPV, Rio de Janeiro. V.2, p. 335-345.

BISHOP, A.W.; HENKEL, D.J. (1972). Measurement of soil properties in the triaxial test. Edward Arnold, London, 2 ed 227p

BARROS, C.T. (1978). Bases Estabilizadas Executadas com Solos Argilosos Laterizados. São Paulo, Dissertação (Mestrado) - Escola Politécnica, Universidade de São Paulo.

CAMAPUM DE CARVALHO, J.; SILVA, C.M.; LOPES, L.G.R. (1991). Comportamento e propriedades de solos lateríticos compactados em laboratório e no campo. In: 25a REUNIÃO ANUAL DE PAVIMENTAÇÃO, São Paulo. Anais. ABPV, Rio de Janeiro. p.726-742.

COMMITTEE ON TROPICAL SOILS OF THE ISSMFE (1985). Peculiarities or geotechnical behavior of tropical laterítico and saprolitic soils: progress report. Associação Brasileira de Mecânica dos Solos, São Paulo, 449p. 
CORRÊA, F.C. (1975). Comportamento de Trechos Experimentais com Bases de Solos Arenosos Finos. São Carlos, Dissertação (Mestrado) - Escola de Engenharia de São Carlos, Universidade de São Paulo.

CORRÊA, F.C. (1981). Solo-Brita com Argila Laterítica na Região da Grande São Paulo. In SIMPÓSIO BRASILEIRO DE SOLOS TROPICAIS EM ENGENHARIA. COPPE/UFRJ, Rio de Janeiro.

COSTA, C.R.V. (1983). Relação entre Índice de Suporte Califórnia (CBR) com Imersão e sem Imersão para Solos Lateríticos. In: $18^{\mathrm{a}}$ REUNIÃO ANUAL DE PAVIMENTAÇÃO. Porto Alegre. Anais. ABPv, Rio de Janeiro. v.1, p. 486-497.

DUNCAN, J.M. E CHANG, C.-Y. (1970) Nonlinear analysis of stress and strain in soils. In: JOURNAL OF THE SOIL MECHANICS AND FOUNDATIONS DIVION, v.96, n.5, p. 1629-1653.

FABBRI, G.T.P. (1994). Caracterização da fração fina de solos tropicais através da adsorção de azul de metileno. São Carlos, tese (Doutorado) - Escola de Engenharia de São Carlos, Universidade de São Paulo.

FERNANDES, E. (2006). Estudo comparativo da aplicação de diferentes sistemas de classificações geotécnicas aplicadas aos solos tropicais.São Carlos, Dissertação (Mestrado) - Escola de Engenharia de São Carlos, Universidade de São Paulo.

FERREIRA, M.A.G. (1986). Considerações sobre Misturas Solo-Agregado Compostas por Materiais Tropicais para uso em Pavimentação. São Carlos, Dissertação (Mestrado) - Escola de Engenharia de São Carlos, Universidade de São Paulo.

FRANZOI, S. (1990). Algumas Peculiaridades Resilientes de Solos Lateríticos e Saprolíticos. São Paulo, Dissertação (Mestrado) - Escola Politécnica, Universidade de São Paulo. 
GODOY, H.; BERNUCCl, (2002) O método das pastilhas na compreensão das propriedades geotécnicas básicas dos solos: um recurso dodático. In: XVI ANPET, Natal-RN. Anais. V.1, p. 145-156.

HEAD, K.H. (1986). Manual of Soil laboratory testing. ELE International Limited, Pentech Press, London. V3 1238p

KIM, D.-S., KWEON, G.-C. E LEE, K.-H. (2001) Alternative Method of Determining Resilient Modulus of Subgrade Soils Using a Static Triaxial Test. In: CANADIAN GEOTECHNICAL JOURNAL, v.38, n.1, p. 107-116.

LEE, W.; BOHA, N. C.; ALTSChAEFFL, WHITE, T. D. (1995). Resilient Modulus of Cohesive Soils and the Effect of Freeze-Thaw. In: JOURNAL OD GEOTECNHICAL ENGINEERING. V123, n.2, p.131-136.

MITCHELL, J.K. (1993). Fundamentals of Soil Behavior. Wiley Inter Science. University of California, Berkeley. $2^{\mathrm{a}}$ ed, 437p.

MOTTA, L.M.; ARANOVICH, L.A.S.; CERATTI, J.A.P. (1985) Comportamento Resiliente de Solos Utilizados em Pavimentos de Baixo Custo. In: SOLOS E ROCHAS, Rio de Janeiro. V.8, p. 15-42.

NOGAMI, J.S. E VILLIBOR, D.F. (1979). Soil Characterization of Mapping Units for Highway Purposes in a Tropical Área. In: BULLETIN OF THE INTERNATIONAL ASSOCIATION OF ENGINEERING GEOLOGY, nº 19, p.196-199.

NOGAMI, J.S. E VILLIBOR, D.F. (1981) Uma Nova Classificação de Solos para Finalidades Rodoviárias. In: SIMPÓSIO BRASILEIRO DE SOLOS TROPICAIS EM ENGENHARIA, Rio de Janeiro. Anais. COPPE/UFRJ - CNPq - ABMS, Rio de Janeiro, p. 30-41. 
NOGAMI, J.S. E VILLIBOR, D.F. (1994) Identificação expedita dos grupos da classificação MCT para solos tropicais. In: X CONGRESSO BRASILEIRO DE MECÂNICA DOS SOLOS E ENGENHARIA DE FUNDAÇÕES, AfOZ DO Iguaçu-PR. Anais. V.4, p. 1293-1300.

NOGAMI, J.S. E VILLIBOR, D. F. (1995) Pavimentação de Baixo Custo com Solos Lateríticos. 213p., Ed. Villibor, São Paulo.

NOGAMI, J.S.; VILLIBOR, D. F.; BELIGNI, M. E CINCERRE, J. R. (2000) Pavimento com solos lateríticos e gestão de manutenção de vias urbanas. 138p., ABPv, São Paulo.

NOGAMI, J.S. E VILLIBOR, D.F. (2003) Modificações recentes na classificação geotécnica MCT. In: 34 a REUNIÃO ANUAL DE PAVIMENTAÇÃO, Campinas-SP. Anais. p.44-68.

PARREIRA, A.B. (1991). Análise de túneis rasos em solos - o túnel mineiro Paraíso da linha paulista do metropolitano da cidade de São Paulo. Rio de Janeiro, Tese (Doutorado) - Pontifícia Universidade Católica do Rio de Janeiro.

PARREIRA, A.B., CUNTO, J.F.C., CARMO, C.T.E RODRIGUES, J.K.G. (1998). O Módulo de Resiliência de Alguns Materiais de Pavimentação e a sua Estimativa a Partir de Ensaios de Compressão Simples. In: XI CONGRESSO BRASILEIRO DE MECÂNICA DOS SOLOS E ENGENHARIA GEOTÉCNICA, Brasília. Anais. ABMS, v.1, p. 383-388.

PARREIRA, A.B., TAKEDA, M.C., LUZ, M.P. (2004). Avaliação da Influência do Período de Imersão nos Resultados do Ensaio CBR de Solos Tropicias. In: $5^{\circ}$ SIMPÓSIO BRASILEIRO DE SOLOS NÃO SATURADOS, São Carlos. Anais. ABMS, v.1, p. 149-156. 
PREUSSLER, E.S.; MEDINA, J.; PINTO, S. (1981) Resiliência de Solos Tropicais e sua Aplicação à Mecânica dos Pavimentos. In: SIMPÓSIO BRASILEIRO DE SOLOS TROPICAIS EM ENGENHARIA, Rio de Janeiro. Anais. COPPE/UFRJ - CNPq ABMS, Rio de Janeiro, p. 591-614.

PREUSSLER, E.S. e PINTO, S. (1982) Proposição de Método para projeto de Reforço de Pavimentos Flexíveis, considerando a Resiliência. In: $17^{a}$ REUNIÃO ANUAL DE PAVIMENTAÇÃO, Brasília. Anais. ABPv, Rio de Janeiro. V.1, p. 2.2042.263 .

REIS, R.M.; VILAR, O.M. (2004). Resistência ao cisalhamento de dois solos residuais de gnaisse não saturados. In: $5^{\circ}$ SIMPÓSIO BRASILEIRO DE SOLOS NÃO SATURADOS, São Carlos. Anais. ABMS, v.1, p. 109-114.

ROHM, S.A.; VILAR, O.M. (1995). Shear strength of na unsaturated Sandy soil. In: ${ }^{\circ}$ INTERNACIONAL CONFERENCE ON UNSATURATED SOIL, Paris. Anais.p. 189193.

SOUZA PINTO, C. (2002). Curso Básico de Mecânica dos Solos. $2^{\mathrm{a}}$ ed. 355p., Ed. Oficina de textos, São Paulo.

TAKEDA, M.C. (2006) A Influência da Variação da Umidade Pós-Compactação no Comportamento Mecânico de Solos de Rodovias do Interior Paulista. São Carlos, Tese (Doutorado) - Escola de Engenharia de São Carlos, Universidade de São Paulo.

THOMPSON, M.R.; ROBNETT, Q.L. (1979). RESILIENT Properties of Subgrade Soils. In: TRANSPORTE ENGINEERING JOURNAL, v.125, p. 71-89

VERTAMATTI, E. (1988) Novas considerações geotécnicas sobre solos tropicais amazônicos de textura fina. In: $23^{a}$ REUNIÃO ANUAL DE PAVIMENTAÇÃO, Florianópolis-SC. Anais. ABPv, Rio de Janeiro. p. 533-564. 
VILAR, O. M. (1990). Resistência ao Cisalhamento. Notas de Aula.

VILLIBOR, D.F. (1974). Utilização de Solo Arenoso Fino na Execução de Bases para Pavimentação de Baixo Custo, São Carlos. Dissertação (Mestrado) - Escola de Engenharia de São Carlos, Universidade de São Paulo.

VILLIBOR, D.F., NOGAMI, J.S., (1990). Características e Desempenho de Segmentos de Pavimentos Rodoviários com Base de Argila Laterítica. In $24^{\mathrm{a}}$ REUNIÃO ANUAL DE PAVIMENTAÇÃO, Belém. Anais. ABPV, Rio de Janeiro. v.2, p. 291-304.

VILLIBOR, D.F., NOGAMI, J.S., SERRA, P.R.M. E ZUPPOLINI NETO, A. (1996). Procedimentos não-tradicionais na pavimentação com solos e ambientes tropicais. In: 30a REUNIÃO ANUAL DE PAVIMENTAÇÃO, Salvador. Anais. ABPv, Rio de Janeiro, v.3, p.1603-1633.

ZAMAN, M., CHEN, D. E LAGUROS, J. (1994). Resilient moduli of Granular Materials. In: JOURNAL OF GEOTECHNICAL ENGINEERING, v120, n.6, p.976988. 


\section{Apêndice A}

Apresenta-se a seguir as envoltórias de ruptura obtidas a partir dos círculos de Mohr para os pares 1, 2 e 3. 


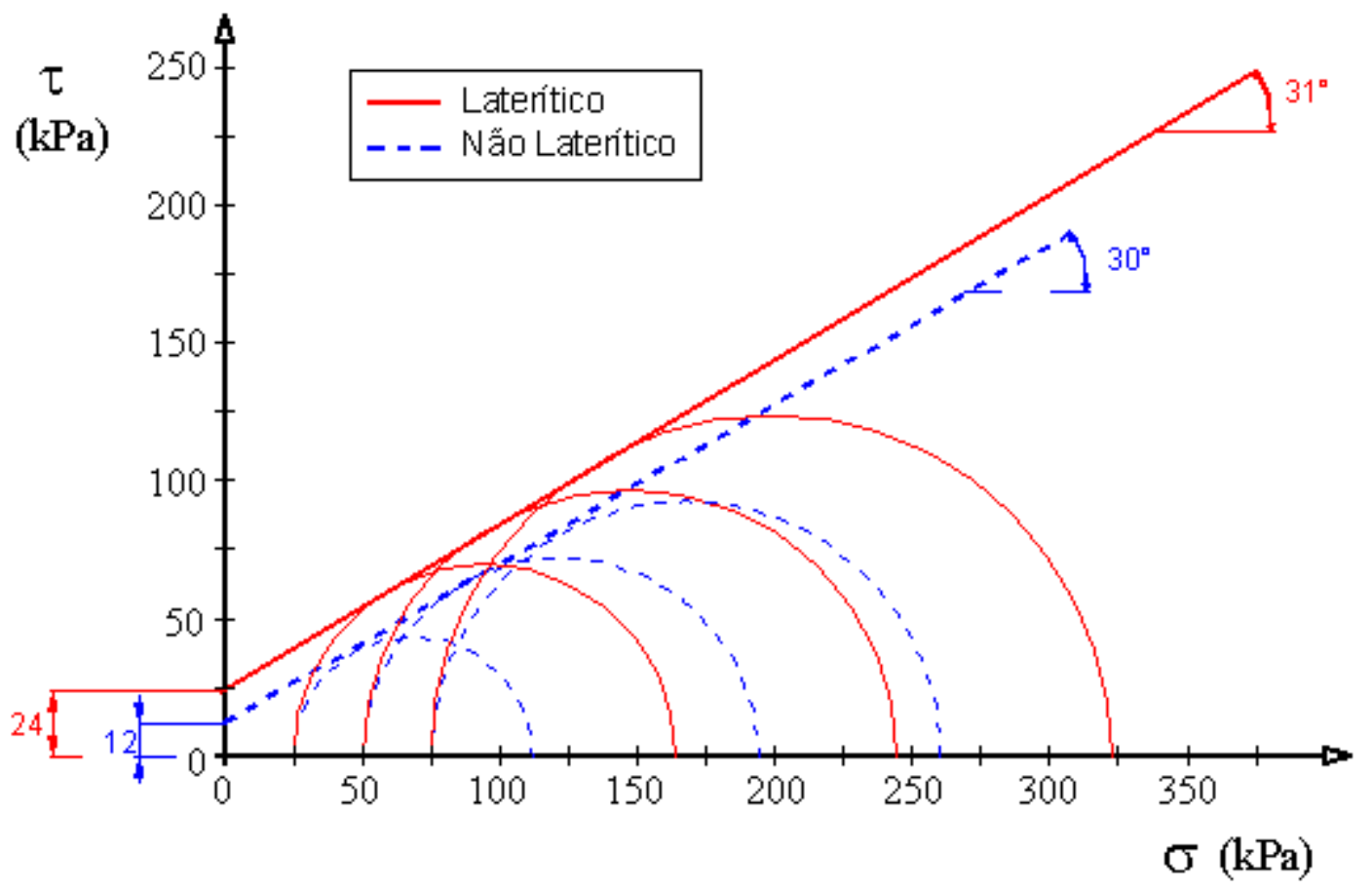

Envoltória de Ruptura dos solos do par 1, ensaios saturados

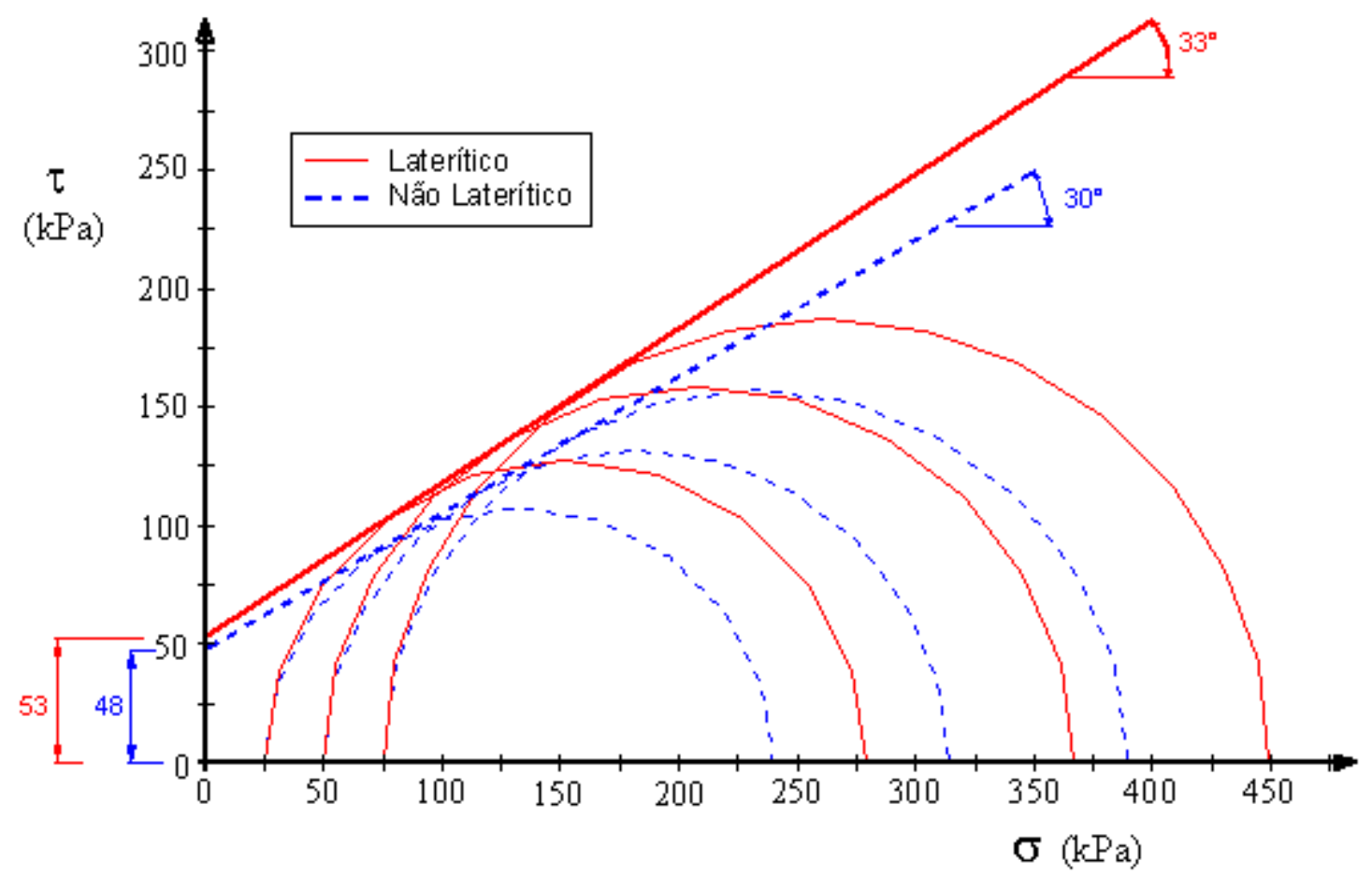

Envoltória de Ruptura dos solos do par 1, ensaios não saturados 


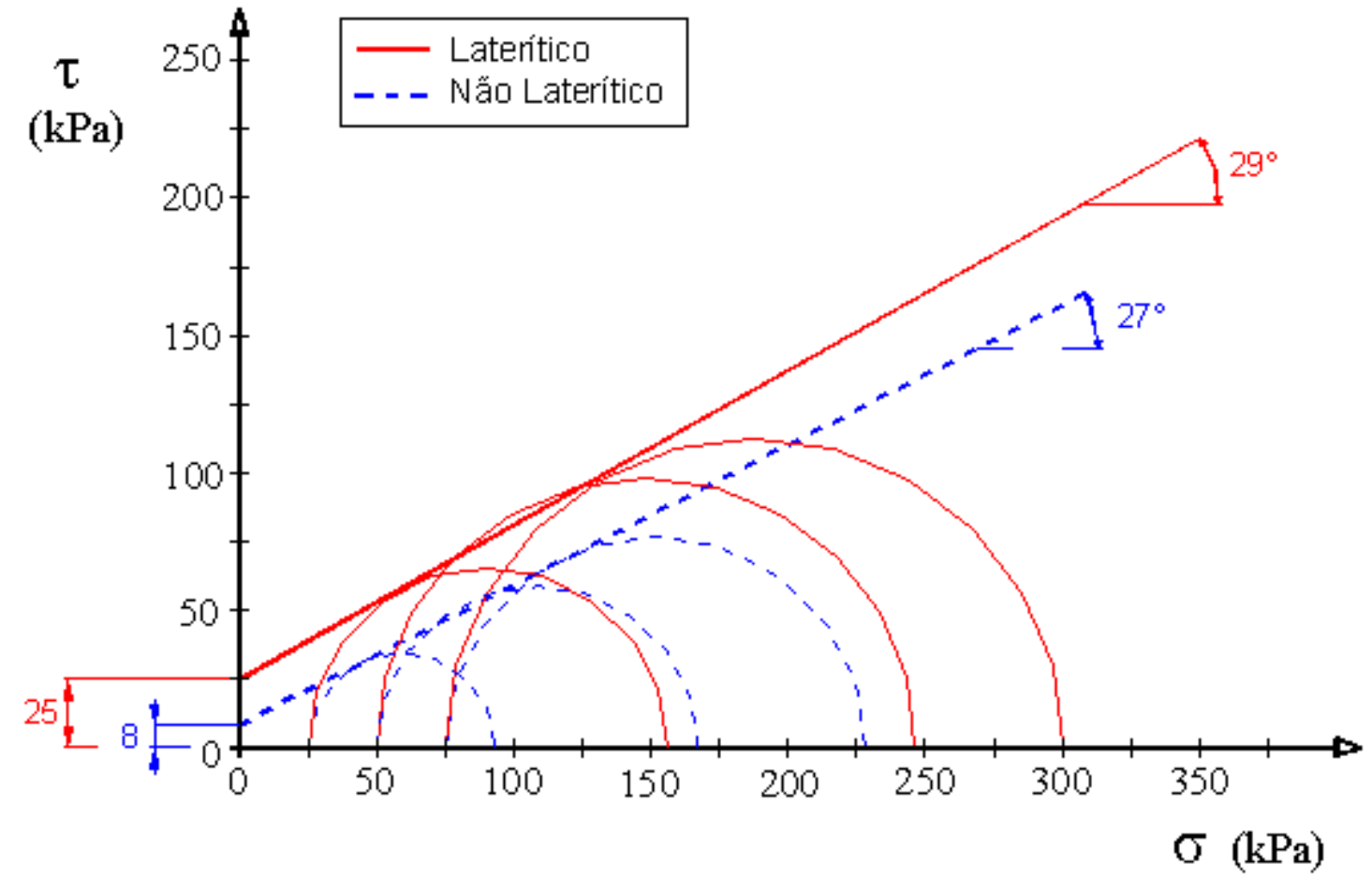

Envoltória de Ruptura dos solos do par 2, ensaios saturados

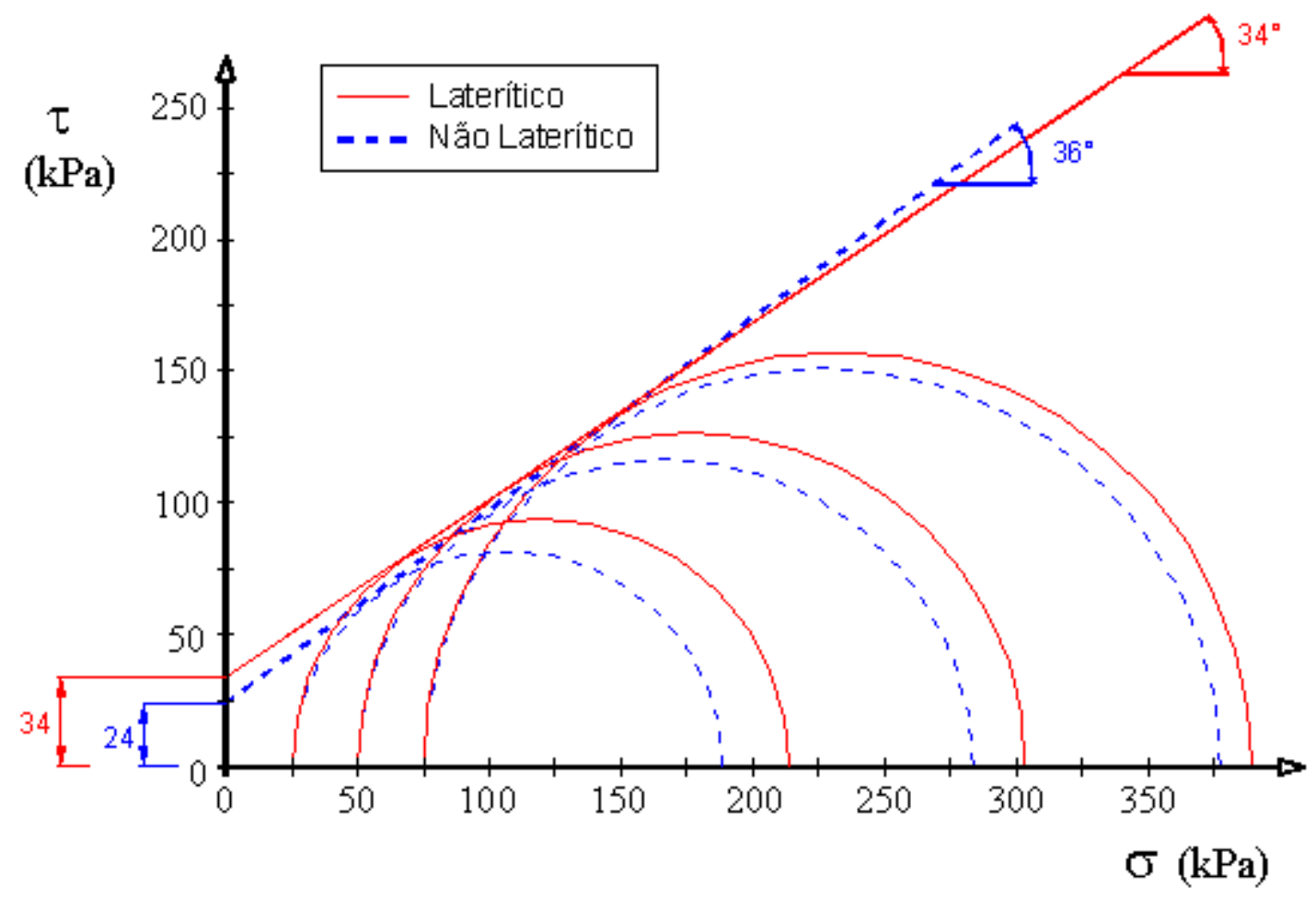

Envoltória de Ruptura dos solos do par 3, ensaios saturados 


\section{Apendice B}

Apresenta-se a seguir as curvas $\varepsilon /\left(\sigma_{1}-\sigma_{3}\right)$ versus $\varepsilon$ do modelo hiperbólico preconizado por Duncan e Chang (1970) juntamente com as curvas $\varepsilon /\left(\sigma_{1}-\sigma_{3}\right)$ versus $\varepsilon$ resultantes dos ensaios realizados para os pares 1,2 e 3 . 

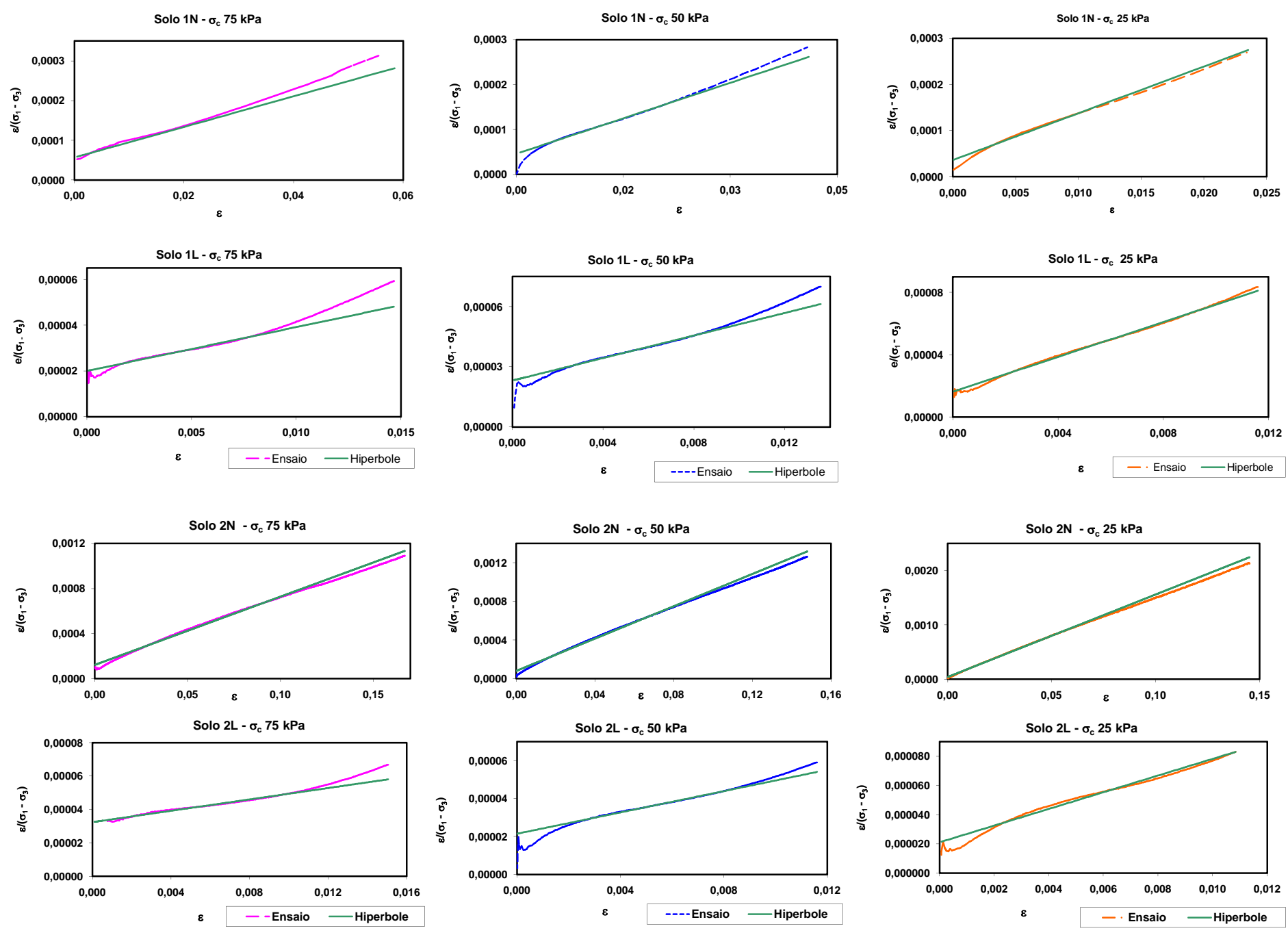

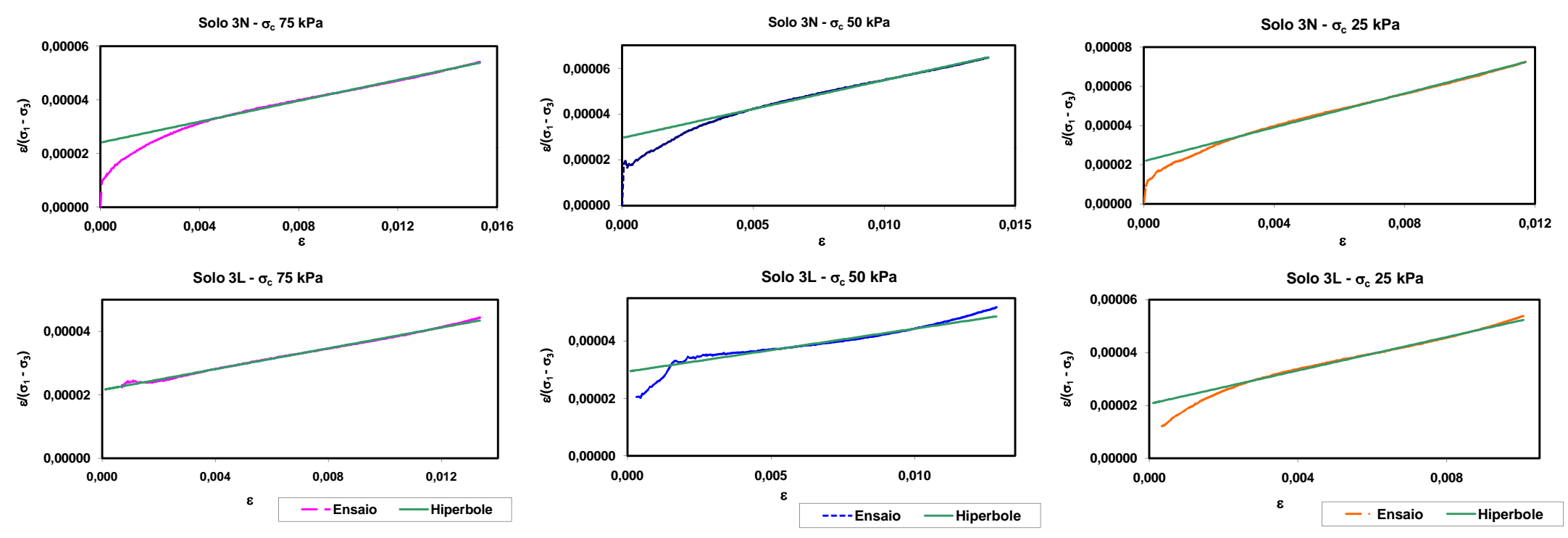